\title{
High-Speed Digital Project, HSD Test Capability
}

Kansas City Division

RIECEIVED

MAY 111994

R. E. Markley,

J. L. Elarton, and

OSTI

C. T. Allen

KCP-613-5292

Published April 1994

Topical Report

C. T. Allen, Project Leader

Approved for public release; distribution is unlimited.

\section{MASTER}

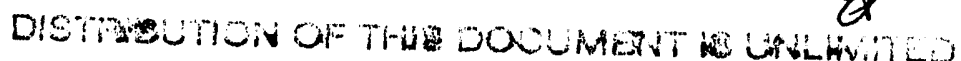

Prepared Under Contract Number DE-ACO4-76-DP00613 for the United States Department of Energy 


\section{DISCLAIMER}

This report was prepared as an account of work sponsored by an agency of the United States Government. Neither the United States Government nor any agency thereof, nor any of their employees, makes any warranty, express or implied, or assumes any legal liability or responsibility for the accuracy, completeness, or usefulness of any information, apparatus, product, or process disclosed, or represents that its use would not infringe privately owned rights. Reference herein to any specific commercial product, process, or service by trade name, trademark, manufacturer, or otherwise, does not necessarily constitute or imply its endorsement, recommendation, or favoring by the United States Government or any agency thereof. The views and opinions of authors expressed herein do not necessarily state or reflect those of the United States Government or any agency thereof.

Printed in the United States of America.

This report has been reproduced from the best available copy.

Available to DOE and DOE contractors from the Office of Scientific and Technical Information, P. O. Box 62, Oak Ridge, Tennesse日 37831; prices available from (615) 576-8401, FTS 626-8401.

Available to the public from the National Technical Information Service, U. S. Department of Commerce, 5285 Port Royal Rd., Springfield, Virginia 22161.

A prime contractor with the United States

Department of Energy under Contract Number DE-ACO4-76-DP00613.
AlledSignal Inc. Kansas City Division P.O. Box 419159 Kansas City, Missouri 64141-6159 


\title{
HIGH-SPEED DIGITAL PROJECT,
} HSD TEST CAPABILITY

\author{
R. E. Markley, \\ J. L. Elarton, and \\ C. T. Allen \\ Published April 1994 \\ Topical Report \\ C. T. Allen, Project Leader \\ Project Team: \\ T. F. Boehm \\ J. L. Elarton \\ C. G. Harkness \\ R. E. Markley
}




\section{Contents}

$\begin{array}{ll}\text { Section } & \text { Page }\end{array}$

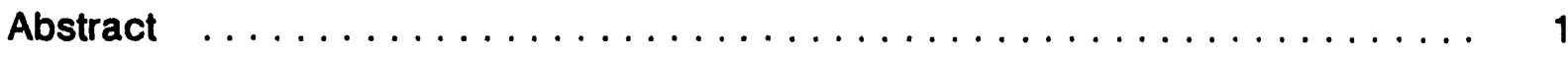

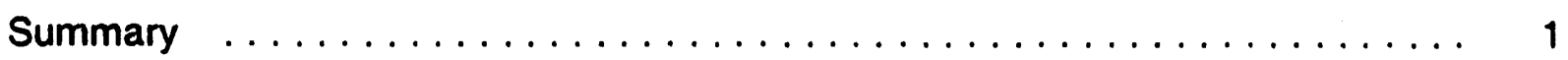

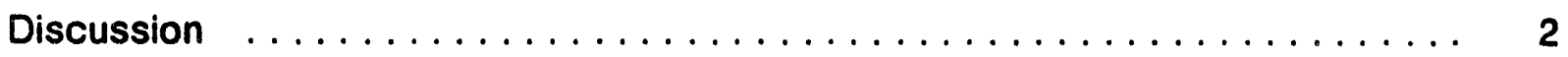

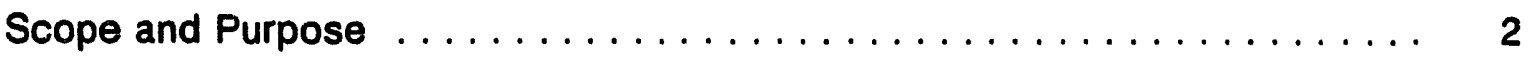

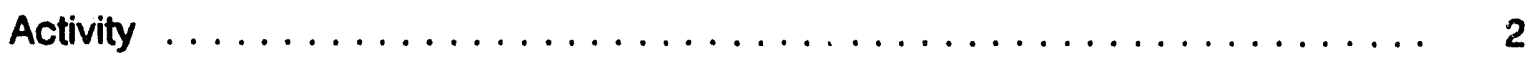

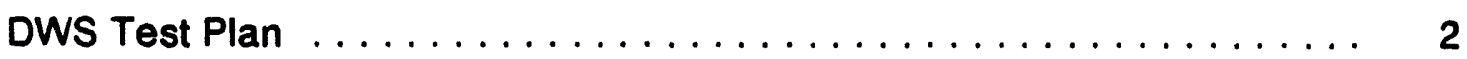

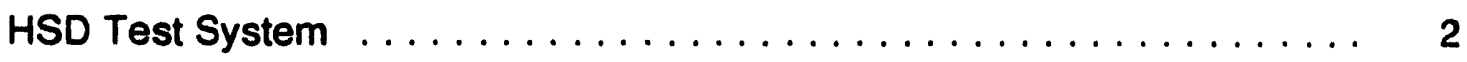

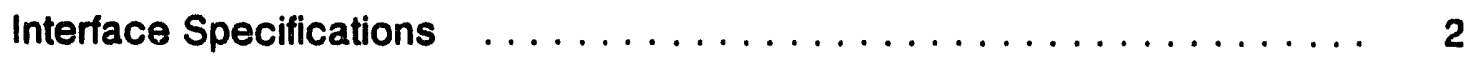

DWS Test Interface $\ldots \ldots \ldots \ldots \ldots \ldots \ldots \ldots \ldots \ldots \ldots \ldots \ldots$

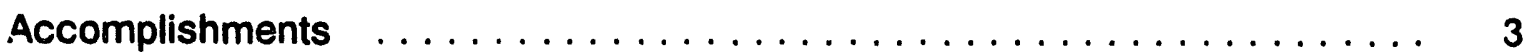

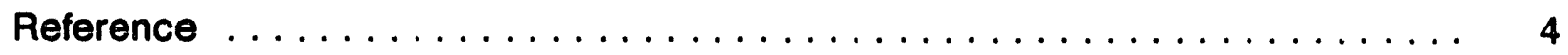

Appendices

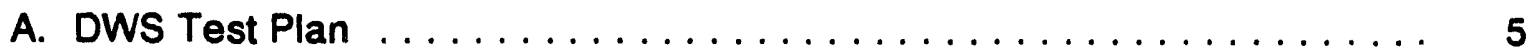

B. High Speed Digital Test System $\ldots \ldots \ldots \ldots \ldots \ldots \ldots \ldots \ldots \ldots$

C. Specifications for a High Speed Testing Interface ............. 61

D. DWS Test Interface $\ldots \ldots \ldots \ldots \ldots \ldots \ldots \ldots \ldots \ldots \ldots$ 


\section{Illustrations}

Appendix A. DWS Test Plan

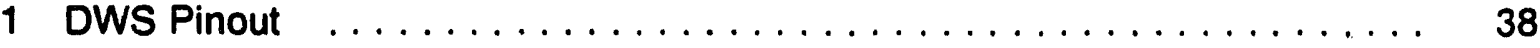

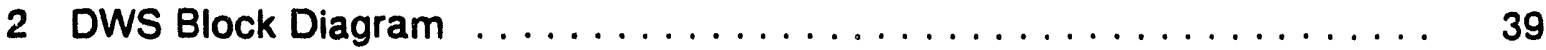

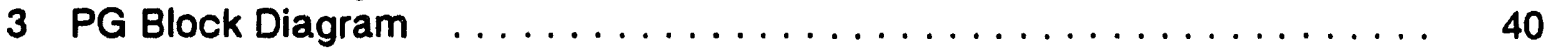

4 DWS Timing Diagram $\ldots \ldots \ldots \ldots \ldots \ldots \ldots \ldots \ldots \ldots \ldots \ldots \ldots \ldots$

5 ECL Input Logic ' 0 ' and '1' Definition $\ldots \ldots \ldots \ldots \ldots \ldots \ldots \ldots \ldots \ldots \ldots$

6 TTL Input Logic ' 0 ' and ' 1 ' Definition $\ldots \ldots \ldots \ldots \ldots \ldots \ldots \ldots \ldots$

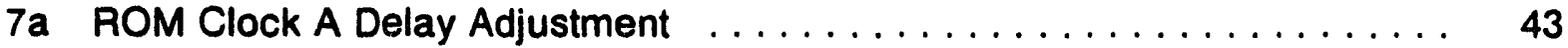

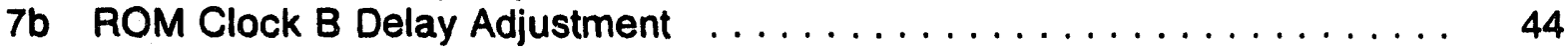

8a PG B DAC_CLK (ROM Select) / ROM A QO_ANHS Delay Adjustment ... 45

8b PG B DAC_CLK (ROM Select) / ROM B QO_B/HS Delay Adjustment . . 46

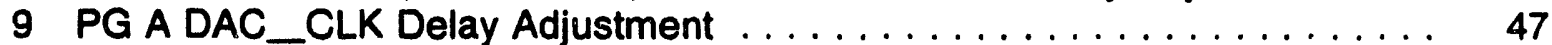

10 Instantaneous Frequency Clock Output Verification $\ldots \ldots \ldots \ldots \ldots \ldots$

Appendix B. High Speed Digital Test System

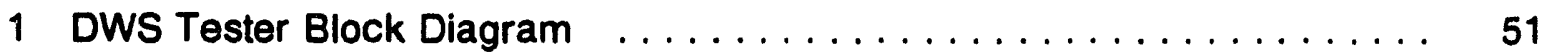

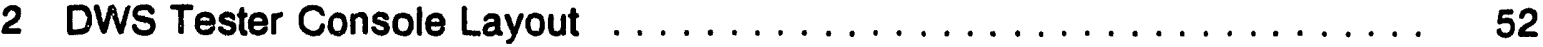

3 DWS Test Console ............................ 53

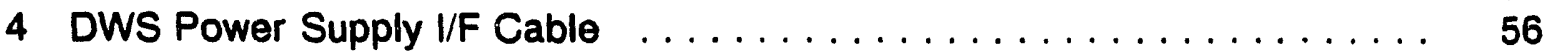

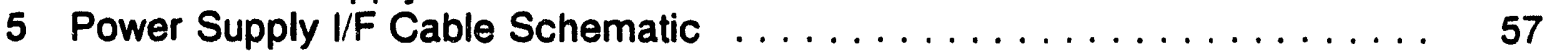

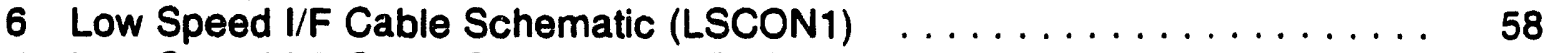

7 Low Speed I/F Cable Schematic (LSCON2) $\ldots \ldots \ldots \ldots \ldots \ldots \ldots \ldots$

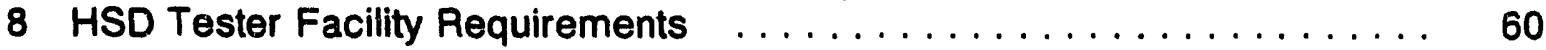

Appendix C. Specifications for a High Speed Testing Interface

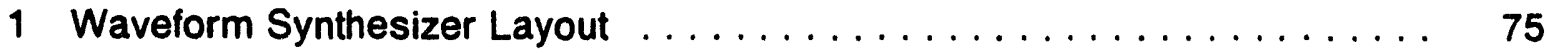

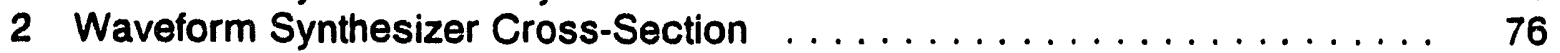

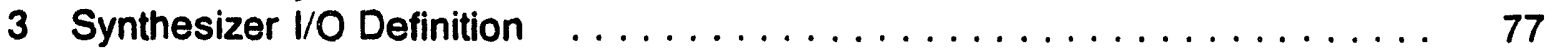

4 Synthesizer High Speed Interconnect $\ldots \ldots \ldots \ldots \ldots \ldots \ldots$

5 Conceptual Interface Board ........................ 79

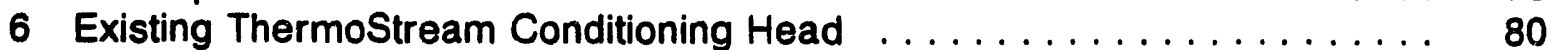

7 Mechanical Constraints, I/F Board Top Surface $\ldots \ldots \ldots \ldots \ldots \ldots$. . . . . . 81

8 Mechanical Constraints, I/F Board Bottom Surface $\ldots \ldots \ldots \ldots \ldots \ldots$

9 ThermoChuck/Board Clearances $\ldots \ldots \ldots \ldots \ldots \ldots \ldots$ 
Appendix D. DWS Test Interface

1 Cross-Section of HS I/F Board $\ldots \ldots \ldots \ldots \ldots \ldots \ldots \ldots \ldots, 89$

2 HS I/F Board With All Metal Layers Visible $\ldots \ldots \ldots \ldots \ldots \ldots \ldots . \ldots 90, \ldots$

3 Probe Station Features (Front View) $\ldots \ldots \ldots \ldots \ldots \ldots \ldots \ldots \ldots, \ldots 1$

4 Probe Station Features (Top View) $\ldots \ldots \ldots \ldots \ldots \ldots \ldots \ldots \ldots \ldots . \ldots 2$

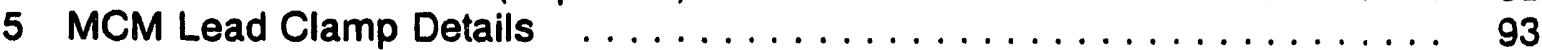

6 High Speed MCM Test System . . . . . . . . . . . . . . . . . . . . . . . . . . 94

7 HS Board MCM Cutout and ThermoChuck ................... 95

$8 \mathrm{MCM}$ Inserted Into the HS Board Cutout $\ldots \ldots \ldots \ldots \ldots \ldots \ldots \ldots \ldots . \ldots 6$

9 MCM Leads Clamped to the HS Board . . . . . . . . . . . . . . . . . . 97

10 Positional Relations of MCM, Board and Station .............. 98

11 HS Probe Setup for MCM In-Process Testing ............... 99

12 HS Probe Tips in Contact With the MCM ................ 100

13 Electrical Interconnect and Thermal Control .................. 101

14 MCM Electrical Interface Schematic ...................... 102

15 Measured Return Loss of HS Board $(S / N$ 1) $\ldots \ldots \ldots \ldots \ldots \ldots . \ldots 103$

\section{Tables}

Number Page

Appendix A. [JWS Test Plan

1 DWS Acceptance Limits $\ldots \ldots \ldots \ldots \ldots \ldots \ldots \ldots \ldots \ldots \ldots \ldots$

Appendix B. High Speed Digital Test System

1 DWS Test Console Equipment $\ldots \ldots \ldots \ldots \ldots \ldots \ldots \ldots \ldots \ldots$

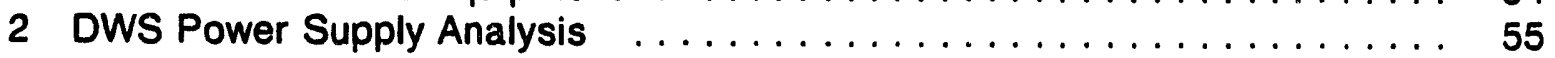

Appendix D. DWS Test Interface

2 High Speed Digital Test Interface Equipment $\ldots \ldots \ldots \ldots \ldots \ldots$ 


\title{
Abstract
}

\begin{abstract}
Establishing a high-speed digital (HSD) test capability for the Digital Waveform Synthesizer (DWS) multichip module (MCM) has required the development of several areas: a detailed test plan for the MCM; design, fabrication and prove-in of the high-speed test console; and the specification, design, and development of the high-speed test and environmental conditioning interface to the DWS. These development activities have been successfully completed at the AlliedSignal Inc., Kansas City Division (KCD), and the test capability described herein is currently supporting DWS MCM testing and can be adapted to similar HSD module testing.
\end{abstract}

\section{Summary}

The design and development of the Digital Waveform Synthesizer (DWS) multichip module (MCM) is documented in a report entitled "High-Speed Digital Project, Waveform Synthesizer (KCP-613-5076). 1 Because the test capability for the DWS MCM was only minimally addressed within that report, the purpose of this report is to document the high-speed digital (HSD) test capability developed for the DWS.

As described within the cited report, the DWS MCM is a complex MCM composed of a number of GaAs ASIC (gallium arsenide application-specific integrated circuit) die and surface mount components assembled on a $2.25 \times 2.25$ inch, 31-layer LTCC (low temperature cofired ceramic) substrate. Of the 104 cantilevered $1 / O$ leads (26 per side), approximately 20 carry signals whose high frequency content exceeds $1 \mathrm{GHz}$. In light of these preliminary facts, a detailed test plan was required to define the testing approach and sequence for such a unit.

Following the development of the detailed test plan, it was then possible to design and lay out a test system which could meet the test requirements contained within the plan. This system is composed of two major parts: a console and an interface. First, the three-bay test console contains all of the commercial equipment (separate from the interface), custom chassis and panels, and interconnect cabling. The console computer provides program control of test event setup, stimuli applications and monitoring of DWS responses, test event sequencing, and test data storage and hardcopy.

The high-speed interface for the DWS consists of a probe station with optics, a high-speed interface board with cabling, and dual thermal control features; and it meets the DWS electrical, physical, and thermal interface requirements both cited and implied within the plan. This interface was created through the development of a KCD interface specification, an RFQ process with interface supplier selection, interface design reviews, status reports, and, finally, acceptance testing and installation. 


\section{Discussion}

\section{Scope and Purpose}

The developed high speed digital (HSD) test capability directly supports the conditioning and testing of the Digital Waveform Synthesizer (DWS) multichip module (MCM), an advanced development HSD test vehicle. This vehicle is the first of perhaps several HSD test vehicles, and the developed test capability can be adapted to the testing of functionally similar vehicles.

\section{Activity}

The activities surrounding the development of the HSD test capability began with the development of a test plan for the DWS MCM. The design, layout, fabrication, and prove-in of the system test console and the specification, procurement, and integration of the high-speed test interface all became subsequent events based on the plan.

\section{DWS Test Plan}

An essential first step in the development of any test system is the development of a test plan for the product requiring the testing. A DWS MCM test plan was developed toward the end of the MCM design, and its evolution required several iterations between the module design engineer and the test equipment engineer. The final version of the "Detailed Test Plan for the High Speed Digital Waveform Synthesizer" is presented in Appendix A and encompasses virtually all aspects of the testing. Addressed items include product definition, assumptions, definitions and equations, expected accuracies and environments, pre-lid and post-lid test sequences, and the definition of each functional test including initialization, setup conditions, and the planned method of test execution and parameter measurement. The plan concludes with the tabulation of limits for each measured parameter for the DWS MCM.

\section{HSD Test System}

The test plan could not be fully developed without just consideration of test techniques, hardware and software implementation, conditioning requirements, etc. Thus, the envisioned test system resulting from the plan included two major parts: a test console and a high-speed interface. The test console is a three-bay unit which houses the digital control equipment (computer with VGA monitor and printer), all electrical stimuli and measurement equipment (supplies, generators, digitizer, oscilloscope, analyzer, DMM, and an optical delay line), and all internal cabling. This console is presented in detail in Appendix B where the system block diagram, console layout (drawing and resulting photo), console equipment list, and cable definitions are provided. This appendix also presents the facility requirements for the test system.

\section{Interface Specifications}

Based on the test plan, an interface specification was drafted to detail the electrical, thermal, and mechanical requirements of the interface for the DWS MCM. In addition to the cited areas of detail, the interface specification also stipulates design reviews and specific 
verification methods to ensure interface conformance to the specification. This "Specifications for a High Speed Testing Interface" is presented in Appendix C, and it served as the basis of an RFQ process leading to the selection of the supplier of the interface.

\section{DWS Test Interface}

The test interface is detailed in Appendix D where the interface development sequence, equipment list, interface board diagrams, schematic and photos, photos of the probe station features, and high-

frequency board verification measurements are all presented. The supplier proved to be a sound choice for this interface because it is a distributor of stations with extensive experience applicable to designing and adapting the high-speed board to the station with attendant thermal and mechanical considerations.

While the system test console possesses many features which may be adapted to testing product functionally similar to the DWS MCM, certain aspects of the highspeed test interface are uniquely designed for DWS testing only. This uniqueness is found primarily in the high-speed interface board where the physical and $1 / O$ features unique to the DWS must be appropriately matched by the interface board. Thus, as a minimum, this interface would require a new interface board if adaptation to another MCM was desired. To a lesser degree, some other interface features may also require modification to accommodate a different MCM size and thickness.

\section{Accomplishments}

A high-speed digital test system, composed of a test console and a highspeed test interface, has been developed and is currently supporting the testing of the digital waveform synthesizer MCM.
Several accomplishments related to the system development can be cited.

- Surplus and laboratory equipment were used to minimize the console cost wherever possible (cabinetry and much of the instrumentation, including computer and printer). Exceptions included power supplies, a highfrequency pulse generation system, and an optical delay line with associated hardware. This console, in conjunction with the interface, provides a DWS MCM test capability at clock rates exceeding $800 \mathrm{MHz}$.

- The system software was developed in Microsoft BASIC 7.1 and includes a general purpose test executive and unique test sequence modules. The executive includes Menu, Limits, Printer and Screen routines, and the test sequence modules define the custom requirements of the MCM where instrument drivers and test sequencing are addressed. Overall, these software items, functioning together, establish semiautomatic test control for the DWS MCM and, with minor modifications, can be adapted to functionally similar units.

- A high-speed digital interface and test station have been specified, procured, assembled, and proved-in. This interface and station meet the unique electrical, mechanical, and thermal requirements demanded by the DWS MCM. Further, an additional capability has also been developed in conjunction with the station which permits the in-process probing and troubleshooting of operating units. 


\section{Reference}

1C. T. Allen and R. E. Markley, High-Speed Digital Project, Waveform Synthesizer (Topical Report). Kansas City Division: KCP-613-5076, June 1993 (Available from NTIS). 


\title{
Appendix A
}

\author{
DWS Test Plan
}




\section{DETAILED TEST PLAN FOR THE \\ HIGH SPEED DIGITAL WAVEFORM SYNTHESIZER}

Date: May 24, 1993

$$
\begin{aligned}
& \text { Prepared by } \\
& \text { Jerry Elarton }
\end{aligned}
$$

Test Equipment Design 
TABLE OF CONTENTS

1. GENERAL . . . . . . . . . . . . . . . . . . . . 4

1.1

1.2

1.3

1.4

2 .

2.1

2.2

2.3

2.4

3.

3.1

3.2

4.

4.1

4.2

4.2 .1

4.2 .2

4.2 .3

4.2 .4

4.3

4.3 .1

4.3 .2

4.3 .3

4.3 .4

4.4

4.5

4.6

4.7

4.8

4.8 .1

4.8 .2

4.9

4.9 .1

Product Description . . . . . . . . . . . . . . . 4

Testing Assumptions . . . . . . . . . . . . . . . . . 4

Definitions . . . . . . . . . . . . . . . . . . . 5

DWS Address and Register Definition . . . . . . . 8

ACCURACIES and ENVIRONMENTS . . . . . . . . . . . 10

Stimuli Accuracies . . . . . . . . . . . . . 10

Measurement Accuracies . . . . . . . . . . . 10

Test Temperatures . . . . . . . . . . . . . . 11

Power Source Definition . . . . . . . . . . . . 11

TEST SEQUENCE • . . . . . . . . . . . . . . . . . . . . 11

Pre-Lid Test Sequence . . . . . . . . . . . . . . . 11

Post-Lid Test Sequence . . . . . . . . . . . . 12

FUNCTIONAL TESTS . . . . . . . . . . . . . . . . 13

Input Voltages and Currents . . . . . . . . . . 13

clock Delay Adjustments (Probing Method) . . . . . 13

ROM CLK A Delay Adjustment

ROM CLK B Delay Adjustment

ROM SELECT Delay Adjustment

DAC_CLK Delay Adjustment

Clock Delay Adjustments (Non-Probing Method) . • . 17

ROM_CLK_A Delay Adjustment

ROM CLK B Delay Adjustment

ROM SELECT Delay Adjustment

DAC CLK Delay Adjustment

Instañtaneous Frequency Clock Output Verification . . 20

Instantaneous Frequency Verification . . . . . . . . 21

Output Clocks Verification . . . . . . . . . . . 23

SINE ROM Verification . . . . . . . . . . . . . 23

Verification of Frequency Registers . . . . . . . . . 24

PG $A$ and PG B TX Frequency Register Verification

PG $A$ and PG B Rx Frequency Register Verification

Verification of External Phase Registers . . . . . . 27

External Phase Register $A$ and $B$ Verification

4.10

Chirp Pulse Compression Test . . . . . . . . . 29 


\section{EIST OF FIGURES}

Pigure

Page

1 DWS Pinout . . . . . . . . . . . . . . 33

2 DWS Block Diagram . . . . . . . . . . . . . . 34

3 PG Block Diagram . . . . . . . . . . . . . . 35

4 DWS Timing Diagram . . . . . . . . . . . . . 36

5 ECL Input Logic ' $O$ ' and ' 1 ' Definition . . . . . . 37

6 TTL Input Logic ' $O$ ' and ' 1 ' Definition . . . . . . 37

7a ROM CLOCK A Delay Adjustment . . . . . . . . . . 38

7b ROM Clock B Delay Adjustment . . . . . . . . . . 39

8a PG B DAC_CLK (ROM Select) / ROM A QO_A/HS . . . . . 40 Delay Adjustment

8b PG B DAC_CLK (ROM Select) / ROM B QO_B/HS . • . . . 41 Delay Adjustment

9 PG A DAC_CLK Delay Adjustment . . . . . . . . . . . 42

10. Instantaneous Frequency Clock Output Verification . . 43

\section{IIST OF TABLES}

Table

Page

1 DWS Acceptance Limits . . . . . . . . . . 30-32 
1. GENERAL

This test document describes the development test requirements for testing the high speed Digital Waveform Synthesizer (DWS) multichip module (MCM).

\subsection{Product Description}

This product, when properly initialized and triggered, generates a pulsed linear FM (chirp) waveform, used for RADAR applications. It is also capable of generating a continuous wave (CW) output, useful for testing and troubleshooting the product.

This product consists of the following components:

1. multilayer, Low Temperature Co-fired Ceramic (ITCC) substrate;

2. two custom GaAs Phase Generator ASIC's (PG A, PG B);

3. two identically preprogrammed GaAs ROM's containing a SINE lookup table (ROM A, ROM B);

4. one GaAs 8 bit Digital-to-Analog Converter (DAC);

5. miscellaneous digital latches, buffers, resistors and capacitors.

\subsection{Testing Assumptions}

The following assumptions were made in deriving the tests contained herein:

1. the components contained in the MCM passed all component tests;

2. the purpose of production testing is to detect any manufacturing defects of the product, not validate that the product was designed properly (for example, we need only verify that all of the Instantaneous Frequency outputs [7:0] can toggle, not that the outputs represent the correct instantaneous frequency for any given test condition). 


\subsection{Definitions}

The following defined terms are pertinent to this product:

\section{Eymbol}

EXT_PHASE_A Reg Integer

EXT_PHASE_B ${ }_{\text {Reg Integer }}$

$\mathbf{f}_{\mathrm{s}} \quad \mathrm{Hz}$

fo

$\mathrm{f}_{1}^{\circ} \quad \mathrm{Hz}$

$f_{2} \quad \mathrm{~Hz}$

$f(t) \quad \mathrm{Hz}$

$F(n) \quad$ Integer

$F(n)^{\prime}$

K

$\mathbf{K}_{\text {Reg }}$

$\mathrm{K}_{\text {Res }}$

n

$\stackrel{p}{p}(t)$

$P(n)$

$P(n)^{\prime}$

P_ROM (n)

$\mathrm{Rx}$

$\mathrm{RX}_{\text {Reg }}$

Rx $x_{\text {Res }}$

$t$

T

${ }^{T X_{\text {Reg }}}$

Tx $x_{\text {Res }}$
Units

Integer

$\mathrm{MHz} / \mathrm{us}$

Integer

MHz / us

Integer

Cycles

cycles

Integer

Integer

Integer

$\mathrm{Hz}$

Integer

$\mathrm{Hz}$

Seconds

Seconds/cycle

$\mathrm{Hz}$

Integer

$\mathrm{Hz}$
Description

PG A External Phase register (12 bits)

PG B External Phase register (12 bits)

Sample frequency (CLOCK IN/HS)

True chirp starting freq. Programmed chirp starting frequency

Chirp ending frequency

Instantaneous Frequency

Instantaneous Frequency register (24 bits)

Instantaneous Frequency register output (upper 8 bits only of $F(n)$ )

Chirp rate

Chirp rate register (24 bits)

Chirp rate register incremental resolution

Discrete time step increments of period $\mathrm{T}_{\mathrm{S}} ; \mathrm{n}=(0,1,2 \ldots)$

Chirp starting phase Instantaneous phase (integral of $f(t)$ )

Instantaneous Phase register (24 bits)

Instantaneous Phase register output (upper 12 bits only of $P(n)$ )

actual phase register output to ROM as the ROM address (12 bits)

Receive starting freq.

Receive starting freq. register (24 bits)

Rx Register incremental resolution

Time

Period of $f_{s}$

Transmit starting freq. Transmit starting freq. register (24 bits)

Tx Register incremental resolution 
The following are definitions of equations associated with this product:

\section{TIME DOYAIN DEFINITIONS}

$\mathbf{f}_{\mathbf{S}}$ (CLOCK_IN/HS) PERIOD:

$$
T_{s}=\frac{1}{f_{s}} \quad \text { (for example, at } f_{s}=800 \mathrm{MHz}, T_{s}=\frac{1.25 \mathrm{~ns}}{1 \text { cycle }}
$$

FREQUENCY ACCUMULATOR:

$$
f(t)=f_{1}+K * t
$$

PHASE ACCUMULATOR:

$$
p(t)=\left(f_{1}-0.5 * K\right) t+0.5 * K t^{2}+p_{0}
$$

TRUE CHIRP STARTING FREQUENCY:

$$
f_{0}=f_{1}-0.5 * K
$$

\section{DIBCRETE DIGITAL DOMAIN DEFINITIONS}

TX START FREQUENCY REGISTER RESOLUTION (24 bit register):

$$
T x_{\text {Res }}=\frac{f_{s}}{2^{2} \overline{4}} \quad \begin{aligned}
& \left(\text { for example, at } f_{S}=800 \mathrm{MHz},\right. \\
& \left.\mathrm{Tx}_{\text {Res }}=47.68372 \mathrm{~Hz}\right)
\end{aligned}
$$

TX START FREQUENCY REGISTER CONTENTS (24 bit register):

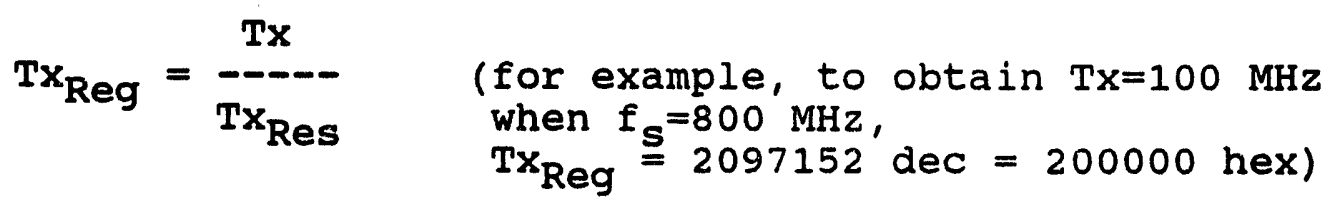

RX START FREQUENCY REGISTER RESOLUTION (24 bit register):

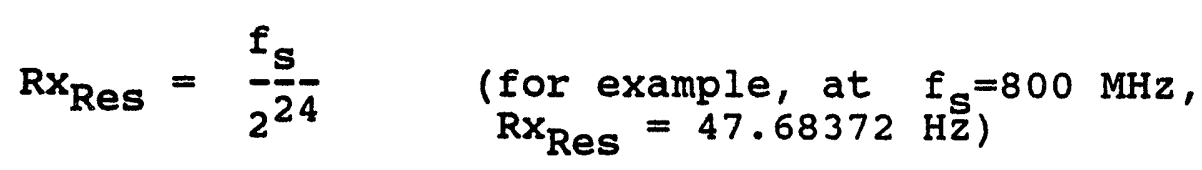


RX START FREQUENCY REGISTER CONTENTS (24 bit registers):

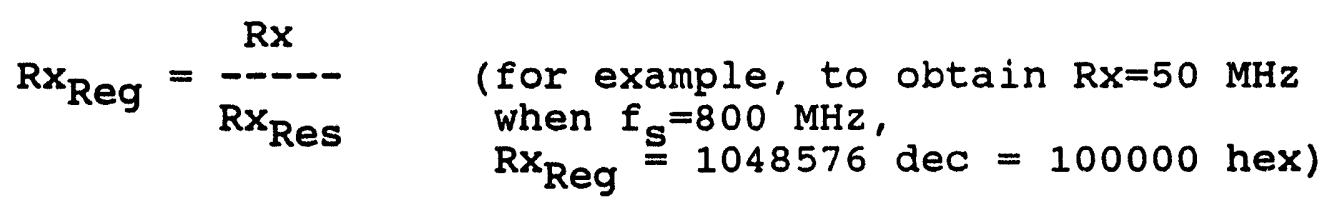

CHIRP RATE REGISTER BIT RESOLUTION (24 bit registers):

$$
\begin{aligned}
& K_{\text {Res }}=\frac{\left(f_{s}\right)^{2}}{2^{24}} \quad \text { where } f_{s} \text { is in } M H z \\
& \text { (for example, at } \mathrm{f}_{\mathrm{s}}=800 \mathrm{MHz} \text {, }
\end{aligned}
$$

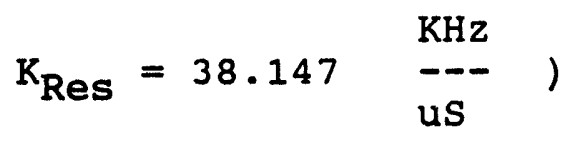

K CHIRP RATE REGISTER CONTENTS (24 bit registers):

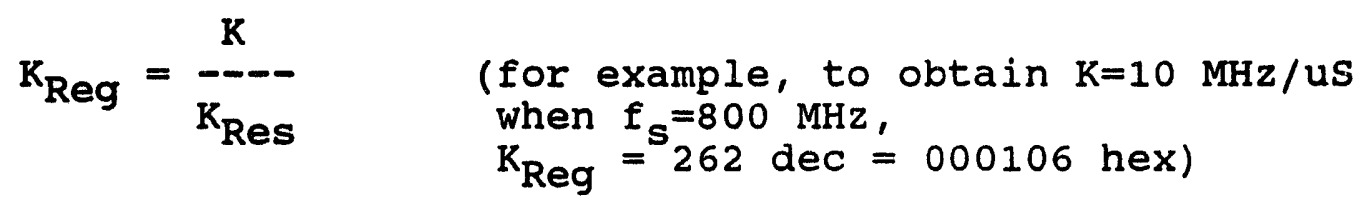

FREQUENCY ACCUMULATOR CONTENTS (24 bit accumulator):

$$
\begin{array}{cc}
F(n)=\mathrm{Tx}_{\text {Reg }}+\mathrm{K}_{\text {Reg }}{ }^{* n} & \text { or } \\
F(n)=R x_{\text {Reg enabled) }}+\mathrm{K}_{\text {Reg }}{ }^{* n} & \text { (Rx enabled) }
\end{array}
$$

PHASE ACCUMULATOR CONTENTS (24 bit accumulator):

$$
\begin{gathered}
P(n)=\left(T x_{\text {Reg }}-0.5 * K_{\text {Reg }}\right) n+0.5 * K_{R e g} n^{2} \quad(T x \text { enabled) } \\
\text { or } \\
P(n)=\left(R x_{\text {Reg }}-0.5 * K_{\text {Reg }}\right) n+0.5 * K_{R e g} n^{2} \quad \text { (Rx enabled) }
\end{gathered}
$$

ACTUAL PHASE OUTPUT (ADDRESS) TO ROM CONTENTS

(12 bit accumulator):

$$
\begin{array}{ll}
\text { P_ROM }(n)=P(n)^{\prime}+\text { EXT_PHASE_A } R e g & \text { (ROM A address) } \\
\text { P_ROM }(n)=P(n)^{\prime}+\text { EXT_PHASE_B Reg } & \text { (ROM B address) }
\end{array}
$$


REQUIRED EXTERNAL PHASE B CONTENTS TO PRODUCE SINE WAVE (12 bit register):

$$
\begin{aligned}
& \text { EXT_PHASE_B }{ }_{\text {Reg }}=0.5 * \mathrm{TX}_{\text {Reg }}+\mathrm{EXT}_{-}{ }^{\mathrm{PHASE}}{ }_{-}{ }_{\mathrm{Reg}} \quad(\mathrm{TX} \text { enab.) } \\
& \text { or } \\
& \text { EXT_PHASE_B }{ }_{\text {Reg }}=0.5 * R x_{\text {Reg }}+E X T \text { PHASE_A }{ }_{\text {Reg }} \text { (Rx enab.) }
\end{aligned}
$$

\subsection{Dw8 Address and Register Definition}

The following information defines the DWS strobes, register modes, and control words. Note that the same data bus, DATA[23:0], is multiplexed to all registers. The falling edge of an TTL logic ' 1 ' to ' $O$ ' on STROBE_A or STROBE_B selects Phase Generator A or B and will load DATA[23:0] into one of four registers selected by MODE1 and MODEO. The rising edge of an 'TT' logic ' 0 ' to ' 1 ' on STROBE_C will load the lower 12 bits, DATA[11:0], into Phase Generatōr B EXT_PHASE_B ${ }_{\text {Reg }}$ and the upper 12 bits, DATA[23:12], into Phase Generator A EXT_PHASE_A Reg.

Refer to Figure 2 (DWS Block Diagram), Figure 3 (PG Block Diagram), and Figure 4 (DWS Timing Diagram) for further information.

\footnotetext{
strobe Function

STROBE_A Strobes DATA[23:0] into PG A register selected by MODE [1:0]

STROBE_B Strobes DATA[23:0] into PG B register selected by MODE [ 1:0]
}

Programming Mode:

$\begin{array}{lllll}\text { KODE1 } & \text { YODEO } & & \text { Register } \\ 0 & 0 & & \text { CONTROL WORD } \\ 0 & 1 & \text { RX START FREQUENCY } & \left(\text { Rx }_{\text {Reg }}\right) \\ 1 & 0 & \text { TX START FREQUENCY } & \left(\mathrm{Tx}_{\text {Reg }}\right) \\ 1 & 1 & \text { CHIRP RATE (K } & \end{array}$


Control word Parameters:

\begin{tabular}{|c|c|c|}
\hline Bits & Value & Function \\
\hline $23: 14$ & $\overline{\operatorname{all} 0^{\prime} \mathrm{s}}$ & Not used \\
\hline $13: 12$ & & IF_CLK = INT_CLK \\
\hline & $\begin{array}{l}01 \\
10\end{array}$ & $\begin{array}{l}I F-C L K=I N T-C L K / 2 \\
I F-C L K=I N T C L K / 4\end{array}$ \\
\hline & 11 & $I F C L K=I N T C L K / 8$ \\
\hline 11 & 0 & EXT̄_PHASE syñchronization enabled \\
\hline & 1 & EXT_PHASE synchronization by-passed \\
\hline 10 & 0 & DAC_CLK as programmed in bits $2: 0$ \\
\hline- & 1 & DAC_CLK = DCLK as programmed in bits \\
\hline \multirow[t]{2}{*}{9} & 0 & INT $C L K=D C L K$ \\
\hline & 1 & $\mathrm{INT}^{-} \mathrm{CLK}=\mathrm{DCLK}$ \\
\hline \multirow[t]{2}{*}{8} & 0 & DCL $\bar{K}=$ IDCLK \\
\hline & 1 & DCLK = EDCLK \\
\hline \multirow[t]{2}{*}{7} & 0 & IDCLK freq $=$ CLOCK_IN freq $\left(f_{S}\right)$ \\
\hline & 1 & IDCLK freq $=$ CLOCK_IN freq/2 $\left.\mathrm{Yf}_{\mathrm{s}} / 2\right)$ \\
\hline 6 & $\begin{array}{l}0 \\
1\end{array}$ & ROM_CLK not inverted \\
\hline \multirow[t]{4}{*}{$5: 4$} & 00 & Delayy of ROM_CLK $=D_{2}$ \\
\hline & 01 & Delay of ROM_CLK $=\mathrm{D}_{2}^{2}+500 \mathrm{pS}$ \\
\hline & 10 & Delay of ROM_CLK $=\mathrm{D}_{2}^{2}+1000 \mathrm{ps}$ \\
\hline & 11 & Delay of ROM_CLK $=D_{2}+1500 p S$ \\
\hline \multirow[t]{2}{*}{3} & 0 & DAC_CLK $=$ CLŌCK_IN freq $\left(f_{S}\right)$ \\
\hline & 1 & DAC_CLK $=$ CLOCK_IN freq/2 $\left(\mathrm{f}_{\mathrm{s}} / 2\right)$ \\
\hline \multirow[t]{2}{*}{2} & 0 & DAC_CLK not inverted \\
\hline & 1 & DAC_CLK inverted \\
\hline \multirow[t]{3}{*}{$1: 0$} & 00 & Delāy of DAC_CLK $=D_{0}$ \\
\hline & 10 & Delay of DAC_CLK $=\mathrm{D}_{0}+500 \mathrm{pS}$ \\
\hline & 11 & $\begin{array}{l}\text { Delay or DAC-CLK }=D_{0}+1000 \mathrm{pS} \\
\text { Delay of } \mathrm{DAC}-\mathrm{CLK}=\mathrm{D}_{0}+1500 \mathrm{pS}\end{array}$ \\
\hline
\end{tabular}

where:

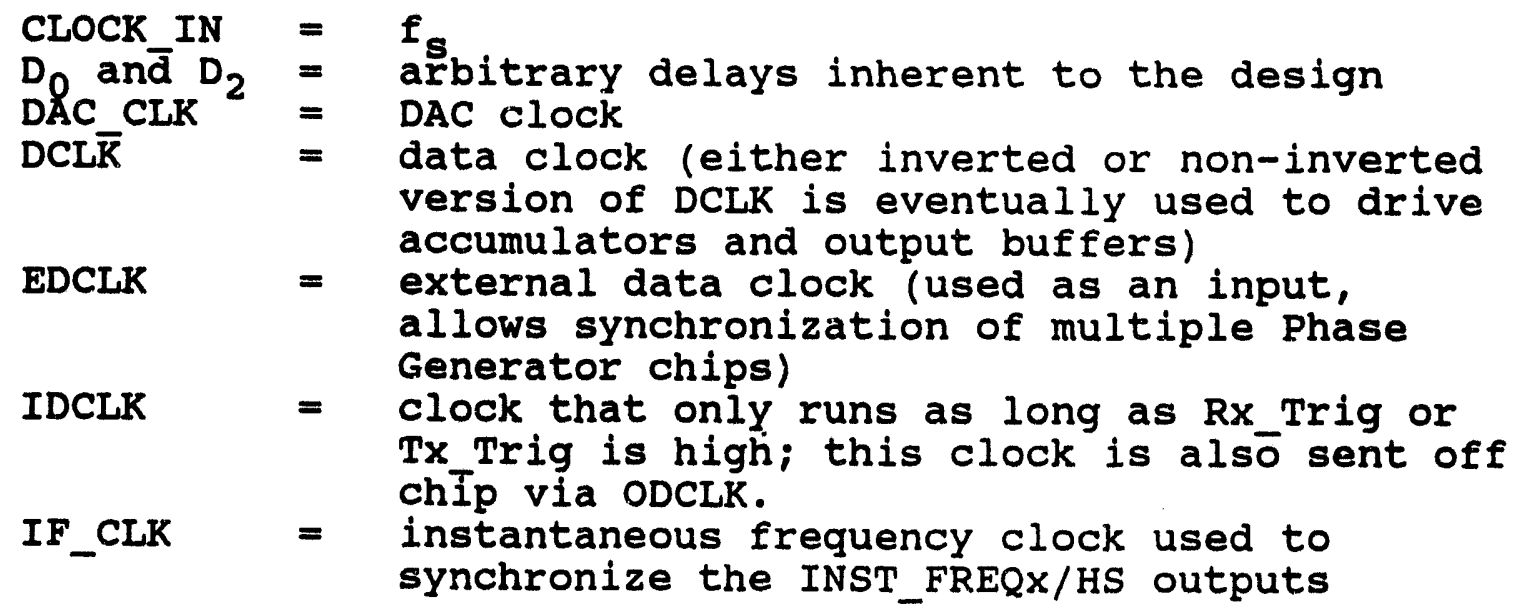




$$
\begin{array}{ll}
\text { INT_CLK = } & \begin{array}{l}
\text { internal data clock that actually drives } \\
\text { accumulators and output buffers and can be } \\
\text { either DCLK or DCLK }
\end{array} \\
\text { ROM_CLK }= & \text { ROM clock }
\end{array}
$$

This particular DWS design requires the following Control Word register defaults (23:14 are don't cares, therefore set to 0 ; $x$ is determined by the control word parameters desired):

PG A:

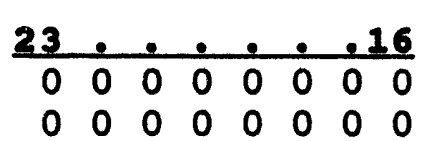

\section{Control word}

PG B:
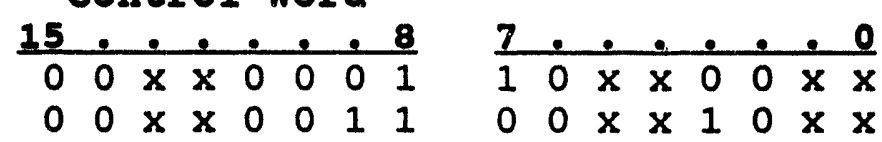

strobe STROBE_C

\section{Function}

Strobes DATA $[11: 0]$ into PG A EXT PHASE_AReg and DATA [23:12] into PG B EXT_PHASE_ $\bar{B}_{\text {Reg }}$

\section{ACCURACIES and ENVIRONMENTS}

\section{1 stimuli Accuracies}

The tester will apply stimuli to the following accuracies:

\section{Btimulus \\ DCV}

Tx\& Rx Pulses: timing amplitude

ECL levels

TTL levels

Temperature
Accurecy

$+/-0.1 \%$ or $10 \mathrm{mV}$, whichever is greater

$$
+/-50 \mathrm{ps}
$$$$
+/-50 \mathrm{mV}
$$$$
+/-50 \mathrm{mV} \text { (see Figure } 5 \text { for }
$$$$
\text { definition of } \log i c
$$
levels)

$+1-0.1 \mathrm{~V}$ (see Figure 6 for definition of logic $+1-3^{\circ} \mathrm{C}$ levels)

\subsection{Measurement Accuracies}

The tester will measure to the following accuracies:

NOTE: The limits stated in this specification (see Table 1) have already been adjusted to allow for these measurement accuracies. Therefore, the limits as stated may be used without further tightening. 


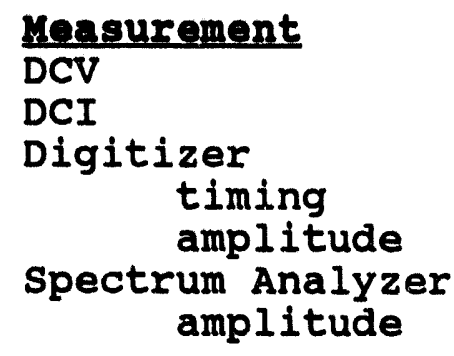

2.3 Test Temperatures

Temperature code

AT (AMB)

CT (COLD)

HT (HOT)
Aocuracy

$+/-0.1 \%$

$+1-0.1 \%$

$+1-0.18$

$+/-3 \%$ or $10 \mathrm{mV}$, whichever is greater

$+/-2.2 d B$ flatness

\section{Temperature}

Room Temperature

$-55^{\circ} \mathrm{C}$

$+75^{\circ} \mathrm{C}$

\subsection{Power Bource Definition}

\begin{tabular}{ccc} 
Pover supply & ouT Identification & \multicolumn{1}{l}{ Applied Voltage } \\
\cline { 2 - 3 } & V5 & $+5.0+/-.1$ VDC \\
PS1 & VN2 & $-2.0+/-.1$ VDC \\
PS3 & VN3 & $-3.4+/-.1$ VDC \\
PS4 & VN5 & $-5.2+/-.1$ VDC \\
PS5 & VN5A & $-5.2+/-.1$ VDC
\end{tabular}

3. TEST BEQUENCE

\subsection{Pre-Lid Test sequence}

The following sequence is planned for pre-lid testing. Note that the sequence may be performed in any order except as noted.

\section{Pre-Ifid Test sequence}

Temperature Notes

4.1 Input Voltages and Currents

4.2 Clock Delay Adj. (Probing)

4.3 Clock Delay Adj. (Non-Probing)

4.4 Instantaneous Frequency clock Output Ver. AT

4.5 Instantaneous Frequency Verification

4.6 Output Clocks Verification

1

AT

AT 1,2

AT 1,3

AT

AT

AT

4.8 PG A and PG B Frequency Registers Ver. AT

4.9 Verification of External Phase Registers AT

4.10 Chirp Pulse Compression Test

Notes:

$$
\begin{aligned}
& 1=\text { must be performed first and in order listed } \\
& 2=\text { development only } \\
& 3=\text { production only }
\end{aligned}
$$




\subsection{Post-Iid Test sequence}

The following sequences are planned for post-lid testing. Note that these sequences may be performed in any order except as noted.

\section{Post-Ifd Test sequence}

4.1 Input Voltages and Currents

4.3 Clock Delay Adj. (Non-Probing)

Temperature Notes

4.4 Instantaneous Frequency Clock

4.5 Instantaneous Frequency Verification AT

4.6 Output Clocks Verification AT

4.7 SINE ROM Verification AT

4.8 PG A and PG B Frequency Registers Ver. AT

4.9 Verification of External Phase Registers AT

4.10 Chirp Pulse Compression Test AT

4.1 Input Voltages and Currents CT

4.3 Clock Delay Adj. (Non-Probing) CT

4.4 Instantaneous Frequency Clock Output Ver. CT

4.5 Instantaneous Frequency Verification CT

4.6 Output Clocks Verification CT

4.7 SINE ROM Verification CT

4.8 PG A and PG B Frequency Registers Ver. CT

4.9 Verification of External Phase Registers CT

4.10 Chirp Pulse Compression Test CT

4.1 Input Voltages and Currents HT 1

4.3 Clock Delay Adj. (Non-Probing) HT

4.4 Instantaneous Frequency Clock Output Ver. H

4.5 Instantaneous Frequency Verification HT

4.6 Output clocks Verification HT

4.7 SINE ROM Verification HT

4.8 PG A and PG B Frequency Registers Ver. HT

4.9 Verification of External Phase Registers HT

4.10 Chirp Pulse Compression Test HT

4.1 Input Voltages and currents AT 1

4.3 Clock Delay Adj. (Non-Probing) AT

4.4 Instantaneous Frequency Clock Output Ver. AT

4.5 Instantaneous Frequency Verification AT

4.6 Output Clocks Verification AT

4.7 SINE ROM Verification AT

4.8 PG A and PG B Frequency Registers Ver. AT

4.9 Verification of External Phase Registers AT

4.10 Chirp Pulse Compression Test AT

Notes: $\quad 1$ = must be performed first and in order listed at each temperature usage.

2 = development only

3 = production only 
4. TUNCTIONAL TESTS

The following tests (except 4.1) assume that the UUT has been initialized to the following default conditions before each test is run, and Phase Generators $A$ and $B$ are abbreviated PG A and PG $B$, respectively.

\section{Initializing sequence:}

1. Apply Power Supplies 1 thru 5 (PS1, PS2, PS3, PS4, PS5) to UUT. Apply $800 \mathrm{MHz}$ clock to UUT (see Figure 1 for DWS pinout).

2. PG A EXTERNAL PHASE Register $=000$ Hex PG B EXTERNAL PHASE Register $=000 \mathrm{Hex}$

3. Apply an TTL logic ' $O$ ' and then back to an TTL logic ' 1 ' to TTL_RESET (resets PG A \& PG B to their normal idle states)

4. PG A Tx Start Frequency Register $=000000$ Hex

Rx Start Frequency Register $=000000$ Hex

Chirp Rate Register $=000000$ Hex

Clock Control Register $=000180 \mathrm{Hex}$

(add delay values to clock Control Register when they are known)

5. PG B TX Start Frequency Register $=000000 \mathrm{Hex}$

Rx Start Frequency Register $=000000$ Hex

Chirp Rate Register $=000000 \mathrm{Hex}$

Clock Control Register $=000308$ Hex

(add delay values to Clock Control Register when they are known)

\subsection{Input Voltages and Currents}

Apply Power Supplies 1 thru 5 (PS1, PS2, PS3, PS4, PS5) to UUT. Measure input voltages and currents and compare to limits. If any voltage or current fails its limits, do not continue testing until the problem is resolved.

\subsection{Clock Delay Adjustments (Probing Method)}

The following paragraphs describe how to determine the correct programmable clock delays using the digitizer probing method. This method, unless the probing placement is automated, would probably take too long in a production environment and, therefore, is specified as a development requirement only.

\subsubsection{ROX_CLR_A Delay Adjustment}

This test will determine what delay value to load into PG $A$, Delay of ROM_CLK_A (CLOCK CONTROL REGISTER, bits 5:4), in order to compensāte for inherent circuit delays. The delay should be such that the Phase data (ADDRx_A/HS) have time to 
stabilize before the ROM Clock (ROM CLK A/HS) strobes these data. The four possible delay combínations $(00,01,10,11$ binary) represent approximately 0, 500, 1000, and 1500 ps delays, respectively.

The sample clock frequency (CLOCK_IN/HS) is $800 \mathrm{MHz}$.

The transmit frequency register contents are chosen such that the ADDRO A/HS bit will toggle at the fastest rate possible (200 MHz) and update the Digitizer waveforms as rapidly as possible.

The frequency is chosen as follows (see section 1.3 for the general form of these equations): $\therefore$

$$
\begin{array}{ll}
\mathrm{P} \operatorname{ROM}(\mathrm{n}) & =\mathrm{P}(\mathrm{n})^{\prime}+\mathrm{EXT} \text { PHASE } \mathrm{A}_{\mathrm{Reg}} \\
\mathrm{P}(\mathrm{n})^{\prime} & =\text { upper } 12 \text { biEs of } \mathrm{P}(\mathrm{n})^{\prime} \\
\mathrm{P}(\mathrm{n}) & =\left(\mathrm{TX}_{\text {Reg }}\right)^{\prime} * \mathrm{n}
\end{array}
$$

$$
i\left(\text { since } \mathrm{K}_{\mathrm{Reg}}=0\right)
$$

Therefore, by setting $\mathrm{Tx}_{\mathrm{Reg}}=001000$ hex, the ADDRO_A/HS bit will toggle as rapidly as possible (ROM's are clockéd at 400 MHz, ADDRO_A/HS toggles at $200 \mathrm{MHz}$ ).

a. Connect Digitizer CH1 to PG A ADDRO_A/HS (R59). Connect Digitizer CH2 to PG A ROM_CLK_A/HS (R54). Set Digitizer to trigger on CH1 UP edge-

b. Program PG A and PG B for a Transmit Frequency of 195312.5 Hz ( $\left.\mathrm{TX}_{\text {Reg }}=001000 \mathrm{hex}\right)$.

c. Apply an ECL logic '1' DC level to Tx_Trig/HS (enables CW mode).

d. Repeatedly read Digitizer and adjust PG A Delay of ROM_CLK_A (CLOCK CONTROL REGISTER, bits 5:4) until PG A ADD $\bar{R} 0$ AT/HS and PG A ROM_CLK_A/HS edge placement is correct (see $\bar{F}$ igure $7 a$ ). Verify $\bar{y} \bar{l}$ ay count is a valid number.

\subsubsection{ROM_CHR_B Delay Adjustment}

This test will determine what delay value to load into PG B, Delay of ROM_CLK_B (CLOCK CONTROL REGISmER, bits 5:4), in order to compensāte for inherent circuit delays. The delay should be such that the Phase data (ADDRx_B/HS) have time to stabilize before the ROM Clock (ROM CLK BTHS) strobes these data. The four possible delay combinations $(00,01,10,11$ binary) represent approximately 0,500, 1000, and 1500 ps delays, respectively.

The sample clock frequency (CLOCK_IN/HS) is $800 \mathrm{MHz}$.

The transmit frequency register contents were chosen such that the ADDRO_B/HS bit will toggle at the fastest rate possible 
(200 MHz) and update the Digitizer waveforms as rapidly as possible.

The frequency is chosen as follows (see section 1.3 for the general form of these equations):

$$
\begin{array}{ll}
\mathrm{P} \operatorname{ROM}(\mathrm{n}) & =\mathrm{P}(\mathrm{n})^{\prime}+\text { EXT PHASE } \mathrm{B}_{\mathrm{Reg}} \\
\mathrm{P}(\mathrm{n})^{\prime} & =\text { upper } 12 \text { biEs of } \overline{\mathrm{P}}(\mathrm{n})^{\prime} \\
\mathrm{P}(\mathrm{n}) & =\left(\mathrm{TX}_{\text {Reg }}\right)^{\prime}{ }^{\prime} \mathrm{n}
\end{array}
$$$$
\text { ; }\left(\text { since } \mathrm{K}_{\mathrm{Reg}}=0\right. \text { ) }
$$

Therefore, by setting $\mathrm{Tx}_{\mathrm{Reg}}=001000 \mathrm{hex}$, the ADDRO_B/HS bit will toggle as rapidiy as porsible (ROM's are clockéd at 400 MHz, ADDRO_B/HS toggles at 2 $20 \mathrm{MHz}$ ).

a. Connect Digitizer CH1 to PG B ADDRO_B/HS (R35) - Connect Digitizer CH2 to PG B ROM_CLK_B/HS (R33). Set Digitizer to trigger on $\mathrm{CH} 1$ UP edge.

b. Program PG A and PG B for a Transmit Frequency of 195312.5 Hz ( $\mathrm{Tx}_{\text {Reg }}=001000 \mathrm{hex}$ ).

c. Apply an ECL logic ' 1 ' DC level to Tx_Trig/HS (enables CW mode).

d. Repeatedly read Digitizer and adjust PG B Delay of ROM_CLK_B (CLOCK CONTROL REGISTER, bits 5:4) until PG B $A D D \bar{R} 0$ B THS and PG B ROM_CLK B/HS edge placement is correct (see $\bar{F}$ igure $7 \mathrm{~b}$ ). Verif $\bar{y}$ De $\bar{l}$. Vy count is a valid number.

\subsubsection{RON BELECT Delay Adjustment}

This test will determine what delay value to load into PG B, Delay of DAC_CLK (CLOCK CONTROL REGISTER, bits 1:0), in order to compensaté for inherent circuit delays. Note that PG B DAC_CLK is actually used to select which ROM output data are to be used by the DAC, not as the DAC clock. The delay should be such that the PG B DAC Clock (i.e. ROM select) (SELECT/HS) allows enough time for the ROM data outputs (QX_A/HS, QX_B/HS) to stabilize before the PG A DAC CLK latches and convert $\bar{s}$ the data to an analog output. The four possible delays $(00,01$, 10, 11 binary) represent approximately 0,500, 1000, and 1500 ps delays, respectively. Note that since ROM A and ROM B both have their own programmable ROM Clock delays, ROM B output data may not follow ROM A output data exactly 180 degrees (as shown in Figure 4). Therefore, the DAC CLK delay must be set to ensure that both outputs have sufficient time to stabilize before SELECT/HS is activated.

The sample clock frequency (CLOCK_IN/HS) is $800 \mathrm{MHz}$.

The transmit frequency register contents are chosen such that the ROM A QOA/HS bit will toggle at the fastest rate possible (approximately $200 \mathrm{MHz}$ ) and update the Digitizer waveforms as rapidly as possible. 
The frequency is chosen as follows (see section 1.3 for the general form of these equations):

$$
\begin{array}{ll}
\mathrm{P} \operatorname{ROM}(\mathrm{n}) & =\mathrm{P}(\mathrm{n})^{\prime}+\operatorname{EXT} \mathrm{PHASE}{ }^{\mathrm{A}} \mathrm{Reg} \\
\mathrm{P}(\mathrm{n})^{\prime} & =\text { upper } 12 \text { biEs of } \mathrm{P}(\mathrm{n})^{\prime} \quad ;\left(\text { since } \mathrm{K}_{\text {Reg }}=0\right) \\
\mathrm{P}(\mathrm{n}) & =\left(\mathrm{Tx}_{\text {Reg }}\right)^{\prime} * \mathrm{n}
\end{array}
$$

After manually examining the ROM code contents, it appears that the ROM A QO_A/HS bit toggles approximately every 7 th address. Therefore, by setting $\mathrm{Tx}_{\mathrm{Reg}}=007000$ hex, the ROM $A$ QO_A/HS bit will toggle as fast as possible (ROM's are clocked at $400 \mathrm{MHz}$, ROM A 20 A/HS toggles at approximately $200 \mathrm{MHz}$ ).

a. Connect Digitizer CH1 to ROM A QO_A/HS (R19). Connect Digitizer CH2 to SELECT/HS (R47). Set Digitizer to trigger on $\mathrm{CH} 1$ UP edge.

b. Program PG A and PG B for a Transmit Frequency of 1.3671875 $\mathrm{MHz}\left(\mathrm{Tx}_{\mathrm{Reg}}=007000 \mathrm{hex}\right.$ ).

c. Apply an ECL logic ' 1 ' DC level to Tx_Trig/HS (enables CW mode).

d. Repeatedly read Digitizer and adjust PG B Delay of DAC_CLK (CLOCK CONTROL REGISTER, bits 1:0) until ROM A QO_A/HS and SELECT/HS edge placement is correct (see Figure $8 \bar{a}$ ). Verify Delay count is a valid number.

e. Connect Digitizer CH1 to ROM B QO_B/HS (R41).

f. Repeatedly read Digitizer and INCREASE ONLY, if needed, PG B Delay of DAC_CLK (CLOCK CONTROL REGISTER, bits 1:0) until ROM B $20^{-} \mathrm{B} / \mathrm{HS}$ and SELECT/HS edge placement is correct (see Figure $8 \mathrm{~b}$ ). Verify Delay count is a valid number.

Note that the delay should only be increased and never decreased from the delay found in 4.2.3.d to ensure that ROM A timing is still correct.

\subsubsection{DAC_CLK Delay Adjustment}

This test will determine what delay value to load into PG A, Delay of DAC_CLK (CLOCK CONTROL REGISTER, bits 1:0), in order to compensate for inherent circuit delays. The delay should be such that the ROM data ( $Q x_{-} A / H S, Q x_{B} B / H S$ ) have time to stabilize internal to the DAC before the DAC Clock (DAC_CLK_B/HS) latches and converts the data to an analog outpūt. The four possible delays $(00,01,10,11$ binary) represent approximately 0,500, 1000, and 1500 ps delays, respectively. Note that the delays through ROM $A$ and ROM $B$ are expected to be about the same since only one DAC_CLK delay can be programmed. 
The sample clock frequency (CLOCK_IN/HS) is $800 \mathrm{MHz}$.

The Transmit Frequency makes no difference since only SELECT/HS and DAC_CLK_A_BUF/HS are digitized.

a. Connect Digitizer CH1 to SELECT/HS (R47). Connect Digitizer CH2 to PG A DAC_CLK_A BUF/HS (R48). Set Digitizer to trigger on $C \bar{H} 1$ DOWN edge.

b. Program PG A and PG B for a Transmit Frequency of 1.3671875 MHz ( $\mathrm{TX}_{\mathrm{Reg}}=007000 \mathrm{hex}$ ).

c. Apply an ECL logic ' 1 ' DC level to Tx_Trig/HS (enables CW mode).

d. Repeatedly read Digitizer and adjust PG A Delay of DAC_CLK (CLOCK CONTROL REGISTER, bits 1:0) until SELECT/HS and PG A DAC_CLK_A_BUF/HS edge placement is correct (see Figure $9 \bar{T}$. Verify Delay count is a valid number.

\subsection{Clock Delay Adjustments (Non-Probing Method)}

The following paragraphs describe how to determine the correct programmable clock delays using the spectrum analyzer method. This method can not measure the exact pulse delays as is done in section 4.2 ; however, it has the advantage of eliminating internal probing. Therefore, this method is specified as a production requirement and defined as follows:

a. Program the DWS to a slow output frequency such that when all programmed delays are set to their largest values (i.e. 11 binary), it is guaranteed to work;

b. Program all delays to 11 binary;

c. Decrease the following delays, one at a time and in the order listed, until the frequency spectrum of the output CW sine wave indicates an increased harmonic distortion or until the particular delay value is 00 . Then, add 01 to the delay count (i.e. if distortion occurs at 00 binary, the correct delay count would be 01 binary for that particular delay; if no distortion occurs at 00 binary, then the correct count would still be 01 binary):
1. PG A ROM CLOCK Delay
2. PG B ROM CLOCK Delay
3. ROM SELECT Delay
4. DAC CLOCK Delay 


\subsubsection{ROX_CLR_A Delay Adjustment}

This test will determine what delay value to load into PG $A$, Delay of ROM CLK A (CLOCK CONTROL REGISTER, bits 5:4), in order to compensāte for inherent circuit delays. The delay should be such that the Phase data (ADDR $x$ A/HS) have time to stabilize before the ROM Clock (ROM CLK $\bar{A} / \bar{H} S$ ) strobes these data. The four possible delay combinations $(00,01,10,11$ binary) represent approximately 0,500, 1000, and $1500 \mathrm{ps}$ delays, respectively.

The sample clock frequency (CLOCK_IN/HS) is $800 \mathrm{MHz}$.

a. Connect DWS OUTPUT/HS to the spectrum Analyzer input.

b. Program PG A and PG B for a Transmit Frequency of $50 \mathrm{MHz}$ $\left(\mathrm{TX}_{\mathrm{Reg}}=100000 \mathrm{hex}\right)$.

c. Apply an ECL logic ' 1 ' DC level to Tx_Trig/HS (enables CW mode).

d. Read the harmonic distortion (i.e. maximum amplitude of any harmonic frequency relative to the fundamental frequency) and compare to limits.

e. Decrement PG A Delay of ROM_CLK_A (CLOCK CONTROL REGISTER, bits 5:4) and read the harmonic distortion for delays of 10, 01, and 00. Select the delay count which results in the lowest harmonic distortion and verify that the delay count is a valid number.

\subsubsection{ROK_CLR_B Delay Adjustment}

This test will determine what delay value to load into PG B, Delay of ROM_CLK_B (CLOCK CONTROL REGISTER, bits 5:4), in order to compensāte for inherent circuit delays. The delay should be such that the Phase data (ADDR $x$ B/HS) have time to stabilize before the ROM Clock (ROM CLK $\bar{B} / \bar{H} S$ ) strobes these data. The four possible delay combinations $(00,01,10,11$ binary) represent approximately 0,500, 1000, and 1500 ps delays, respectively.

The sample clock frequency (CLOCK_IN/HS) is $800 \mathrm{MHz}$.

a. Connect DWS OUTPUT/HS to the spectrum Analyzer input.

b. Program PG A and PG B for a Transmit Frequency of $50 \mathrm{MHz}$ $\left(\mathrm{TX}_{\mathrm{Reg}}=100000 \mathrm{hex}\right)$.

c. Apply an ECL logic '1' DC level to Tx_Trig/HS (enables CW mode). 
d. Read the baseline harmonic distortion (i.e. maximum amplitude of any harmonic frequency relative to the fundamental frequency) and compare to limits.

e. Decrement PG B Delay of ROM_CLK_B (CLOCK CONTROL REGISTER, bits $5: 4$ ) and read the harmonic distortion for delays of 10,01 , and 00 . Select the delay count which results in the lowest harmonic distortion and verify that the delay count is a valid number.

\subsubsection{ROM 8ELECT Delay Adjustment}

This test will determine what delay value to load into PG $B$, Delay of DAC_CLK (CLOCK CONTROL REGISTER, bits 1:0), in order to compensate for inherent circuit delays. Note that PG B DAC CLK is actually used to select which ROM output data is be used by the DAC, not as the DAC clock. The delay should be such that the PG B DAC CLK (i.e. ROM select, SELECT/HS) allows enough time for the ROM data outputs ( $\bar{M} \_A / H S, Q x \_B / H S$ ) to stabilize before the PG A DAC CLK latches and converts the data to an analog output. The four possible delays $(00,01$, 10, 11 binary) represent approximately 0, 500, 1000, and 1500 ps delays, respectively. Note that since ROM $A$ and ROM B both have their own programmable ROM clock delays, ROM B output data may not follow ROM A output data exactly 180 degrees (as shown in Figure 4). Therefore, the DAC CLK delay must be set to ensure that both outputs have sufficient time to stabilize before SELECT/HS is activated.

The sample clock frequency (CLOCK_IN/HS) is $800 \mathrm{MHz}$.

a. Connect DWS OUTPUT/HS to the spectrum Analyzer input.

b. Program PG A and PG B for a Transmit Frequency of $50 \mathrm{MHz}$ $\left(\mathrm{Tx}_{\mathrm{Reg}}=100000 \mathrm{hex}\right)$.

c. Apply an ECL logic ' 1 ' DC level to Tx_Trig/HS (enables CW mode).

d. Read the baseline harmonic distortion (i.e. maximum amplitude of any harmonic frequency relative to the fundamental frequency) and compare to limits.

e. Decrement PG B DAC_CLK (CLOCK CONTROL REGISTER, bits 1:0) and read the harmoñic distortion for delays of 10,01 , and 00. Select the delay count which results in the lowest harmonic distortion and verify that the delay count is a valid number.

\subsubsection{DAC_CLR Delay Adjustment}

This test will determine what delay value to load into PG $A$, Delay of DAC_CLK (CLOCK CONTROL REGISTER, bits 1:0), in order to compensate for inherent circuit delays. The delay should 
be such that the ROM data (QXA/HS, QX B/HS) have time to stabilize internal to the DAC before the DAC Clock (DAC_CLK_B/HS) latches and converts the data to an analog outpūt. The four possible delays $(00,01,10,11$ binary) represent approximately 0, 500, 1000, and 1500 ps delays, respectively. Note that the delays through ROM A and ROM $B$ are expected to be about the same since only one DAC_CLK delay can be programmed.

The sample clock frequency (CLOCK_IN/HS) is $800 \mathrm{MHz}$.

a. Connect LWS OUTPUT/HS to the Spectrum Analyzer input.

b. Program PG A and PG B for a Transmit Frequency of $50 \mathrm{MHz}$ $\left(\mathrm{TX}_{\mathrm{Reg}}=100000 \mathrm{hex}\right)$.

c. Apply an ECL logic ' 1 ' DC level to Tx_Trig/HS (enables CW mode).

d. Read the baseline harmonic distortion (i.e. maximum amplitude of any harmonic frequency relative to the fundamental frequency) and compare to limits.

e. Decrement PG A DAC CLK (CLOCK CONTROL REGISTER, bits 1:0) and read the harmonic distortion for delays of 10, 01, and 00. Select the delay count which results in the lowest harmonic distortion and verify that the delay count is a valid number.

\subsection{Instantaneous Frequency clock Output Verification}

This test will verify that PG B, IF_CLK dividers (CLOCK CONTROL REGISTER, bits $13: 12$ ) are functional and that the timing relationship between INST_FREQ_CLK_TTL/HS and

INST_FREQX/HS is correct. Note that Ehis timing relationship is not programmable; it is designed into the Phase Generator. Note also that PG A Instantaneous Frequency Data and Clock ASIC die outputs are not connected beyond the die; therefore, the PG A IF_CLK dividers can not be tested.

The sample clock frequency (CLOCK_IN/HS) is $800 \mathrm{MHz}$.

The chirp frequency register contents are chosen such that the INST_FREQO/HS bit will toggle at the fastest rate possible (200-MHz); INST_FREQ1/HS will toggle at half the INST_FREQ0/HS rate $(100 \mathrm{MHz})$; ect. This fundamental toggle rate wiIl update the Digitizer waveform as rapidly as possible.

The chirp frequency is chosen as follows (see section 1.3 for the general form of these equations):

$$
\begin{aligned}
& F(n),=K_{\text {Reg }}{ }^{*} n \\
& F(n)=\text { upper } 8 \text { bits of } F(n) \quad ;\left(\text { since } \mathrm{Tx}_{\mathrm{Reg}}=0\right. \text { ) }
\end{aligned}
$$


Therefore, by setting $K_{\mathrm{Reg}}=010000$ hex $\left(i . e . F(n)^{\prime}=01 * n\right.$ ) the INST_FREQ0/HS bit will toggle as fast as possible (INST_FREQO/HS toggles at $200 \mathrm{MHz}$ ).

a. Connect Frequency Counter to INST_FREQ_CLK_TTL/HS.

b. Program PG A and PG B, Transmit Frequency $=0 \mathrm{~Hz}$ $\left(\mathrm{Tx}_{\text {Reg }}=000000\right.$ hex).

Program PG A and PG B, Chirp Rate $=2500 \mathrm{MHz} / \mathrm{uS}$ $\left(K_{\text {Reg }}=010000\right.$ hex).

Thisg rate will yield a linear Instantaneous Frequency output.

c. Apply an ECL logic ' 1 ' DC level to Tx_Trig/HS (enables continuous chirp mode).

d. Program PG B, IF_CLK divider (CLOCK CONTROL REGISTER, bits 13:12) to 00 binary.

e. Read frequency and compare to limits.

f. Program PG B, IF_CLK divider (CLOCK CONTROL REGISTER, bits 13:12) to 01 binäry.

g. Read frequency and compare to limits.

h. Program PG B, IF_CLK divider (CLOCK CONTROL REGISTER, bits $13: 12$ ) to 10 bināry.

i. Read frequency and compare to limits.

j. Program PG B, IF_CLK divider (CLOCK CONTROL REGISTER, bits 13:12) to 11 bināry.

k. Read frequency and compare to limits.

1. Connect Digitizer CHI to INST_FREQO/HS. Connect Digitizer CH2 to INST_FREQ_CLK_TTL/HS. Sset Digitizer to trigger on CH1 UP edge.

m. Verify timing relationship as shown in Figure 10 .

\subsection{Instantaneous Frequency Verification}

This test will verify that every Instantaneous Frequency bit (INST_FREQX/HS) toggles between an TTL logic ' 0 ' and ' 1 '. This verification is done by programming a chirp rate such that every INST_FREQx/HS bit toggles. Note that only PG B is tested; PG A Ins̄tantaneous Frequency Data and Clock ASIC die outputs are not connected beyond the die; therefore, the PG A Instantaneous Frequency circuitry can not be tested.

The sample clock frequency (CLOCK_IN/HS) is $800 \mathrm{MHz}$. 
The chirp frequency register contents are chosen such that the INST_FREQO/HS bit will toggle at the fastest rate possible $\left(200^{-} \mathrm{MHz}\right)$; INST_FREQ1/HS will toggle at half the INST_FREQ0/HS rate $(100 \mathrm{MHz})$; ect. This fundamental toggle rate wiIl update the Digitizer waveform as rapidly as possible.

The chirp frequency is chosen as follows (see section 1.3 for the general form of these equations):

$$
\begin{aligned}
& F(n)=K_{\text {Reg }}{ }^{*} n \\
& F(n), \quad ;\left(\text { since } T x_{\text {Reg }}=0\right)
\end{aligned}
$$

Therefore, by setting $K_{\text {Reg }}=010000$ hex $\left(i . e . F(n){ }^{\prime}=01 * n\right.$ ) the INST_FREQO/HS bit will toggle as fast as possible (INST_FRËQ/HS toggles at $200 \mathrm{MHz}$ ).

a. Connect Frequency Counter to INST_FREQO/HS.

b. Program PG A and PG B, Transmit Frequency $=0 \mathrm{~Hz}$ ( $\mathrm{Tx}_{\mathrm{Reg}}=000000 \mathrm{hex}$ ).

Program PG A and PG B, Chirp Rate $=2500 \mathrm{MHz} / \mathrm{uS}$ $\left(\mathrm{K}_{\text {Reg }}=010000\right.$ hex $)$.

c. Apply an ECL logic ' 1 ' DC level to Tx_Trig/HS (enables continuous chirp mode).

d. Read frequency and compare to limits.

e. Connect Frequency Counter to INST_FREQ1/HS.

f. Read frequency and compare to limits.

g. Connect Frequency Counter to INST_FREQ2/HS.

h. Read frequency and compare to limits.

i. Connect Frequency Counter to INST_FREQ3/HS.

j. Read frequency and compare to limits.

k. Connect Frequency Counter to INST_FREQ4/HS.

1. Read frequency and compare to limits.

m. Connect Frequency Counter to INST_FREQ5/HS.

n. Read frequency and compare to limits.

o. Connect Frequency Counter to INST_FREQ6/HS.

p. Read frequency and compare to limits.

q. Connect Frequency Counter to INST_FREQ7/HS. 
r. Read frequency and compare to limits.

\subsection{Output clooks Vorification}

This test will verify that the clock buffers and clock dividers are functional.

The sample clock frequency (CLOCK_IN/HS) is $800 \mathrm{MHz}$.

The frequency selected makes no difference since only

SELECT/HS and DAC_CLK_A_BUF/HS are digitized.

a. Program PG A and PG B for a Transmit Frequency of $50 \mathrm{MHz}$. $\left(\mathrm{TX}_{\mathrm{Reg}}=100000 \mathrm{hex}\right)$.

b. Apply an ECL logic ' 1 ' DC level to Tx_Trig/HS (enables DAC clock).

c. Connect Frequency Counter to CLOCK_OUT/HS.

d. Read frequency and compare to limits.

e. Connect Frequency Counter to DAC_CLK_OUTPljT/HS.

f. Read frequency and compare to limits.

g. Connect Frequency Counter to CLK_2/HS.

h. Read frequency and compare to limits.

i. Connect Frequency Counter to CLK_4/HS.

j. Read frequency and compare to limits.

k. Connect Frequency Counter to CLK_8/HS.

1. Read frequency and compare to limits.

m. Connect Frequency Counter to CLK_16/HS.

n. Read frequency and compare to limits.

\subsection{BINE ROM Verification}

This test will verify the following (by inference):

1. SINE ADDR[11:0] wirebonds are correct;

2. SINE ROMs contain the correct data pattern;

3. DAC $A[7: 0]$ wirebonds from both ROMs are correct;

4. DAC has no missing Digital-to-Analog codes;

5. DAC has acceptable linearity.

The overall verification is accomplished by sequencing through every ROM address ( 000 hex to FFF hex), thereby accessing 
every data storage location, and checking the analog output for excessive harmonic distortion and excessive signal-toNoise Ratio. Distortion will occur if the DAC output is not a relatively pure sine wave (1.e. ROM A has a missing ADDRx wirebond; ROM $B$ has incorrect mask data; DAC has a missing $A x$ bondwire; ect).

Note that a successful overall verification infers verification of the cited categories. If the verification falls, the categorical cause of the failure can not be determined without internal probing.

The sample clock frequency (CLOCK_IN/HS) is $800 \mathrm{MHz}$.

The frequency is chosen as follows (see section 1.3 for the general form of these equations):

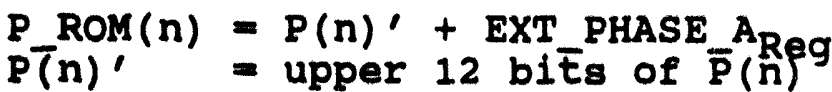

$$
\begin{aligned}
& P(n) \quad=\left(\mathrm{Tx}_{\text {Reg }}\right) * \mathrm{n} \quad ;\left(\text { since } \mathrm{K}_{\text {Reg }}=0\right)
\end{aligned}
$$

Therefore, by setting $\mathrm{Tx}_{\mathrm{R}}=001000$ hex

(i.e. $\left.P(n)^{\prime}=.001 * n\right),{ }^{2} g_{R O M}(n)$ will sequentially cycle from 000 to FFF hex, thus accessing every ROM location.
a. Program PG A and PG B, Transmit Frequency $=195312.5 \mathrm{~Hz}$ $\left(T X_{\text {Reg }}=001000\right.$ hex).
b. Apply an ECL logic ' 1 ' DC level to Tx_Trig/HS (enables CW mode).
c. Read the baseline harmonic distortion (i.e. maximum amplitude of any harmonic frequency relative to the fundamental frequency) and compare to limits.

d. Read the signal-to-Nolse Ratio and compare to limits.

\subsection{Verification of Frequenoy Regiaters}

This test will verify that every $T x$ and Rx Frequency Register bit is functional. This verification is done by walking a ' 1 ' through every bit and reading the resulting frequency.

\subsubsection{PG $A$ and PG B TX Frequenoy Register Verification}

The following equations are reproduced from section 1.3:

$$
\begin{aligned}
& \mathrm{Tx}_{\text {Res }}=\frac{\mathrm{f}_{\mathrm{g}}}{2^{24}} \quad \text { or } \quad \mathrm{f}_{\mathrm{s}}=T \mathrm{Tx}_{\text {Res }} * 2^{24}
\end{aligned}
$$

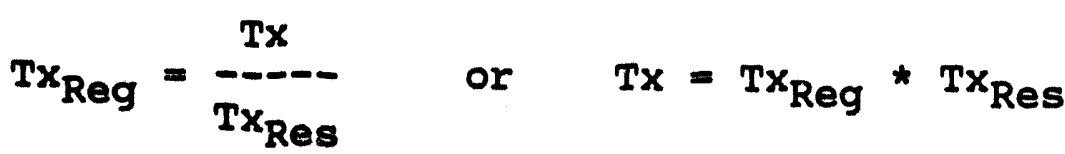


To generate output Tx frequencies in multiples of $25 \mathrm{~Hz}$ (1.e. $T X_{\text {Res }}=25$ ) dictates that $f_{s}=419.4304 \mathrm{MHz}$. This TX step size frequency is chosen to simplify the frequency measurements and limit comparisons.

Program the sample clock frequency (CLOCK_IN/HS) to 419.4309 MHz.

a. Connect DWS OUYPUT/HS to a $300 \mathrm{MHz}$, low pass filter. Connect filter output to Frequency counter input.

b. Program PG A and PG B Transmit Frequency Register to 000001 hex (TX $x_{\text {Reg }}=000001$ hex; Frequency $=25 \mathrm{~Hz}$ ).

c. Apply an ECL logic ' 1 ' DC level to TX_Trig/HS (enables CW mode).

d. Read frequency and compare to limits.

e. Apply an ECL logic ' $O$ ' DC level to Tx_Trig/HS (disables CW mode).

f. Repeat paragraph b through e, except set the Transmit Frequency Register to the the following counts:

TP. Regititer (hex)

000002

000004

000008

000010

000020

000040

000080

000100

000200

000400

000800

001000

002000

004000

008000

010000

020000

040000

080000

100000

200000

400000

800000

\section{Resulting Ix Frequenoy}

$$
50 \mathrm{~Hz}
$$

100

200

400

800

$1.6 \mathrm{kHz}$

3.2

6.4

12.8

25.6

51.2

102.4

204.8

409.6

819.2

$1.6384 \mathrm{Mhz}$

3.2768

6.5536

13.1072

26.2144

52.4288

104.8576

209.7152 
4.8.2 PG A and PC B RX Prequenoy Regiater verification

The following equations are reproduced from section 1.3 :

$R_{\text {Kes }}=\frac{f_{s}}{2^{24}} \quad$ or $\quad f_{s}=R x_{\text {Res }} * 2^{24}$

$R_{\text {Reg }}=\frac{R x}{\mathbf{R x}_{\text {Res }}} \quad$ or $\quad R x=R x_{\text {Reg }} * R_{\text {Res }}$

To generate output $\mathrm{Rx}$ frequencies in multiples of $25 \mathrm{~Hz}$ (i.e. $R x_{\text {Res }}=25$ ) dictates that $f_{s}=419.4304 \mathrm{MHz}$. This $\mathrm{Rx}$ step size frequency is chosen to simplify the frequency measurements and limit comparisons.

Program the sample clock frequency (CLOCK_IN/HS) to 419.4309 MHz.

a. Connect DWS OUTPUT/HS to a $300 \mathrm{MHz}$, low pass filter. Connect filter output to Frequency Counter input.

b. Program PG A and PG B Receive Frequency Register to 000001 hex ( $\mathrm{Rx}_{\mathrm{Reg}}=000001$ hex; Frequency=25 Hz).

c. Apply an ECL logic ' 1 ' DC level to Rx_Trig/HS (enables CW mode).

d. Read frequency and compare to limits.

e. Apply an ECL logic ' $O$ ' DC level to Rx_Trig/HS (disables CW mode).

f. Repeat paragraph b through e, except set the Receive Frequency Register to the the following counts:

R- Register (hex) Resulting Rx Frequency

000002

000004

000008

Hz

000010

000020

000040

000080

000100

000200

100

200

400

800

000400

$1.6 \mathrm{kHz}$

3.2

6.4

12.8

25.6

000800

51.2

001000

102.4

002000

204.8

004000

008000

010000

409.6

819.2

020000

$1.6384 \mathrm{Mhz}$

3.2768 


$\begin{array}{lr}040000 & 6.5536 \\ 080000 & 13.1072 \\ 100000 & 26.2144 \\ 200000 & 52.4288 \\ 400000 & 104.8576 \\ 800000 & 209.7152\end{array}$

\subsection{Vorffication of External Phase Registers}

This test will verify that every External Phase Register bit is functional. This verification is done by walking a ' 1 ' through every bit and reading the resulting time shift of the OUTPUT/HS (DAC output) versus the CLOCK_IN/HS input.

\subsection{1 sxternal Phase Register $A$ and B Verification}

Program the sample clock frequency (CLOCK_IN/HS) to 97.65625 MHz (this value will result in $2^{\mathrm{n}}$ multiples of 5 ps delays for the bit tests).

The sample clock frequency (CLOCK_IN/HS) is $97.65625 \mathrm{MHz}$.

The frequencies are chosen as follows (see section 1.3 for the general form of these equations):

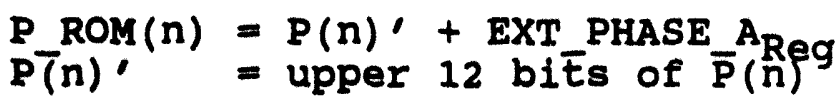

$$
\begin{aligned}
& \mathrm{P}(\mathrm{n}) \quad=\left(\mathrm{T} \mathrm{x}_{\mathrm{Reg}}\right) * \mathrm{n} \quad ;\left(\text { since } \mathrm{K}_{\mathrm{Reg}}=0\right)
\end{aligned}
$$

Therefore, by setting

$$
\begin{aligned}
& \mathrm{TX}_{\mathrm{Reg}}=800000 \mathrm{hex} ;(\mathrm{TX}=48.828125 \mathrm{MHz}) \\
& \text { EXI_PHASE_A }{ }_{\text {Reg }}=\text { EXT_PHASE_B }{ }_{\text {Reg }} \text {; (eliminates stair } \\
& \text { step output) }
\end{aligned}
$$

the following P_ROM(n) input adresses will generate a $48.828125 \mathrm{MHz}$ square wave (CLOCK_IN/HS / 2) when EXT_PHASE_A ${ }_{\text {Reg }}=000$ hex:

\begin{tabular}{ccc} 
Croc5 IH CYCLE & ROK A ADDRESB & ROK B ADDRES8 \\
\hline 1 & 800 & 800 \\
2 & 000 & 000 \\
3 & 800 & 800 \\
4 & 000 & 000
\end{tabular}

The corresponding time delay for the EXT_PHASE_A and EXT_PHASE_B registers is as follows:

$$
\text { Time Delay }=2^{n} * \frac{1}{2^{1}} * \frac{1 \mathrm{sec}}{(\text { CLOCK_IN } / 2)}=2^{n} * 5 \mathrm{ps}
$$


Note that $2^{12}$ is the number of levels in the 12 bit external phase registers; CLOCK IN is divided by 2 since each phase generator is operated $\bar{a}$ this divided frequency; and $n$ is the bit location of the external phase registers ( $n=11$ is MSB, $n=0$ is LSB).

Therefore, the following table shows the time delay for each external phase register bit:

FXY PRABE RECIBTFRS (heX)

000

001

002

004

008

010

020

040

080

100

200

400

800

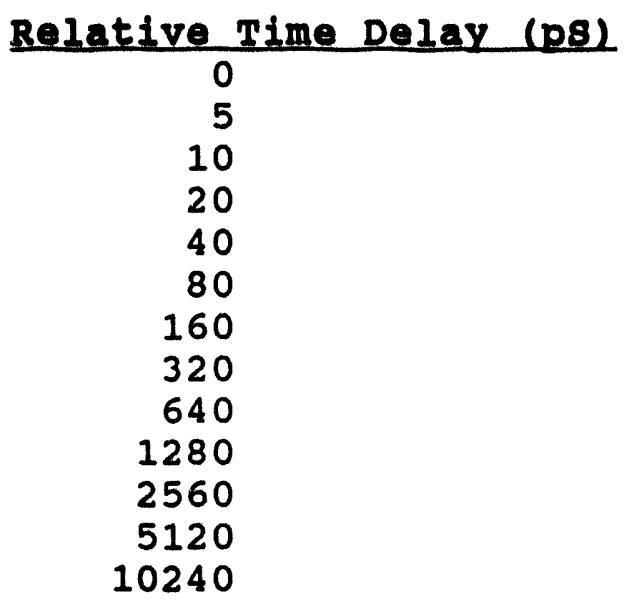

a. Connect Digitizer CH1 to CLOCK_IN/HS. Connect DWS OUTPUT/HS to a $300 \mathrm{MHz}$, low passs filter and filter output to Digitizer $\mathrm{CH} 2$.

b. Program PG A and PG B Transmit Frequency Register to 800000 hex ( $\mathrm{TX}_{\mathrm{Reg}}=800000$ hex; $\mathrm{TX}=48.828125 \mathrm{MHz}$ ). Program EXT_PHASE_A Reg and EXT_PHASE_B ${ }_{\text {Reg }}$ to 000 hex.

c. Apply an ECL logic ' 1 ' DC level to Tx_Trig/HS (enables CW mode).

d. Read time delay between Digitizer $\mathrm{CH} 1$ and $\mathrm{CH} 2$ rising edges. This time delay will be subtracted from the following bit test time delays to generate a relative time delay for each bit.

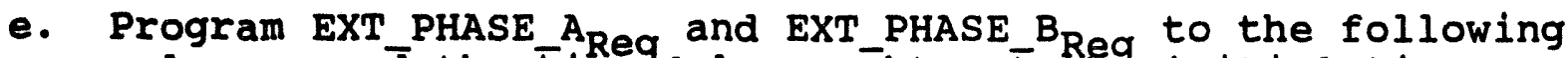
values; read the Eime delay; subtracE the initial time delay found in paragraph do obtain the relative time delay; compare to limits:

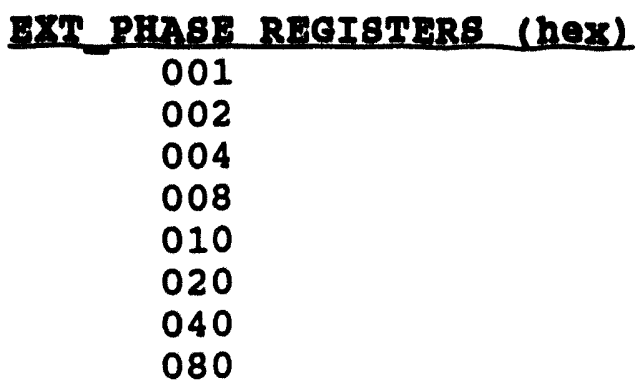




\subsection{Chirp pulse compression rest}

This test will verify the following:

1. Frequency Linearity;

2. Amplitude Flatness;

3. Signal-to-Noise Ratio.

This verification is done by performing a pulse compression per the following steps:

1. Split the Chirp output into two equal signals;

2. Feed one of these signals to a time delay line;

3. Feed the second split signal directly to a mixer;

4. Feed the output of the time delay line (delayed Chirp) also to the mixer;

5. Feed the mixer output to the spectrum Analyzer.

The product of the mixer (with both inputs present) is a pulse of constant frequency. Therefore, the pureness of this constant frequency is a measure of the quality of the Chirp waveform.

The mixer output is a pulsed sinusoid, where the pulse frequency is the Time of Delay Line $* K$, and $K$ is the chirp rate in MHZ/us.

The sample clock frequency (CLOCK_IN/HS) is $800 \mathrm{MHz}$.

a. Program PG A and PG B, Transmit Frequency $=100 \mathrm{MHz}$ $\left(\mathrm{Tx}_{\mathrm{Reg}}=200000 \mathrm{hex}\right)$. Program PG A and PG B, Chirp Rate $=76.294 \mathrm{kHz} / \mathrm{us}$. $\left(\mathrm{K}_{\mathrm{Reg}}=000002\right.$ hex).

b. Apply an ECL logic ' 1 ', 100 us pulse to Tx_Trig/HS (generates a 100 us wide Chirp).

c. Read the harmonic distortion (i.e. maximum amplitude of any harmonic frequency relative to the fundamental frequency) and compare to limits.

d. Read the signal-to-Noise Ratio and compare to limits. 


\begin{tabular}{|c|c|c|c|c|}
\hline$\frac{\text { Paragraph }}{4.1}$ & $\begin{array}{c}\text { Test Label } \\
\text { V5VOLT } \\
\text { V5CURR } \\
\text { VN2VLT } \\
\text { VN2CUR } \\
\text { VN3VLT } \\
\text { VN3CUR } \\
\text { VN5VLT } \\
\text { VN5CUR } \\
\text { VN5AVT } \\
\text { VN5ACR }\end{array}$ & $\begin{array}{l}\text { Low Limit } \\
4.9 \\
300 \\
-2.1 \\
500.0 \\
-3.5 \\
100.0 \\
-5.3 \\
3000.0 \\
-5.3 \\
50.0\end{array}$ & $\begin{array}{l}\text { High Limit } \\
5.1 \\
600 \\
-1.9 \\
1000.0 \\
-3.3 \\
400.0 \\
-5.1 \\
4000.0 \\
-5.1 \\
200.0\end{array}$ & $\begin{array}{l}\text { Units } \\
\text { Volts } \\
\text { mAmps } \\
\text { Volts } \\
\text { mAmps } \\
\text { Volts } \\
\text { mAmps } \\
\text { Volts } \\
\text { mAmps } \\
\text { Volts } \\
\text { mAmps }\end{array}$ \\
\hline $4.2 .1 . d$ & ROMAD 1 & 00 & 11 & Binary \\
\hline $4.2 .2 . d$ & ROMBD 1 & 00 & 11 & Binary \\
\hline $4 \cdot 2 \cdot 3 \cdot d$ & $\begin{array}{l}\mathrm{DACBD} 1 \\
\mathrm{DACBD} 2\end{array}$ & $\begin{array}{l}00 \\
00\end{array}$ & $\begin{array}{l}11 \\
11\end{array}$ & $\begin{array}{l}\text { Binary } \\
\text { Binary }\end{array}$ \\
\hline $4.2 .4 . d$ & DACAD1 & 00 & 11 & Binary \\
\hline $4 \cdot 3 \cdot 1 \cdot d$ & $\begin{array}{l}\text { DIST31 } \\
\text { ROMAD2 }\end{array}$ & $\begin{array}{l}? ? ? \\
00\end{array}$ & $\begin{array}{l}\text { ??? } \\
11\end{array}$ & $\begin{array}{l}\% \\
\text { Binary }\end{array}$ \\
\hline $\begin{array}{r}4.3 .2 \cdot d \\
e\end{array}$ & $\begin{array}{l}\text { DIST32 } \\
\text { ROMBD2 }\end{array}$ & $\begin{array}{l}? ? ? \\
00\end{array}$ & $\begin{array}{l}? ? ? \\
11\end{array}$ & $\begin{array}{l}\% \\
\text { Binary }\end{array}$ \\
\hline $\begin{array}{r}4 \cdot 3 \cdot 3 \cdot d \\
e\end{array}$ & $\begin{array}{l}\text { DIST33 } \\
\text { DACBD3 }\end{array}$ & $\begin{array}{l}? ? ? \\
00\end{array}$ & $\begin{array}{l}? ? ? \\
11\end{array}$ & $\begin{array}{l}\text { B } \\
\text { Binary }\end{array}$ \\
\hline $\begin{array}{r}4.3 .4 . d \\
e\end{array}$ & $\begin{array}{l}\text { DIST34 } \\
\text { DACAD2 }\end{array}$ & $\begin{array}{l}? ? ? \\
00\end{array}$ & $\begin{array}{l}? ? ? \\
11\end{array}$ & $\begin{array}{l}q \\
\text { Binary }\end{array}$ \\
\hline $\begin{array}{r}4.4 \cdot e \\
\mathrm{~g} \\
\mathrm{i} \\
\mathrm{k} \\
\mathrm{m}\end{array}$ & $\begin{array}{l}\text { IFCLK1 } \\
\text { IFCLK2 } \\
\text { IFCLK4 } \\
\text { IFCLK8 } \\
\text { IFTIME }\end{array}$ & $\begin{array}{c}792.0 \\
396.0 \\
198.0 \\
99.0 \\
--\end{array}$ & $\begin{array}{l}808.0 \\
404.0 \\
202.0 \\
101.0 \\
---\end{array}$ & $\begin{array}{r}\mathrm{MHz} \\
\mathrm{MHz} \\
\mathrm{MHz} \\
\mathrm{MHz} \\
\text { Pass/Fail }\end{array}$ \\
\hline $\begin{array}{r}4.5 . d \\
f \\
h \\
j \\
1 \\
n \\
p \\
r\end{array}$ & $\begin{array}{l}\text { INFRQ0 } \\
\text { INFRQ1 } \\
\text { INFRQ2 } \\
\text { INFRQ3 } \\
\text { INFRQ4 } \\
\text { INFRQ5 } \\
\text { INFRQ6 } \\
\text { INFRQ7 }\end{array}$ & $\begin{array}{r}154.6875 \\
77.3438 \\
38.6719 \\
19.3359 \\
9.6689 \\
4.8340 \\
2.4170 \\
1.2085\end{array}$ & $\begin{array}{r}157.8125 \\
78.9062 \\
39.4531 \\
19.7265 \\
9.8632 \\
4.9316 \\
2.4658 \\
1.2329\end{array}$ & $\begin{array}{l}\mathrm{MHz} \\
\mathrm{MHz} \\
\mathrm{MHz} \\
\mathrm{MHz} \\
\mathrm{MHZ} \\
\mathrm{MHz} \\
\mathrm{MHz} \\
\mathrm{MHz}\end{array}$ \\
\hline
\end{tabular}

TABLE 1. DWS ACCEPTANCE IIMITS 
Paragraph

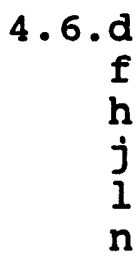

4.7. $c$

$4.8 .1 . d$

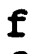

f

$f$

f

f

$f$

f

f

f

f

f

f

f

$f$

f

$4 \cdot 8 \cdot 2 \cdot d$

\section{$f$}

f

f

f

f

$f$

$f$

$f$

f

f

f

f

f

$f$

f
Test Label

CLKOUT
DACCLK
CLKD02
CLKD04
CLKD08
CLKD16

DISTO7

SNRA07

TX0000

TX0001

TX0002

TX0003

TX0004

TX0005

TX0006

TX0007

TX0008

TX0009

TX0010

TX0011

TX0012

TX0013

TX0014

TX0015

RX0000

RX0001

$\mathrm{RX0002}$

RX0003

RX0004

RX0005

RX0006

RX0007

RX0008

RX0009

RX0010

RX0011

RX0012

$\mathrm{RX0013}$

RX0014

RX0015
Low Iimit High Limit

$$
\begin{array}{r}
792.0 \\
792.0 \\
396.0 \\
198.0 \\
99.0 \\
49.5
\end{array}
$$

???

???

24.75

49.50

99.0

198.0

396.0

792.0

1584.0

3168.0

6336.0

12672.0

25344.0

50688.0

101376.0

202752.0

405504.0

811008.0

24.75

49.50

99.0

198.0

396.0

792.0

1584.0

3168.0

6336.0

12672.0

25344.0

50688.0

101376.0

202752.0

405504.0

811008.0
808.0
808.0
404.0
202.0
101.0
50.5

???

???

$$
\begin{array}{r}
25.25 \\
50.50 \\
101.0 \\
202.0 \\
404.0 \\
808.0 \\
1616.0 \\
3232.0 \\
6464.0 \\
12928.0 \\
25856.0 \\
51712.0 \\
103424.0 \\
206848.0 \\
413696.0 \\
827392.0
\end{array}
$$

$$
\begin{array}{r}
25.25 \\
50.50 \\
101.0 \\
202.0 \\
404.0 \\
808.0 \\
1616.0 \\
3232.0 \\
6464.0 \\
12928.0 \\
25856.0 \\
51712.0 \\
103424.0 \\
206848.0 \\
413696.0 \\
827392.0
\end{array}
$$

Units

MHz

MHz

MHz

MHz

MHz

MHZ

$\%$

$\mathrm{dBm}$

$\mathrm{Hz}$

$\mathrm{Hz}$

$\mathrm{Hz}$

$\mathrm{Hz}$

$\mathrm{Hz}$

$\mathrm{Hz}$

$\mathrm{Hz}$

$\mathrm{Hz}$

$\mathrm{Hz}$

$\mathrm{Hz}$

$\mathrm{Hz}$

$\mathrm{Hz}$

$\mathrm{Hz}$

$\mathrm{Hz}$

$\mathrm{Hz}$

$\mathrm{Hz}$

$\mathrm{Hz}$

$\mathrm{Hz}$

$\mathrm{Hz}$

$\mathrm{Hz}$

$\mathrm{Hz}$

$\mathrm{Hz}$

$\mathrm{Hz}$

$\mathrm{Hz}$

$\mathrm{Hz}$

$\mathrm{Hz}$

$\mathrm{Hz}$

$\mathrm{Hz}$

$\mathrm{Hz}$

$\mathrm{Hz}$

$\mathrm{Hz}$

$\mathrm{Hz}$

TABLE 1. DWS ACCEPTANCE LIMITS (cont.) 
Paragraph

$\begin{array}{ll}\text { 4.9.1.e } & \text { PTD000 } \\ \text { PTD001 } \\ \text { PTD002 } \\ \text { PTD003 } \\ \text { PTD004 } \\ \text { PTD005 } \\ \text { PTD006 } \\ \text { PTD007 } \\ \text { PTD008 } \\ \text { PTD009 } \\ \text { PTD010 } \\ \text { PTD011 }\end{array}$

4.10. C
Test Label

DIST10

SNRA10
Low Limit High Limit

Units

4.95
9.90
19.80
39.60
79.20
158.40
316.8
633.6
1267.2
2534.4
5068.8
10137.6

5.05

10.10

20.20

40.40

80.80

161.60

323.20

646.40

1292.8

2585.6

5171.2

10342.4

psec

psec

psec

pSec

psec

pSec

pSec

psec

psec

psec

psec

psec

$\%$

???

???

$\mathrm{dBm}$

TABLE 1. DWS ACCEPTANCE IIMITS (cont.) 

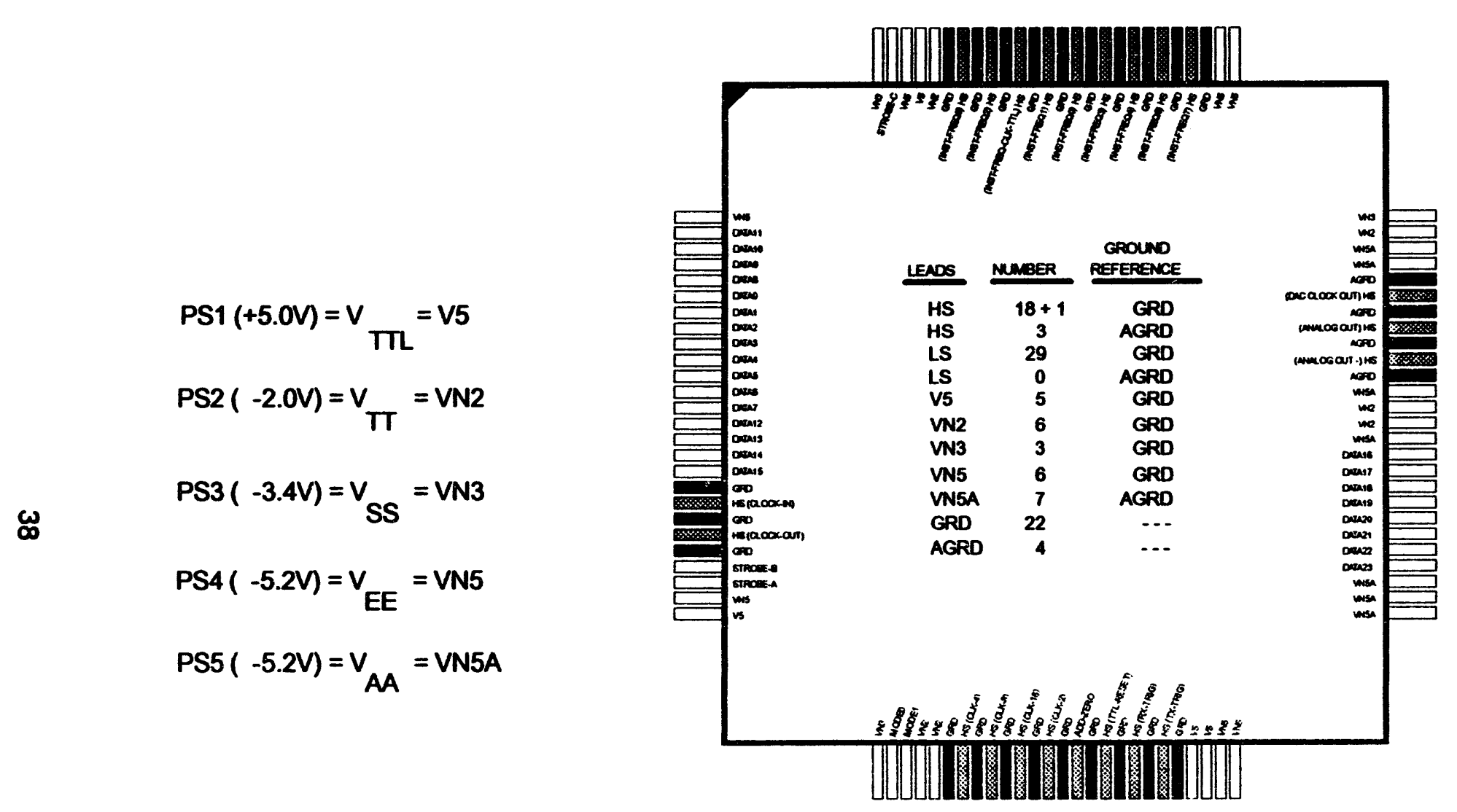

Figure 1 DWS Pinout 


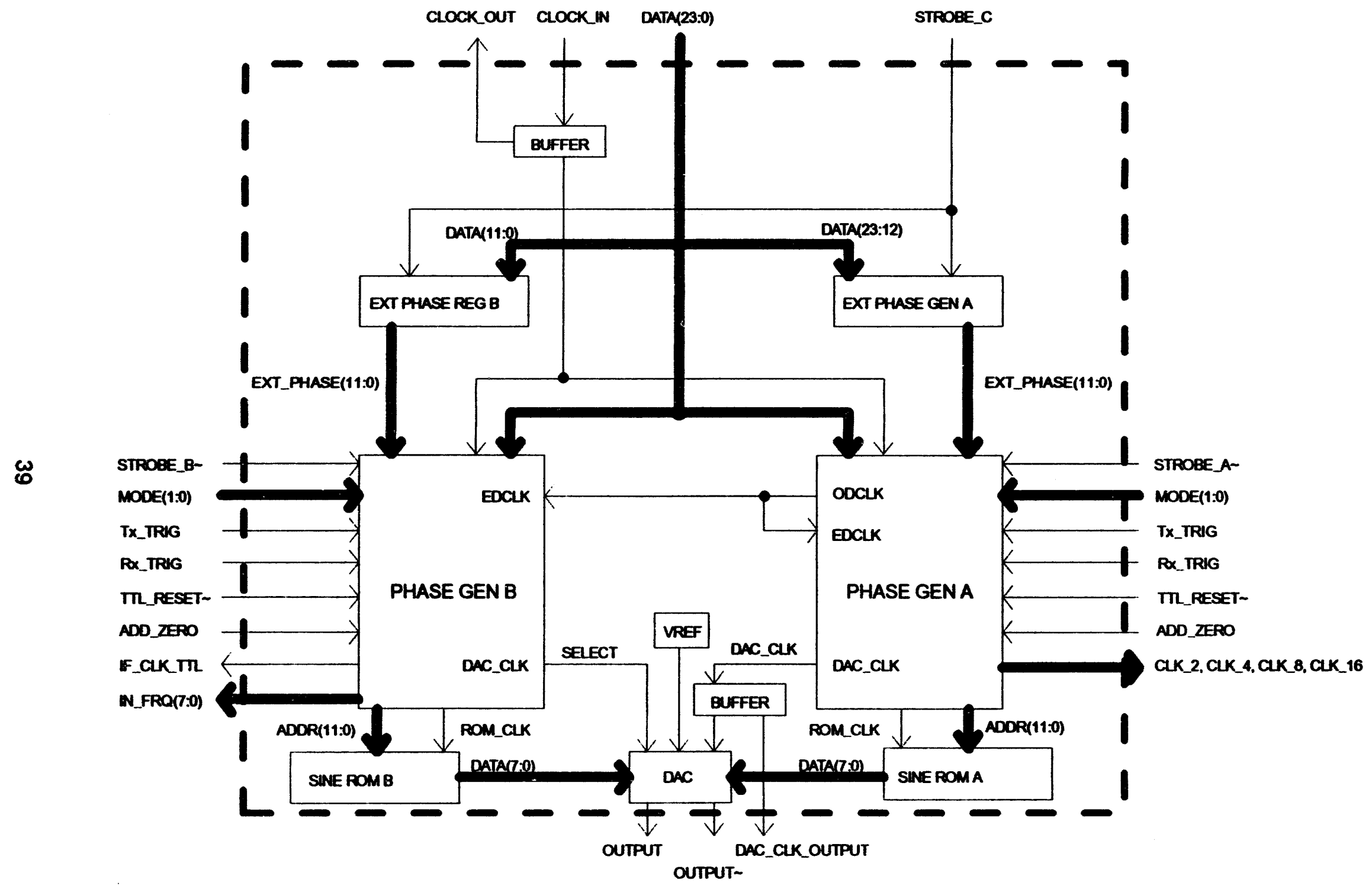

Figure 2 DWS Block Diagram 


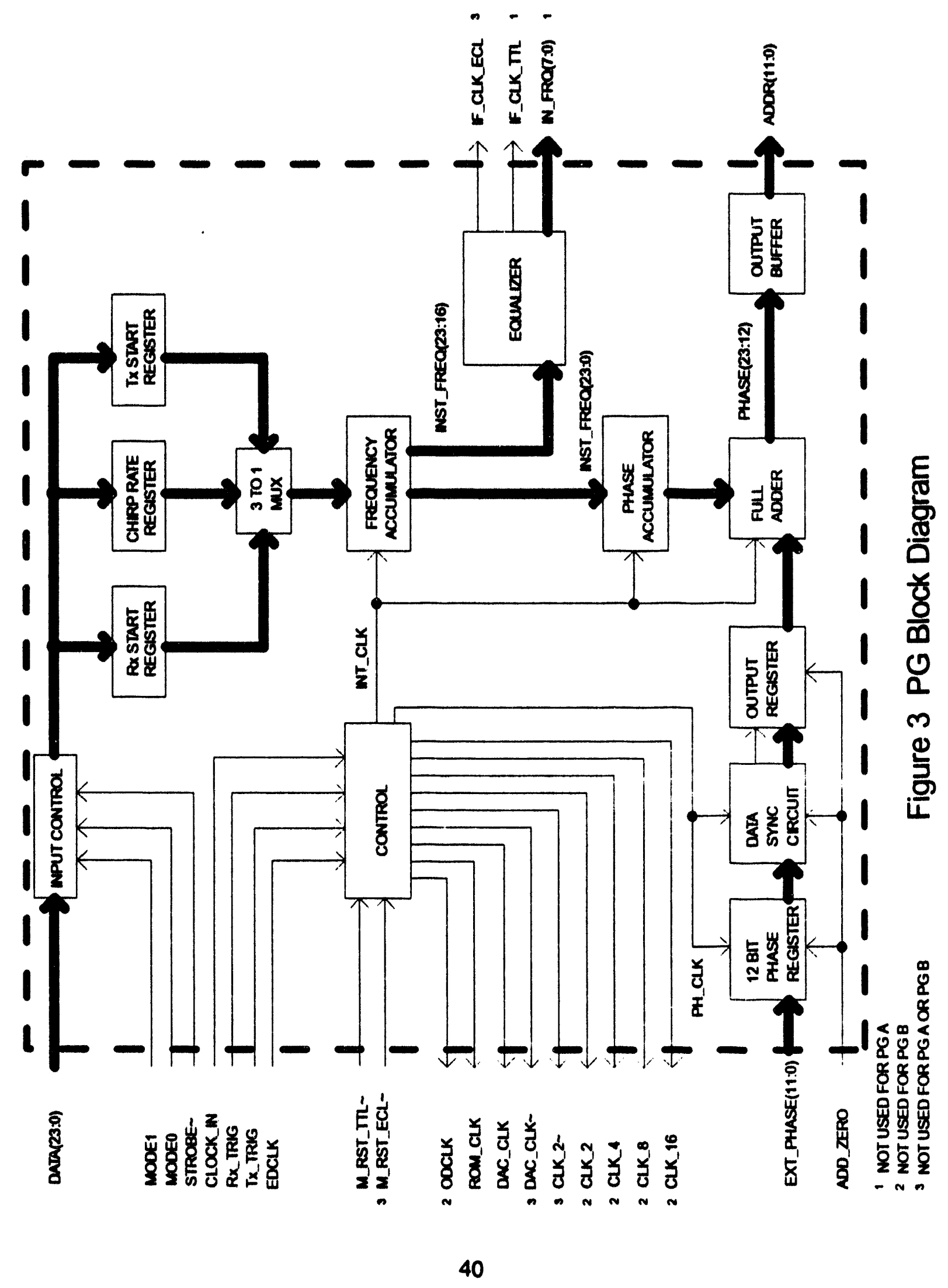




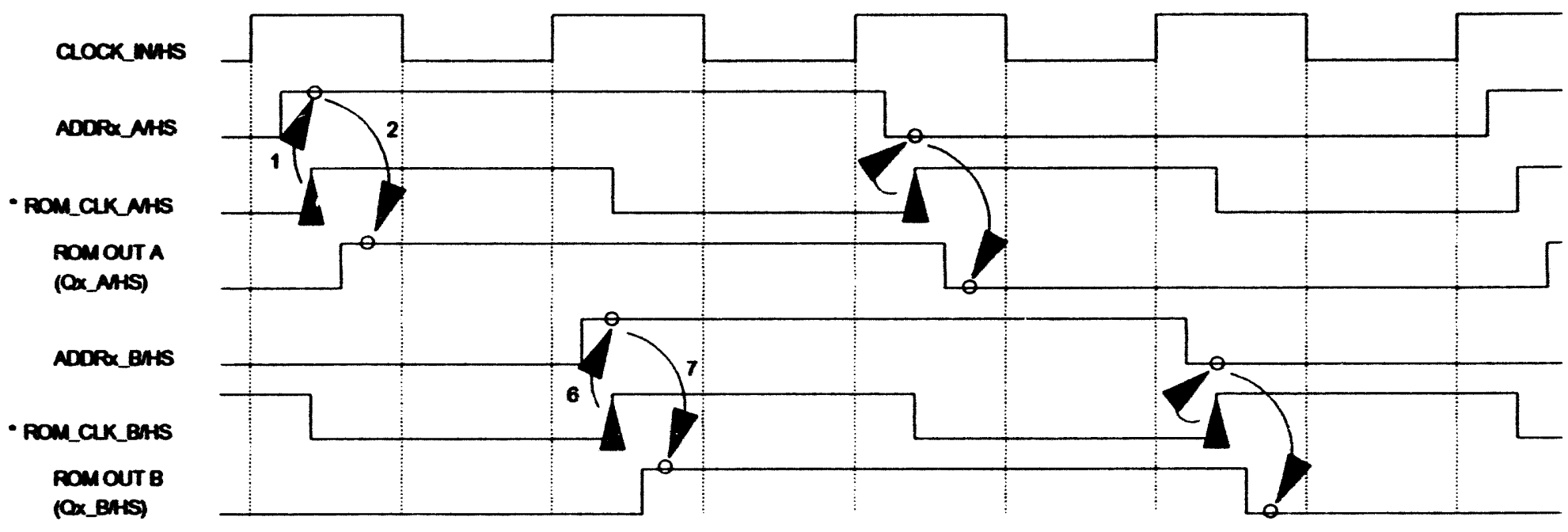

$\pm$

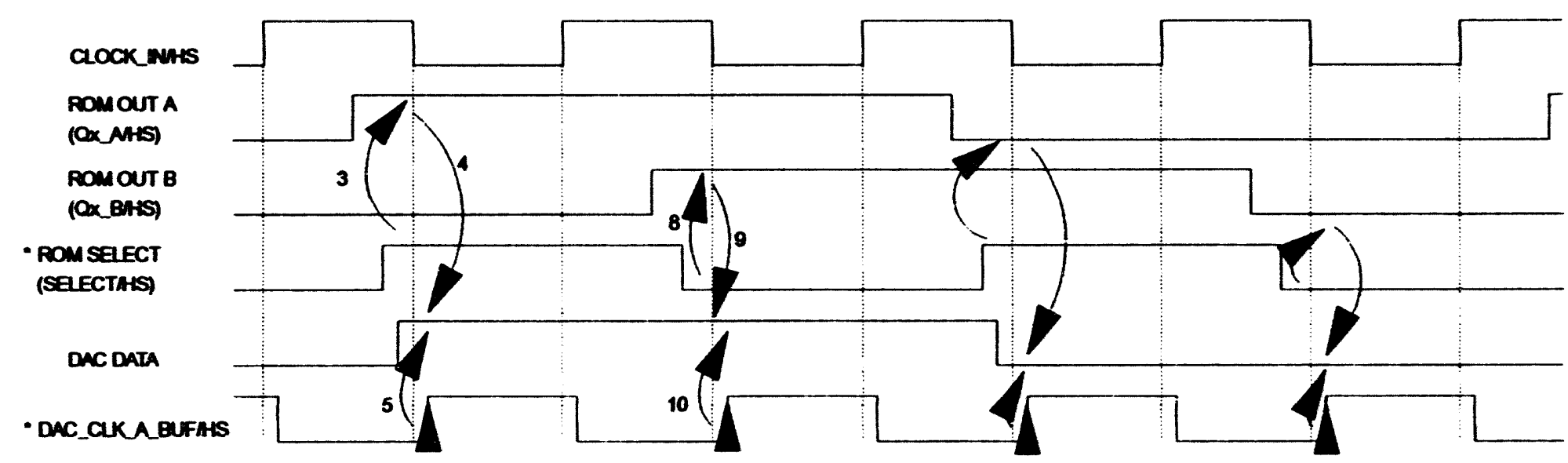

- programande delar

Figure 4 DWS Timing Diagram 

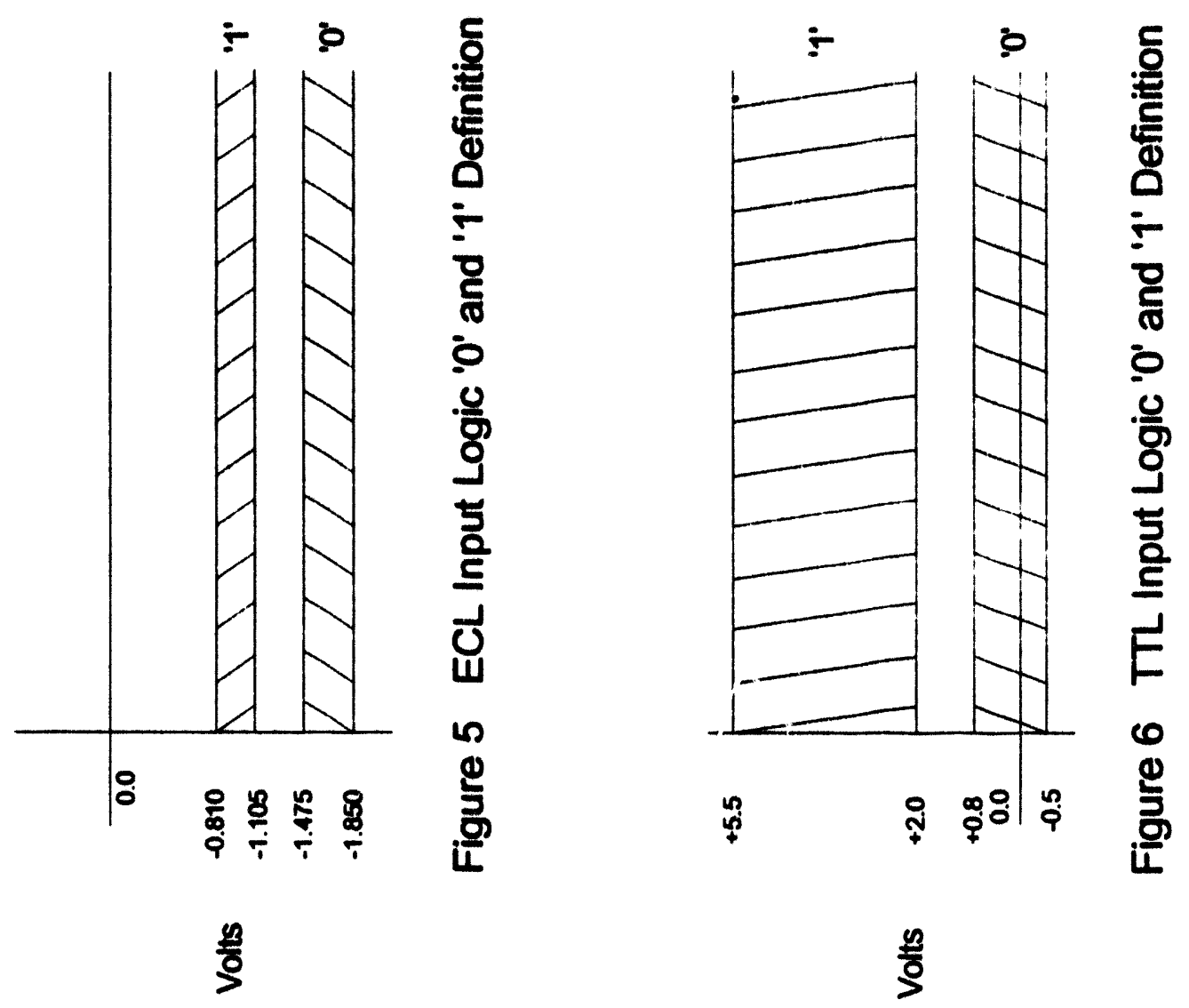


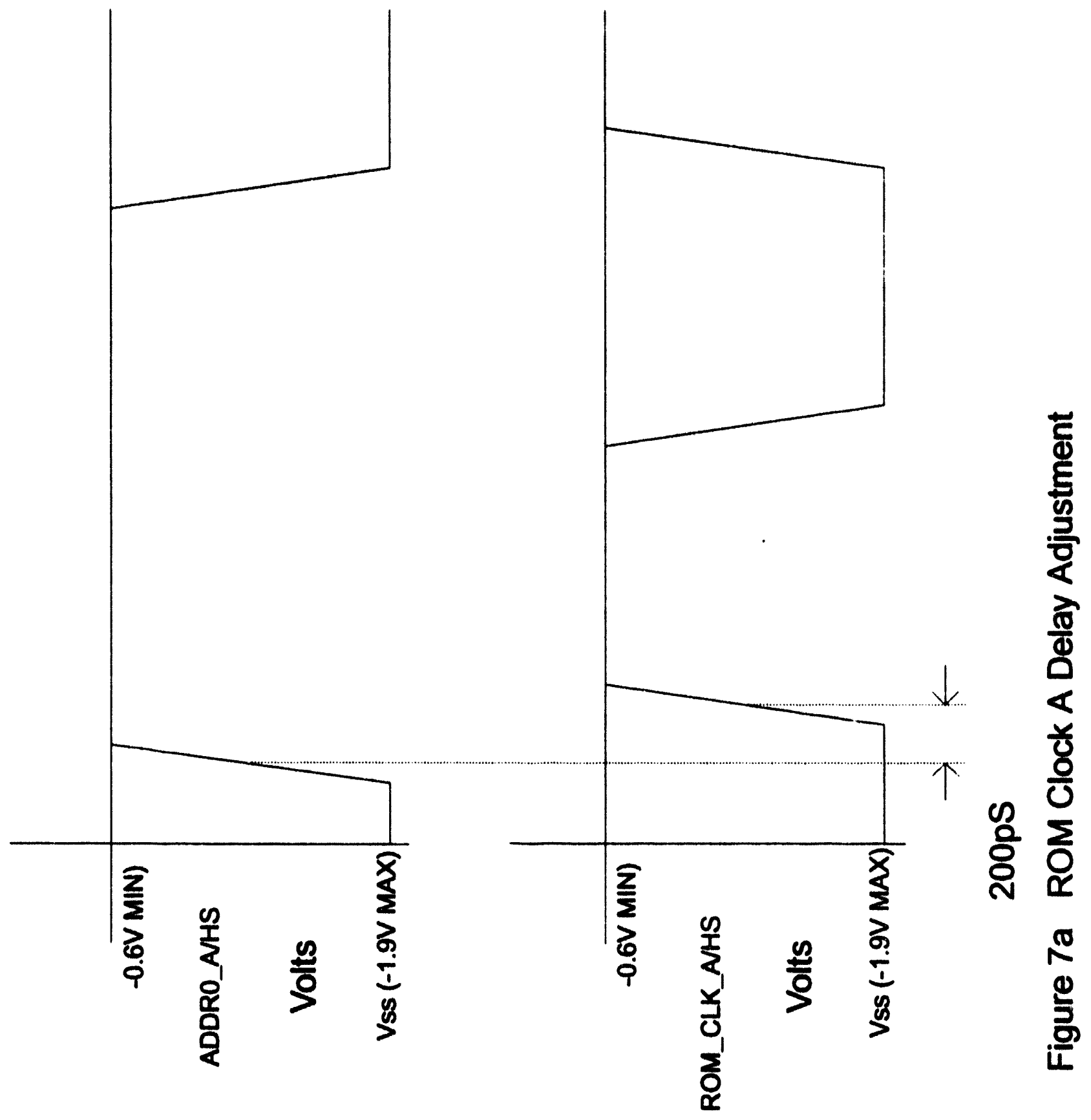




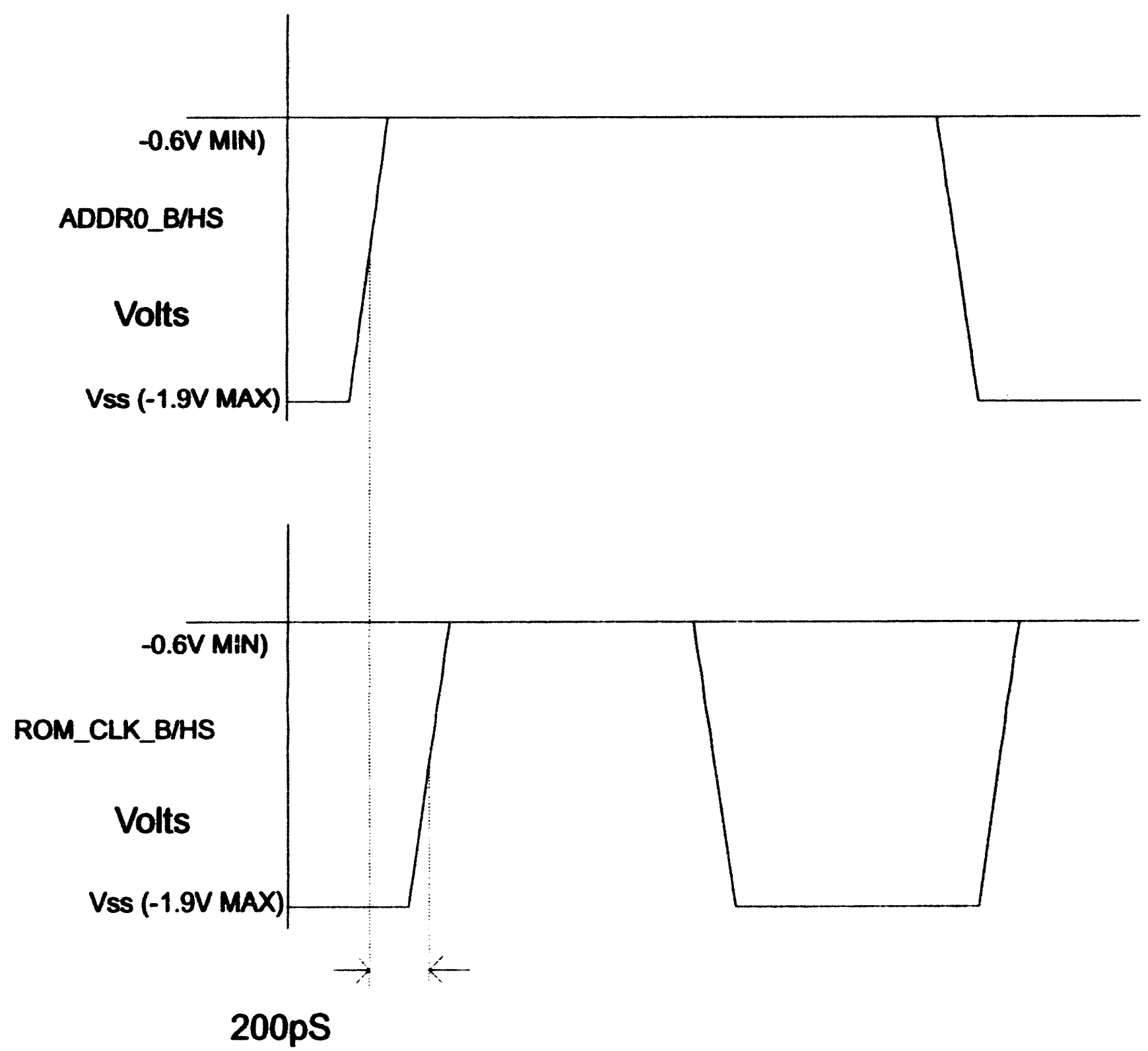

Figure 7b ROM Clock B Delay Adjustment 


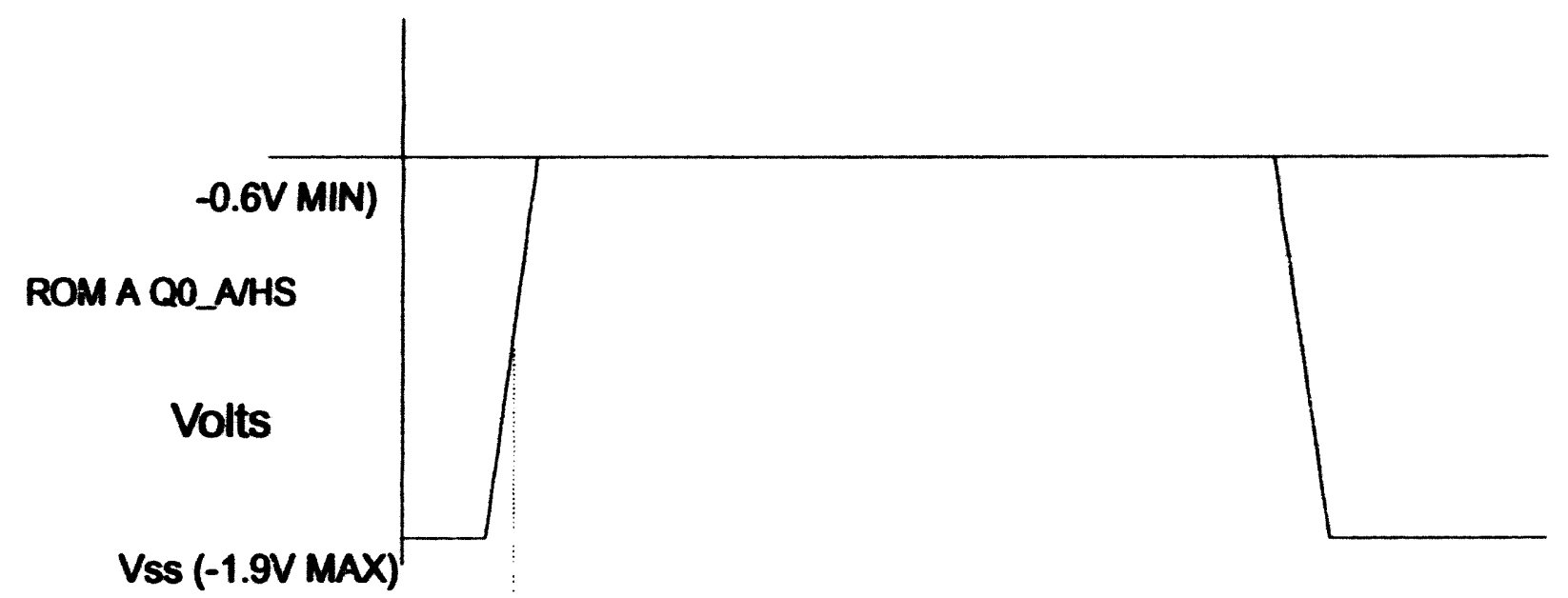

जै

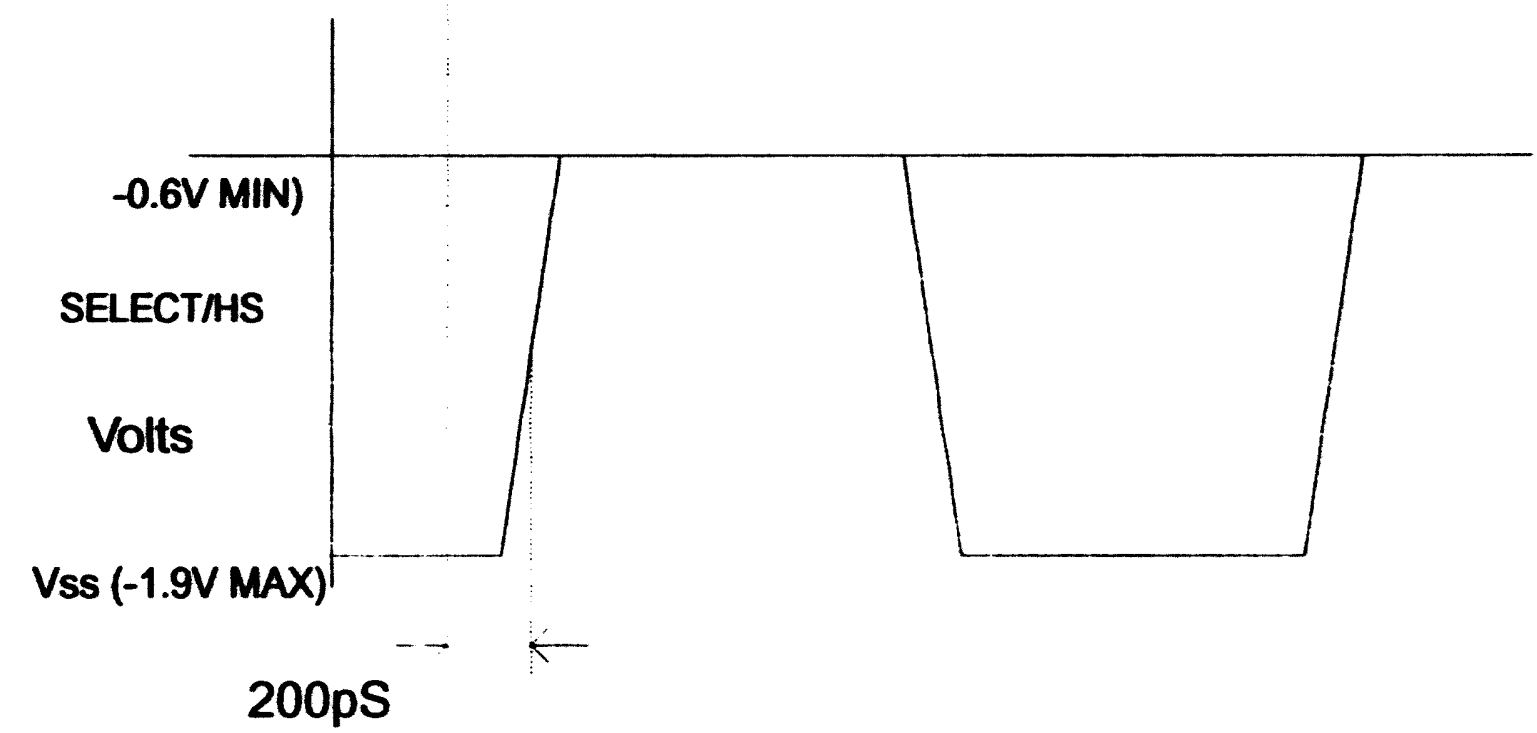

Figure 8a PG B DAC_CLK (ROM Select) / ROM A QO_AHS

Delay Adjustment 


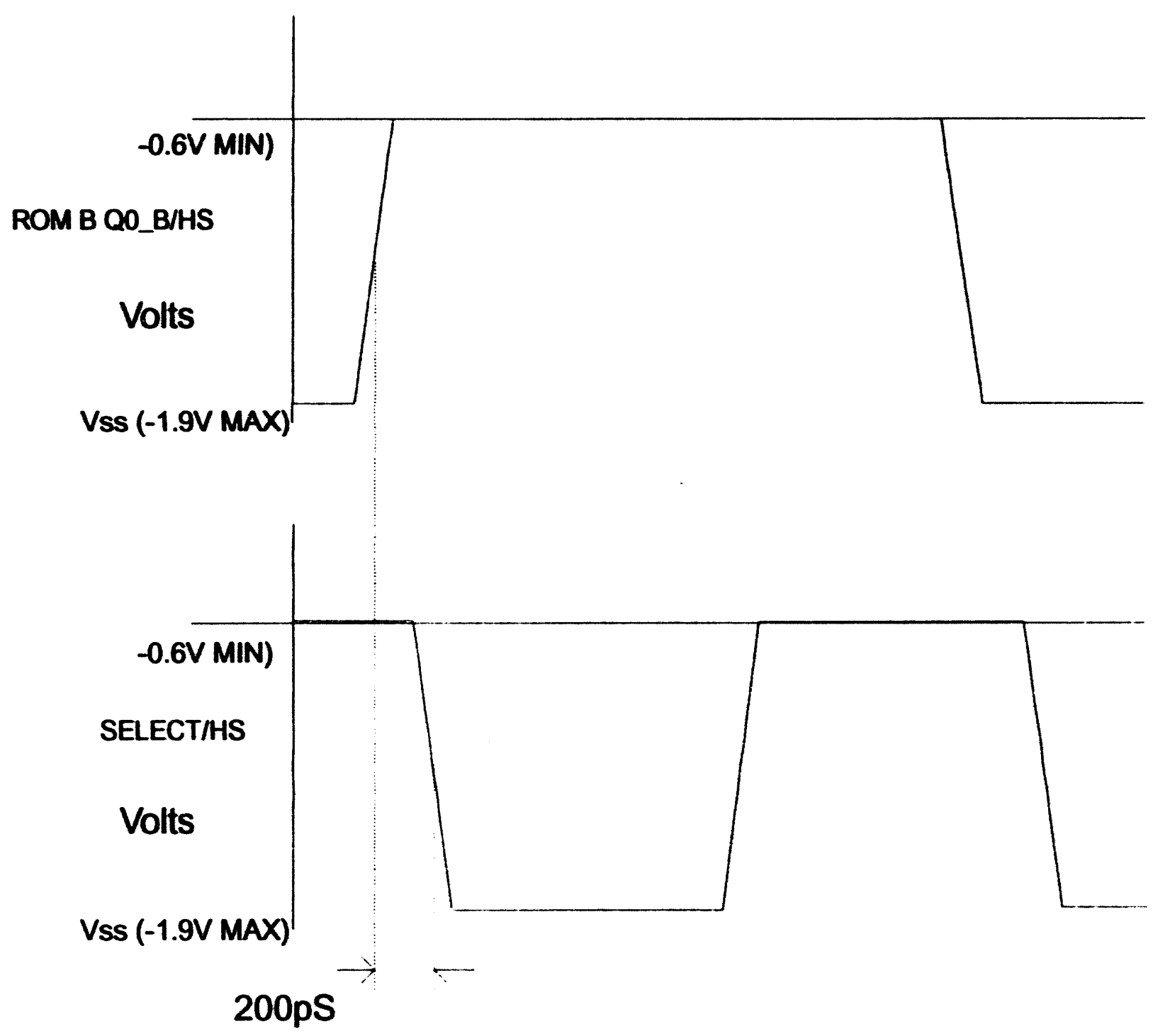

Figure 8b PG B DAC_CLK (ROM Select) / ROM B Q0_B/HS

Delay Adjustment 


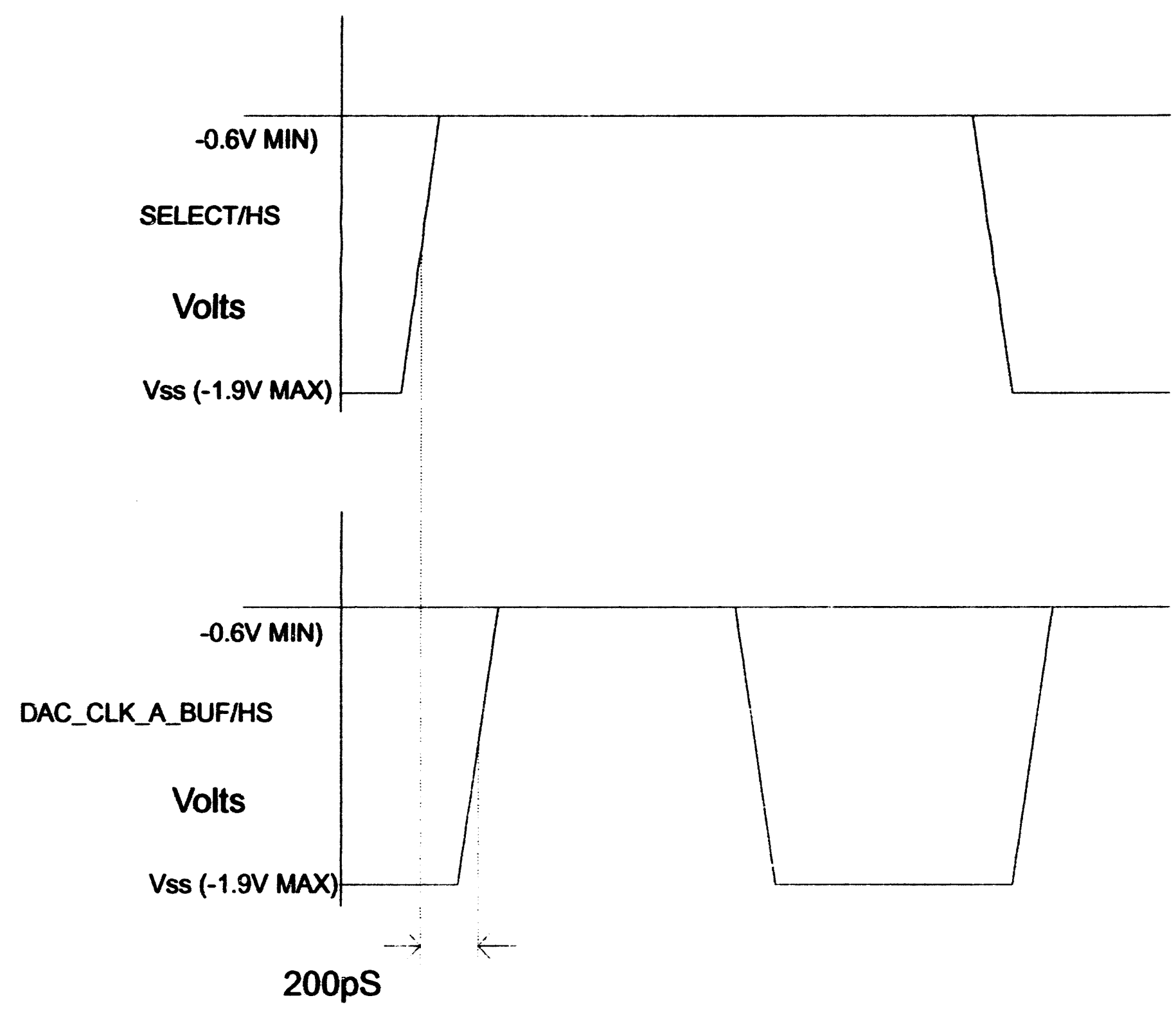

Figure 9 PG A DAC_CLK Delay Adjustment 


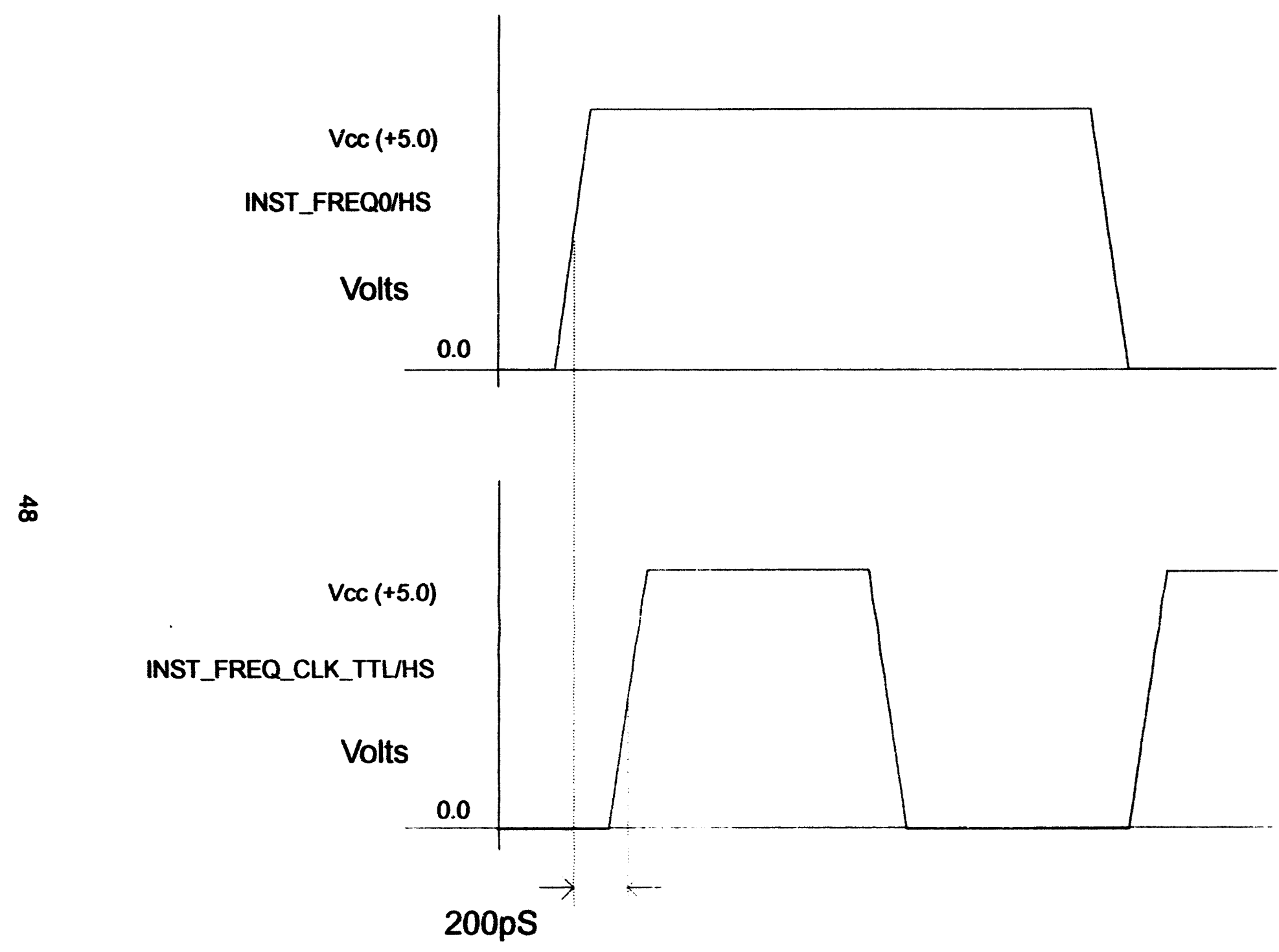

Figure 10 Instantaneous Frequency Clock Output Verification 


\section{Appendix B}

High Speed Digital Test System 
HIGH SPEED DIGITAL TEST SYSTEM

The development of the high speed digital test system has been primarily for the testing of the high speed Digital Waveform Synthesizer (DWS) multichip module. However, the design of this system is not limited to that specific task. With the exception of the DWS custom interface board and thermo-mechanical interface features, this system is also capable of testing other types of high speed digital MCMs once their custom features and programming requirements are satisfied.

Figure 1 presents the block diagram for the test system. This diagram is based on the test requirements of the DWS Test Plan set forth in Appendix A. The plan for racking the equipment into a test console and locating the test station adjacent to the console are shown in Figure 2. This plan is realized in the completed test system depicted in Figure 3 of this appendix and in Figure 6 of Appendix D. The system hardware collected into the test console are tabulated in Table 1. Table 2 presents the power supply analysis for the five supplies required by the DWS. This analysis addresses the interconnect length between each supply and the HS interface board, the nominal current draw from each supply, the necessity for multiple positive and negative leads to the supplies, and the resulting voltage drops to be corrected via the remote sense lines connected to each supply.

The DC and low speed interface cabling between the test console and the HS interface board at the test station are depicted in Figure 4 through Figure 7. Figure 4 presents the power supply cable configuration, and Figure 5 depicts the power supply cable schematic where the five supplies are routed to two identical connectors on the HS I/F board. Figures 6 and 7 present the low speed cabling to the two low speed connectors on the HS I/F board. Figure 14 of Appendix $D$ and Figure 4 of Appendix C imply the remainder of the DC and low speed interconnects to the DWS via the HS I/F board. Finally, the high speed interconnects between the test console and the DWS are implied in Figure 14 of Appendix D where each HS lead of the DWS is connected via the HS I/F board to the HS coaxial I/O panel of the test station. From the panel, each selected HS lead may be individually connected directly to equipment within the test console via high frequency coaxial cable.

Lastly, the facility requirements for the complete system are presented in Figure 8 where space, power, air, vacuum, lighting, etc. are all addressed. 


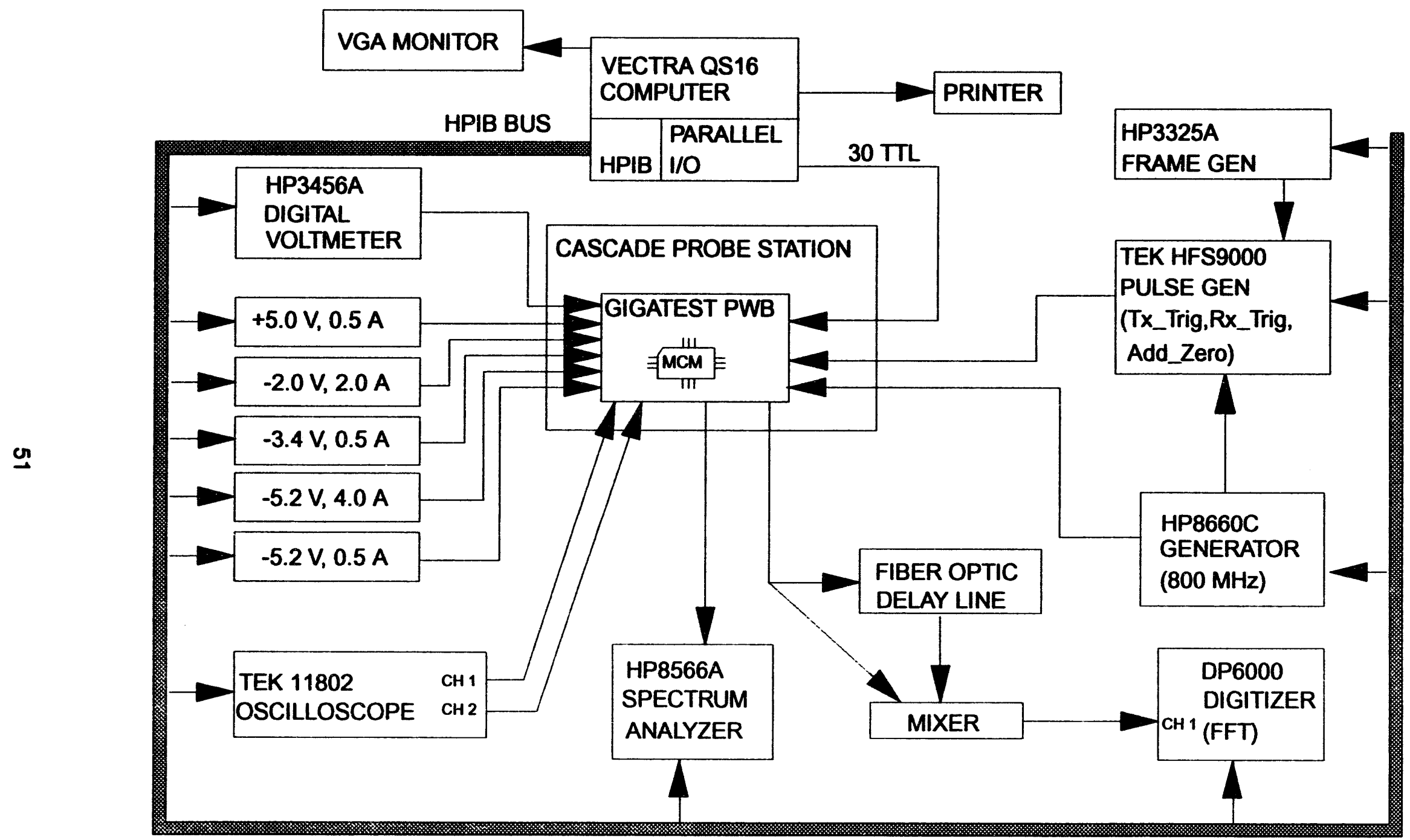

FIGURE 1. DWS TESTER BLOCK DIAGRAM 

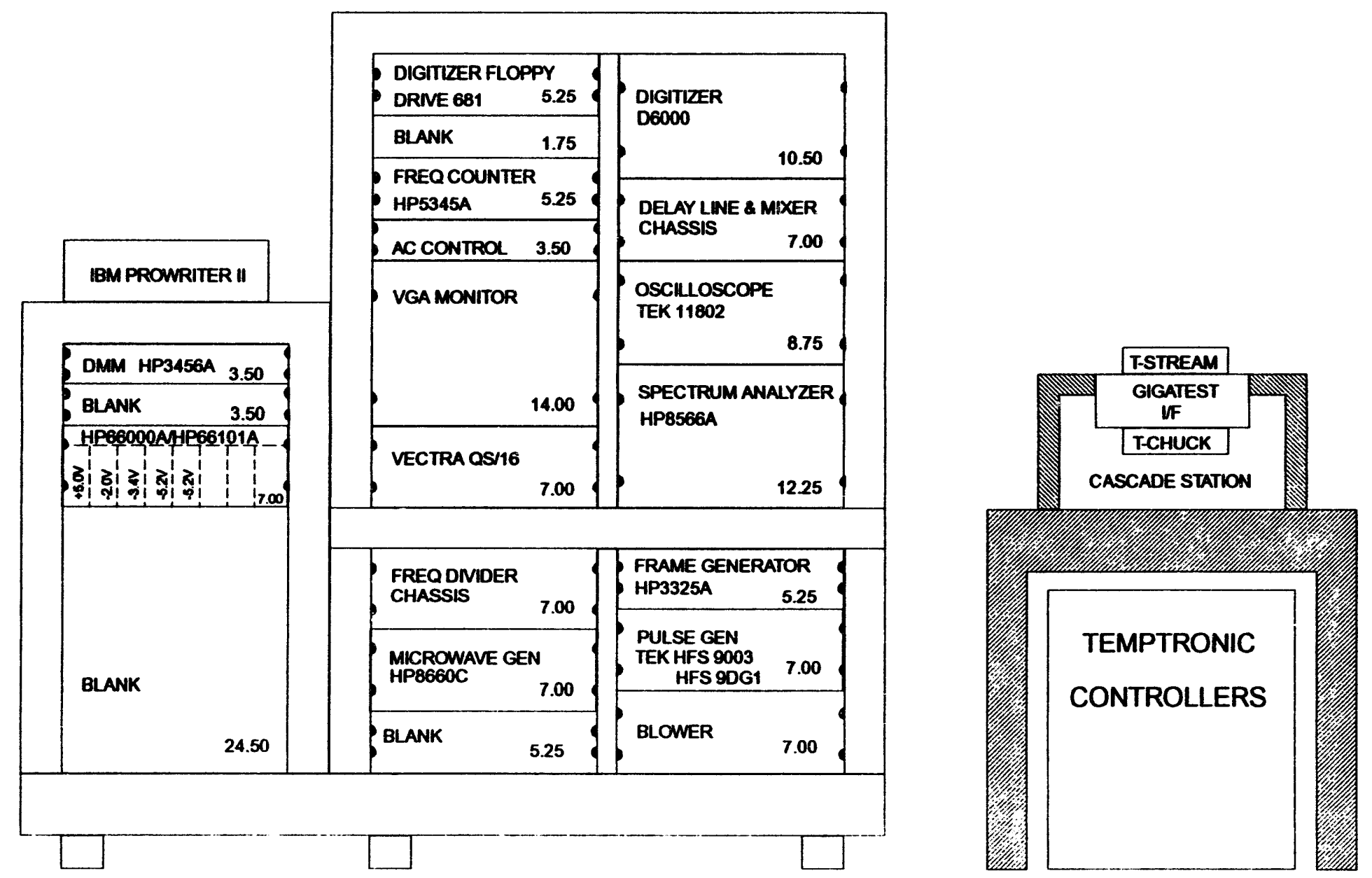

FIGURE 2. DWS TESTER CONSOLE LAYOUT 


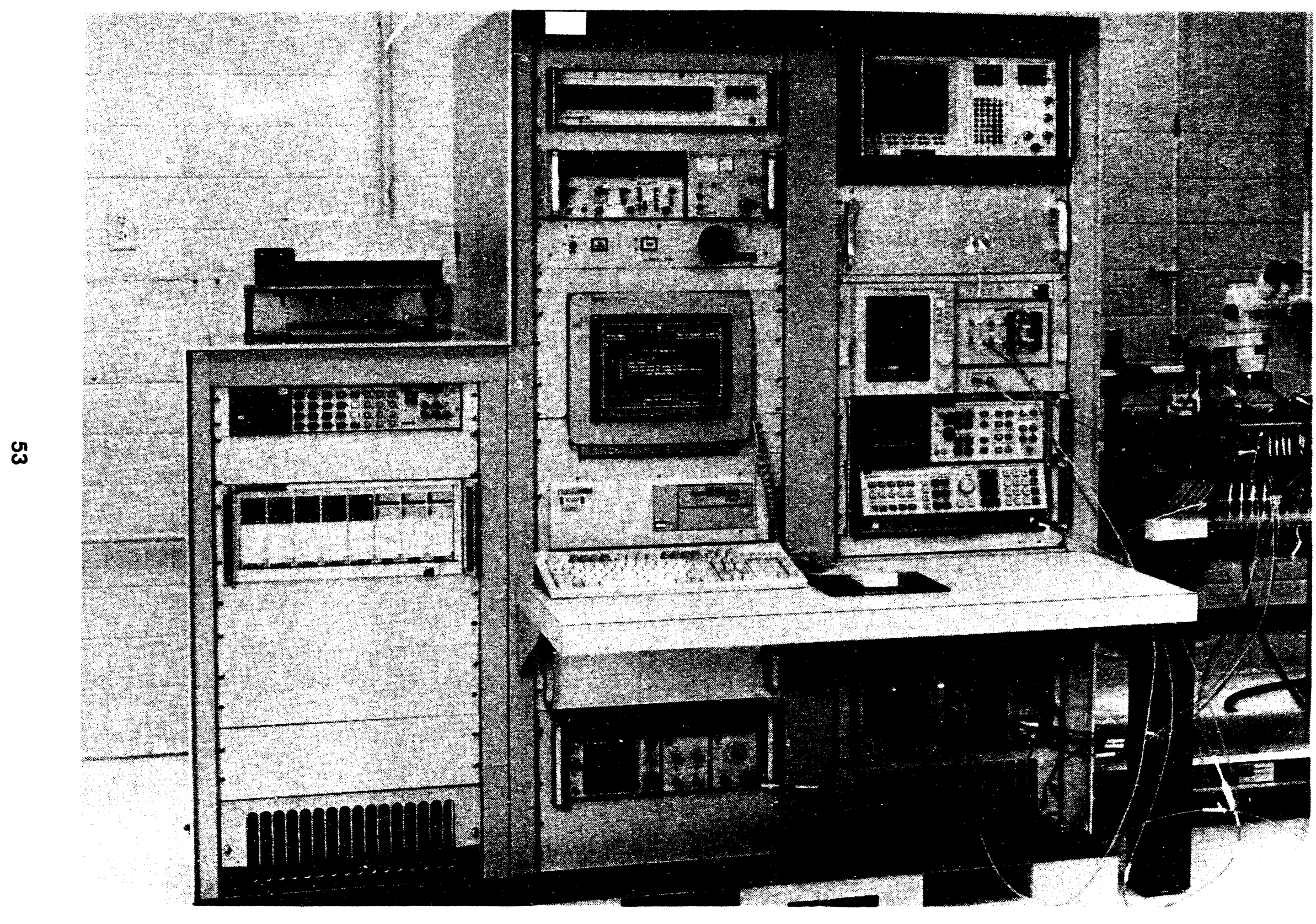




\section{D.8 TEST CONBOT EOUIPYENT}

\section{AETIFTT-PACKARD}

1 Vectra Computer (QS16)

1 VGA Monitor (D1182A)

1 Spectrum Analyzer (HP8566A)

1 Microwave Generator (HP8660C)

1 Power Supplies Mainframe (HP66000A)

5 Power Supply Plug-Ins (HP66101A)

1 DMM (HP3456A)

1 Frame Generator (HP3325A)

1 Frequency Counter (HP5345A)

\section{TEFPRONTX}

1 Pulse Generator (HFS9003

1 Data Generator Plug-In (HFS9DG1)

1 Pulse Generator Plug-In (HSF9PG1)

1 Sampling Head Digitizer (TEK 11802)

IBY

1 IBM Printer (Prowriter II)

\section{METERABYTE}

1 Parallel I/O, 96 bit (PIO-96)

ORTEL

1 Fiber Optic Delay Line, .01-4 GHz, 20uS (5006A-E2000)

\section{DATA PRECIBION}

1 Digitizer Mainframe (D6000)

1 100MHz Digitizing Plug-In (610)

1 Digitizer Floppy Drive (681) 
The high speed I/F board utilizes IDC type 16 pin ribbon connectors for DWS power application. The Power supplies must be wired to minimize the voltage drop in the ribbon cable by paralleling wires as detailed below (also see Power Supply Interface Cable schematic).

These Power Supplies use remote sensing which provides the correct voltage at the high speed I/F board. The maximum voltage drop that the power supplies can compensate is about $1 \mathrm{~V}$, well above the calculated drops cited below.

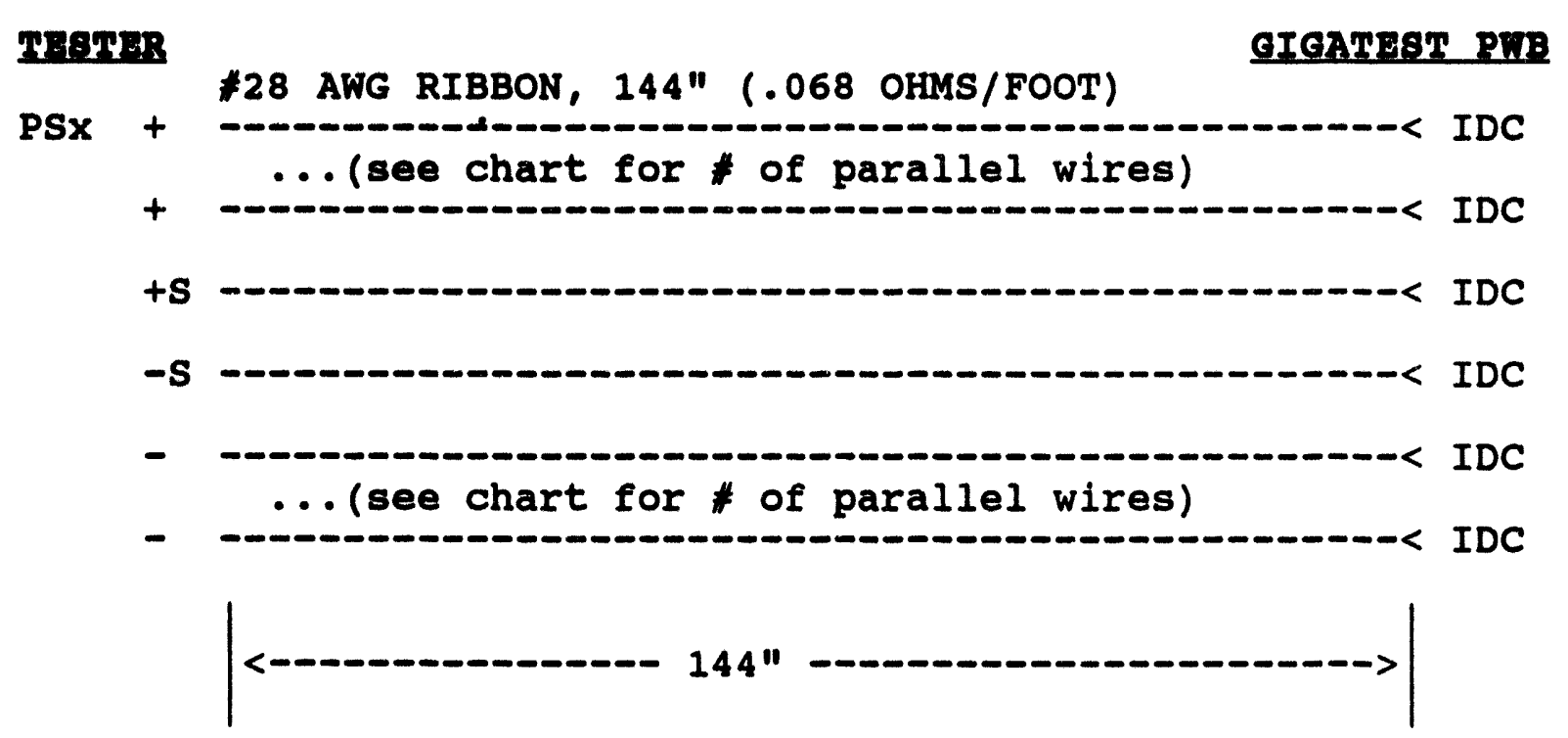

\begin{tabular}{|c|c|c|c|c|c|c|c|}
\hline 8UPPLX & $\begin{array}{l}\text { " } \\
\text { POS. } \\
\text { ETRES }\end{array}$ & $\begin{array}{l}\text { WIRE } \\
\text { RE8. } \\
\text { OPIPY8 }\end{array}$ & $\begin{array}{l}\not " \\
\text { NEC. } \\
\text { nIRES }\end{array}$ & $\begin{array}{l}\text { WIRE } \\
\text { RES. } \\
\text { OEYS }\end{array}$ & $\begin{array}{l}\text { TOTAL } \\
\text { WIRE } \\
\text { RES. }\end{array}$ & $\begin{array}{l}\text { NOM. } \\
\text { CURRENT } \\
\text { AMPS }\end{array}$ & $\begin{array}{l}\text { TOMAT } \\
\text { VOLI. } \\
\text { DROP }\end{array}$ \\
\hline $\begin{array}{l}\text { V5 } \\
\text { VN2 } \\
\text { VN3 } \\
\text { VN5 } \\
\text { VN5A }\end{array}$ & $\begin{array}{l}1 \\
3 \\
1 \\
3 \\
1\end{array}$ & $\begin{array}{l}0.068 \\
0.023 \\
0.068 \\
0.023 \\
0.068\end{array}$ & $\begin{array}{l}1 \\
3 \\
1 \\
7 \\
1\end{array}$ & $\begin{array}{l}0.068 \\
0.023 \\
0.068 \\
0.010 \\
0.068\end{array}$ & $\begin{array}{l}0.136 \\
0.046 \\
0.136 \\
0.033 \\
0.136\end{array}$ & $\begin{array}{l}0.550 \\
0.800 \\
0.250 \\
3.800 \\
0.100\end{array}$ & $\begin{array}{l}0.075 \\
0.037 \\
0.034 \\
0.125 \\
0.014\end{array}$ \\
\hline
\end{tabular}

TABLE 2. DWS POWER SUPPLY ANALYSIS 


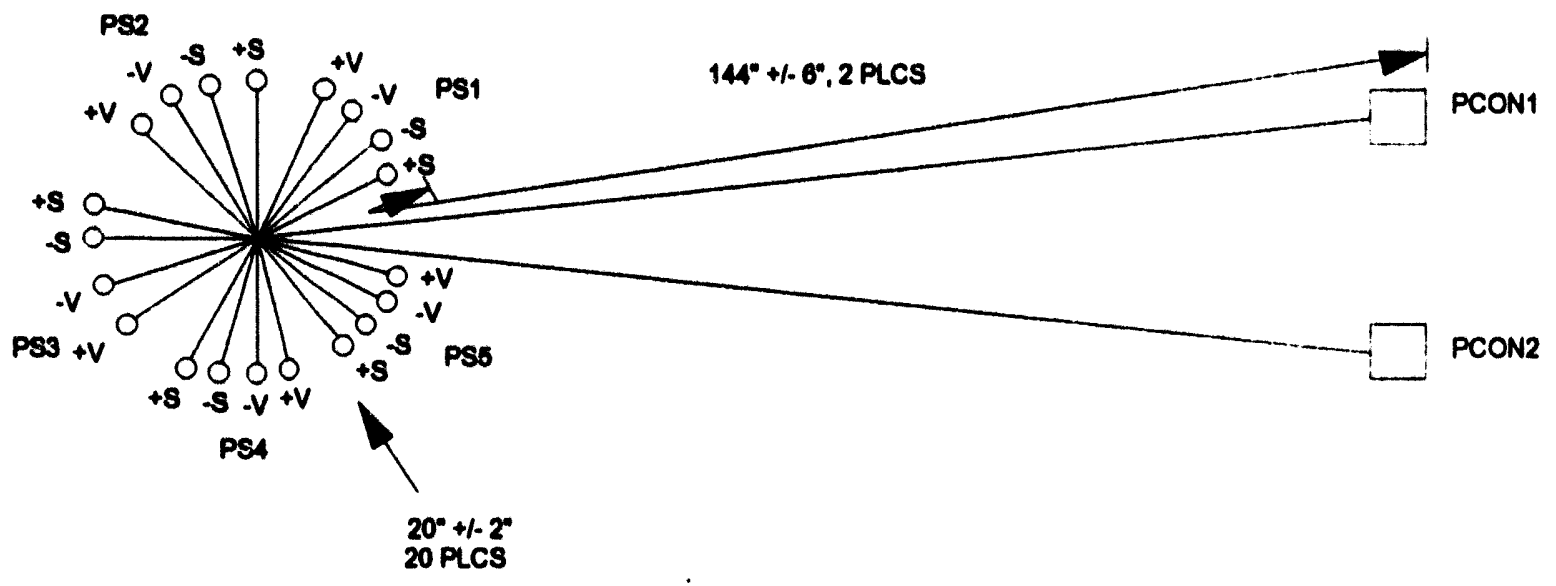

FIGURE 4. DWS POWER SIJPPLY I/F CABLE 
RCON1

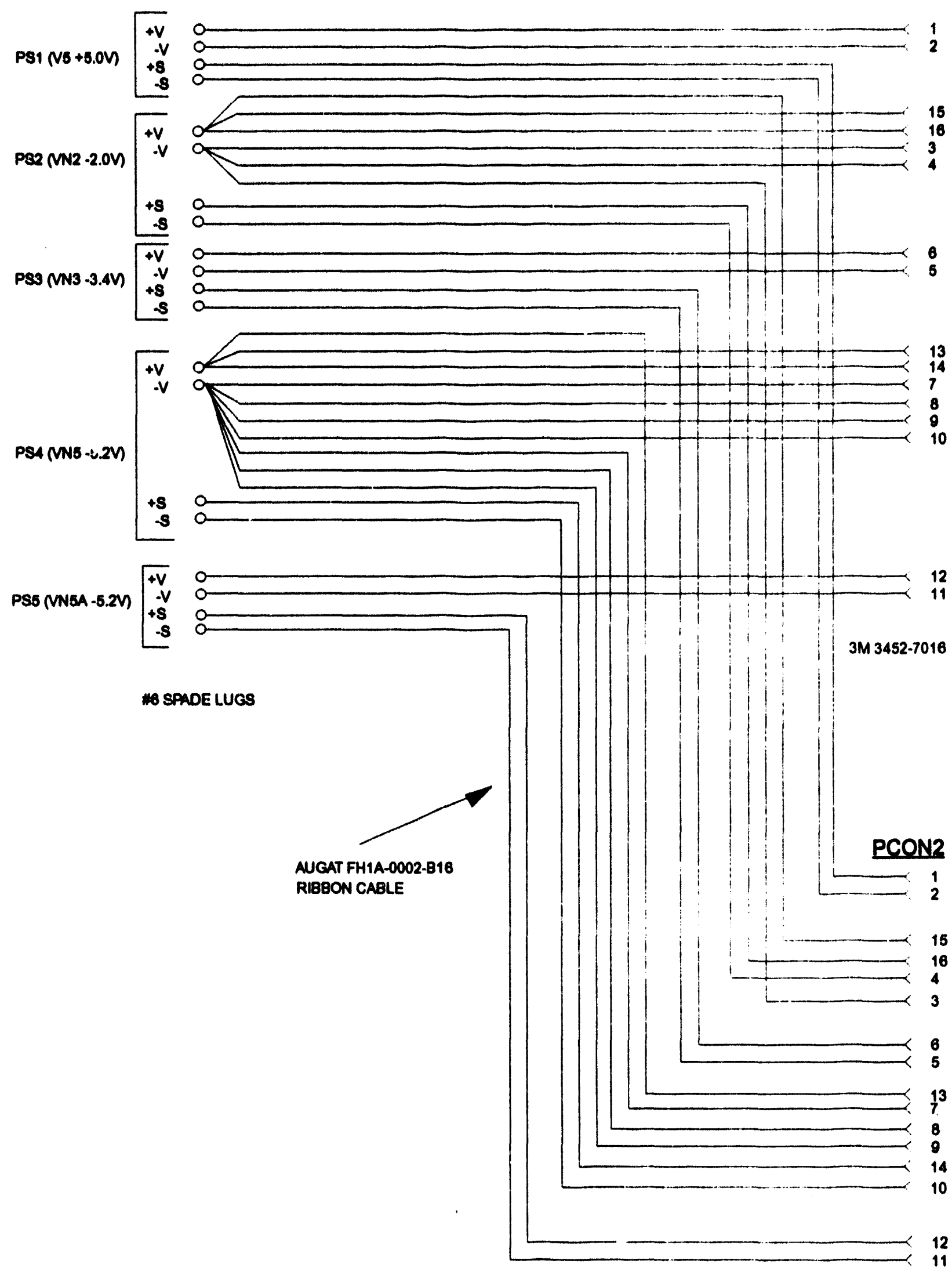

FIGURE 5. POWER SUPPLY I/F CABLE SCHEMATIC 


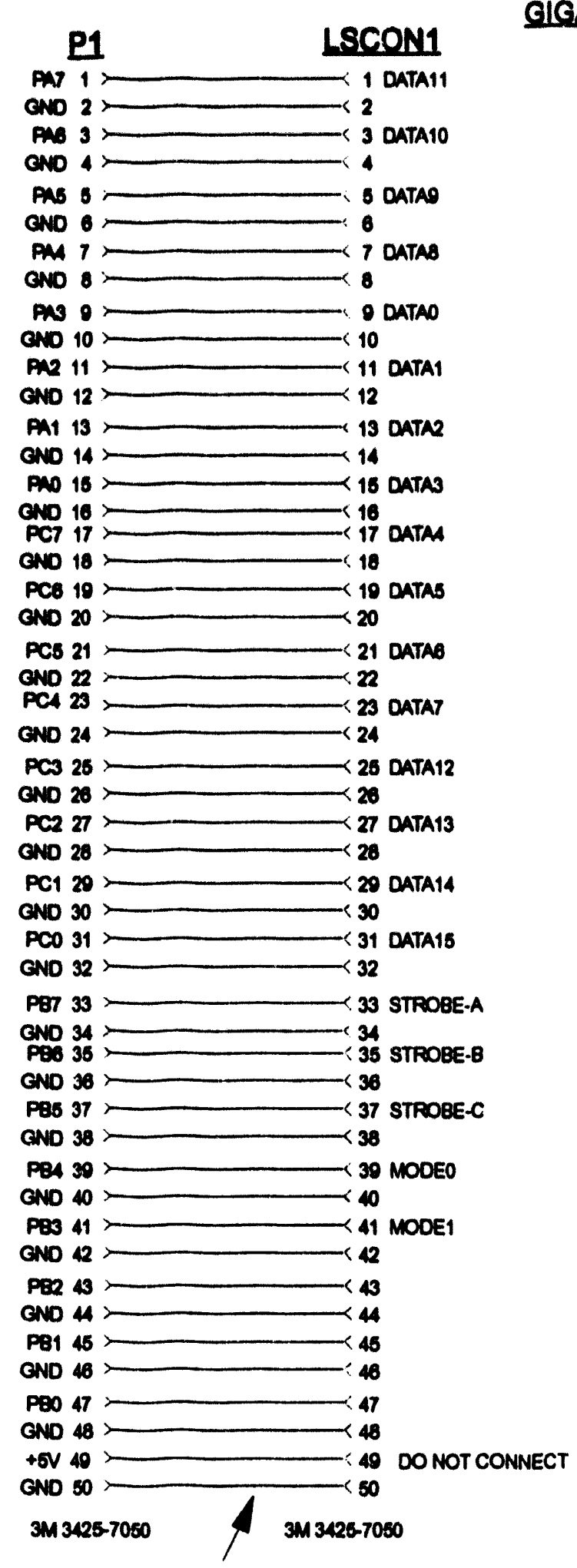

FH1A-0002-BSO, AUGAT, 60 WIRE FLAT CABLE, TWISTED

P1 $\square-120^{\circ}+1-\sigma^{\circ} \longrightarrow$ LSCON1

FIGURE 6. LOW SPEED I/F CABLE SCHEMATIC (LSCON1) 

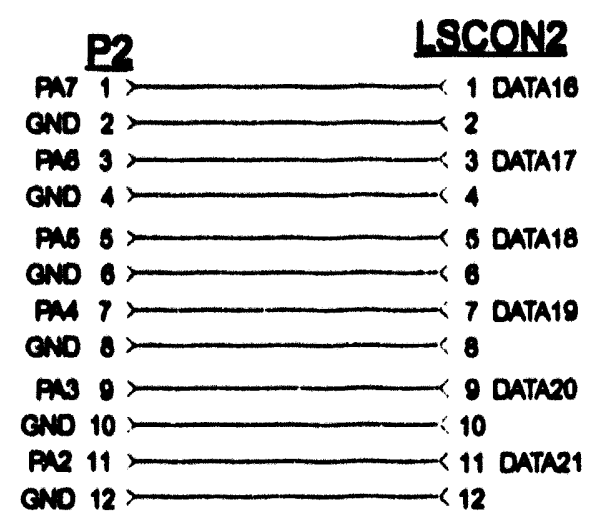

FH1A-0002-B50, AUGAT, 50 WRE FLAT CABLE, TWISTED

P2<smiles>O=S(=O)(O)OCC1CC2CCCCC2C1</smiles>

FIGURE 7. LOW SPEED I/F CABLE SCHEMATIC (LSCON2) 
BACK WAII

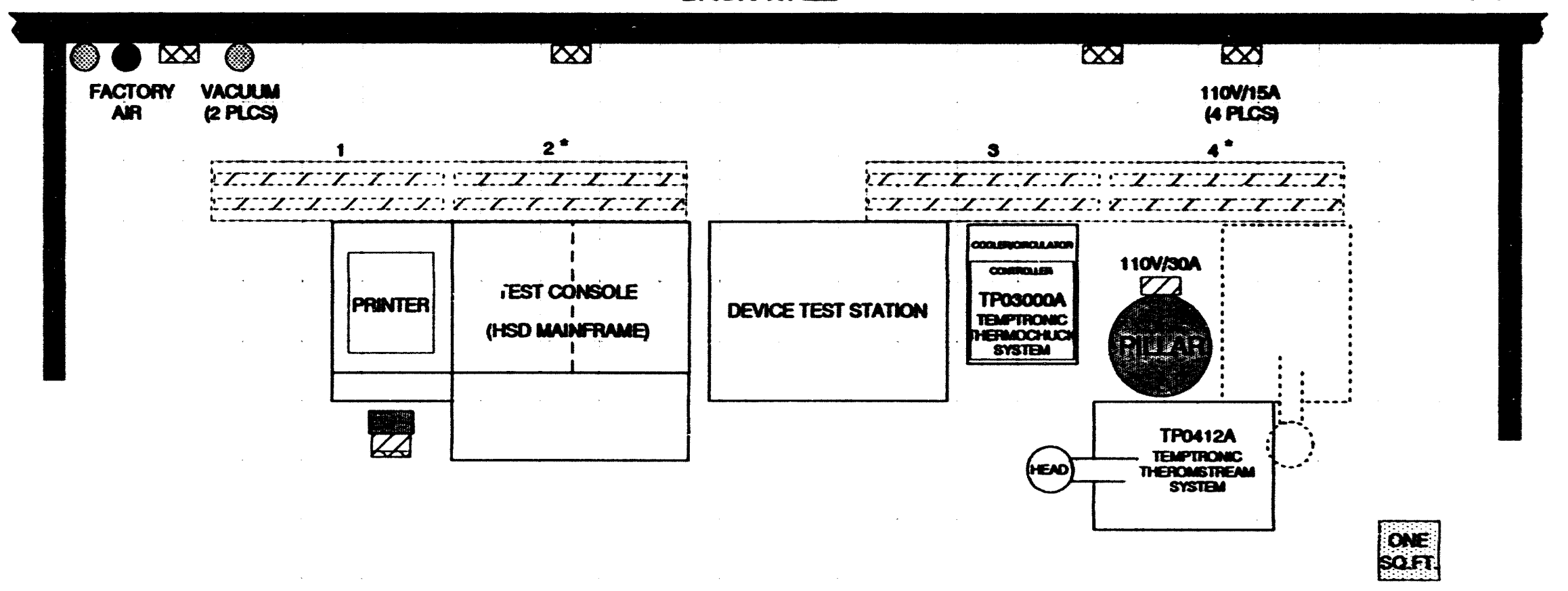

REQUIRED MODIFICATIONS

1. RENOVE FLOOR-ANCHORED DROP IN FRONT OF TEST CONSOLE AND RELOCATE REARMARD ON BACK WALL

2. REACTNATE VACCWM TO THE TWO VACUUM LINES.

3. REACTNATE RLORESCENT FIXTURES 2, 4 AND 6 (\%).

4. ADD 220 VAC, 60 HZ, SINGLE PHUSE, 20 AMP (MUNMUMM) DROP ON BACK WALL BEHND THERMOSTREAM UNT.

5. ADD TEEPHONE SERMCE (HACK LOCATED ON PILAP).

FIGURE 8. HSD TESTER FACILITY REQUIREMENTS 


\section{Appendix C}

Specifications for a High Speed Testing Interface 
B P E I I I A TION 8

$\mathbf{P} \quad \mathbf{R} \mathbf{A}$

II I I P E D T TE TING INTEREACE

Prepared BY

R. E. Markley

and

T. F. Boehm

March 20, 1992

Test Equipment Operations I and II 
1. GELERAL • • • • • • • • • • • • • • • 1

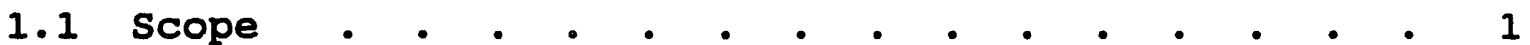

1.2 Changes . . . . . . . . . . . . . . . 1

1.3 Conflicts . . . . . . . . . . . . . . 1

1.4 Figures . . . . . . . . . . . . . . . 1

1.5 Definitions . . . . . . . . . . . . . .1

2. PRODUCT-RELATED INFORMATION.$\quad \cdot \quad \cdot \quad \cdot \quad \cdot \quad \cdot \quad \cdot \quad \cdot 1$

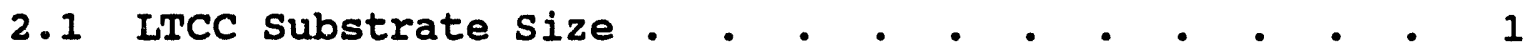

2.2 Heat Spreader Size . . . . . . . . . . . 1

2.3 Kovar Seal Ring . . . . . . . . . . . . 2

2.4 Cantilevered Leads

2.5 Product Handling Cautions . . . . . . . . . 2

3. ELECTRICAL REQUIREMENTS - • - • • • • • • • 2

3.1 Device Cutout . . . . . . . . . . . . . 3

3.2 Device Lead Matching Metallization . . . . . . 3

3.3 Lead Clamping . . . . . . . . . . . . . 3

3.4 High Speed (HS) Interconnect . . . . . . . .3

3.5 Low Speed (IS) Interconnect . . . . . . . . 4

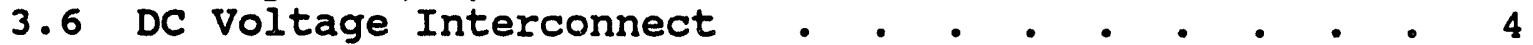

3.7 Grounds . . . . . . . . . . . . . . .4

3.8 Load Components . $. \quad . \quad . \quad . \quad . \quad . \quad . \quad . \quad . \quad . \quad .5$

4. ELECTRICAL VERIFICATIONS • • • • • • • • . 5

4.1 HS Interconnect Verification . . . . . . . . 5

4.2 IS Interconnect Verification . . . . . . . . 5

4.3 DC Voltage Interconnect Verification . . . . . 6

4.4 Ground Interconnect Verification . . . . . . 6

4.5 Load Component Verification . . . . . . . . 7

5. MEChANICAL REQUIREMENTS • • • • • • • • • • 7

5.1 Device Orientation and Mating . . . . . . . $\quad$ - 7

5.2 Clamping and Alignment. . . . . . . . . .8

5.3 Probe station Interface Requirements . . . . . 8

5.4 Blow-by Mechanical Interface . . . . . . . 8

5.5 Thermochuck Mechanical Interface . . . . . . 8

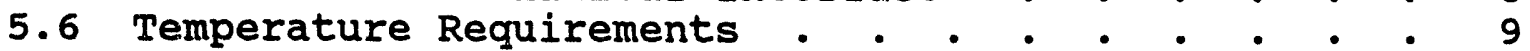

6. MECHANICAL VERIFICATIONS • • • . • • • . . 99

6.1 MCM Interface . . . . . . . . . . . . . 9

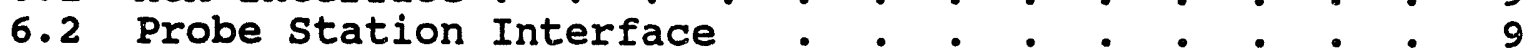

6.3 Blow-by Interface . . . . . . . . . . . .9

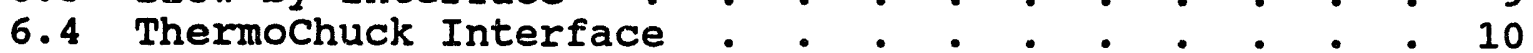

7. DESIGN REVIENS • • • • • • • • • • • • • 10 
1 Waveform Synthesizer Layout

2 Waveform Synthesizer cross-section

3 Waveform Synthesizer I/O Definition

4 Waveform Synthesizer Electrical Interface

5 Conceptual Interface Board

6 Existing Thermostream Conditioning Head

7 Mechanical Constraints, Board Top Surface

8 Mechanical Constraints, Board Bottom Surface

18

9 Thermochuck/Board Clearance, Interface Board 


\section{GENERAL}

1.1 scope. A testing interface is required for a high speed digital waveform synthesizer, and this specification sets forth the minimum requirements for that interface.

1.2 Changes. Recommendations for revisions to this specification will be considered and evaluated on the basis of beneficial results to performance of the testing interface, cost of the interface, and delivery of the interface. Revisions must be approved in writing by the Buyer before they are considered part of this specification.

1.3 Conflicts. Where a conflict exists between this document and any other document specified herein, this specification shall govern.

1.4 Figures. Figures 1 through Figure 9 are part of this specification and are specifically incorporated herein by reference.

1.5 Definitions. The terms "product" and "MCM" and "waveform synthesizer" and "synthesizer" are all different names used within this specification for the device requiring the testing interface. They all identify the same physical entity.

The term "interface" is to be treated as a shortened version of "testing interface" throughout this specification.

\section{PRODUCT-RELATED INFORMATION}

This section conveys product-related information which shall be used by the seller in the design and development of the testing interface.

The Digital Waveform Synthesizer is a multichip module (MCM) composed of a low temperature co-fired ceramic (LTCC) substrate, chip and surface mount devices, and a heat spreader on one surface and a hermetically sealed chip cavity on the opposite surface. The MCM electrical interface results from cantilevered I/O leads projecting from all four sides of the module (reference Fig. 1,2 and 3 ).

2.1 ITCC substrate size. The dimensional aspects of the MCM substrate are as follows:

$$
\begin{array}{rll}
\text { nominal } I \times W= & 2.240 \text { in. } x 2.240 \text { in. } \\
\text { nominal thickness }= & 0.115 \text { (w/o spreader) } \\
& 0.140 \text { (with spreader) }
\end{array}
$$

2.2 Heat spreader size. The heat spreader is located nonsymmetrically on the LTCC substrate and has the following dimensional features: 
nominal $\mathrm{L} \times \mathrm{W} \times \mathrm{T}=1.540$ in. $\mathrm{x} 1.400$ in. $\mathrm{x} .025$ in.

The approximate spreader edge locations are as follows (relative to the LTCC centerlines with the LTCC diagonal corner in the upper left and the spreader on the undersurface of substrate):

$\begin{aligned} \text { left of center: } & 0.815 \mathrm{in} . \\ \text { right of center: } & 0.725 \mathrm{in} . \\ \text { top of center: } & 0.700 \mathrm{in} . \\ \text { bottom of center: } & 0.700 \mathrm{in} .\end{aligned}$

2.3 Rovar seal Ring. The Kovar seal ring is located symmetrically on the LTCC substrate, and it has the following thickness and height dimensions:

approx. ring $\mathrm{T} \times \mathrm{H}=0.060$ in. $\times 0.040$ in.

(leaves about 0.150 LTCC substrate edge all around)

The Kovar lid is 0.015 in. thk. and about 1.86 in. $x 1.86$ in.

2.4 Cantilevered Leads. The MCM has 104 cantilevered leads with 26 exiting each of four sides of the MCM (reference Fig. 3). Each lead has the following dimensional and compositional features:

\author{
width $=0.015$ \\ length $=0.200$ (approximate cantilever length) \\ thickness $=0.007$ \\ pitch $=0.050(0.035$ gaps between leads) \\ material $=95 \%$ copper alloy with gold and nickel plating
}

of the 104 leads, there are 26 flat (although Fig. 2 depicts leads formed after testing for next assembly), cantilevered leads exiting each side of the subsrate. Each set of 26 is symmetrically located about the appropriate LTCC substrate center line ( 13 to one side and 13 to the other side of each center line).

2.5 Product Handling cautions. The MCM has a few features which require handling caution:

1) The LTCC substrate is brittle and "point force" stressing can cause fracture.

2) Do not apply any downward force to any assembled die contained within the hermetic seal ring (air bridges and bond wires).

3) The LTCC assembly must be treated as static sensitive.

\title{
3. ELECTRICAL REQUIREMENTS
}

The seller shall meet the following electrical requirements for the testing interface.

3.1 Device cutout. The testing interface board shall contain a square center cutout to receive the MCM inserted into the cutout 
from above (depicted conceptually in Figure 5). The dimensions of this cutout shall be 2.275 inch $\times 2.275$ inch, giving a nominal all-around clearance of $17.5 \mathrm{mils}$ between the cutout and the edge of the MCM substrate.

3.2 Device Lead Matching Metallization. The interface board shall contain matching metallization pads for each of the 104 cantilevered MCM leads. Pad width and length shall be governed by the high speed interconnect, where each high speed path on the board shall present a 50 ohms characteristic impedance.

The matching metallization pads shall be gold plated to assure repeatable, low resistance contacting between each lead and its respective pad.

3.3 Lead clamping. The electrical design shall provide for clamping the MCM leads to the board metallization following adjustment of the MCM to the board cutout to assure proper alignment of leads to corresponding pads. The effect of the clamp material on the high speed transmission line dielectric shall be taken into account.

3.4 High speed (HS) Interconnect. There are $22 \mathrm{MCM}$ high speed leads as indicated in Figures 3 and 4 . The high speed connection to each of these leads shall include an OSM/SMA coaxial connector launch to/from the interface board (either from the edge or from the surface perimeter), a board transmission line section, and a board transition section to the matching pad of the coplanar HS lead of the MCM. Each connection shall provide a 50 ohm characteristic impedance interconnect from the coaxial connector through the transition to the coplanar pads.

The transmission line design can be microstrip, stripline, coplanar, coaxial, or a combination thereof, provided the required high frequency performance cited in section 4.1 is obtained.

There are three sets of high speed lincs where the lines within each set must be of the same length (to within 0.25 inches).

SET 1

Instantaneous

Frequency

(9 Lines)

INST-FREQ-CLK-TTL

INST-FREQO

INST-FREQ1

INST-FREQ2

INST-FREQ3

INST-FREQ 4

INST-FREQ5

INST-FREQ 6

INST-FREQ7
SET 2

Analog

Outputs

(2 Lines)

ANALOG-OUT

ANALOG-OUT
SET 3

Clock/Trigger

Signals

(9 Lines)

\author{
CLOCK-IN \\ CLOCK-OUT \\ DAC-CLK-OUT \\ CLK-2 \\ CLK-4 \\ CLK-8 \\ CLK-16 \\ TX-TRIG \\ RX-TRIG
}


The two remaining HS lines (ADD-ZERO and TTL-RESET) do not require line length matching.

3.5 Ior speed (LS) Interconnect, There are 29 MCM LS leads as indicated in Figures 3 and 4 . The testing interface board shall provide a path to each LS lead, where each path begins at the MCM lead matching metallization pad and terminates at a pin of the Low speed connector. All of the IS paths are to be collected in a single, board-mounted connector, and additionally, at least four GRD connections shall be routed to this connector (reference Fig. 4 and note that AGRD is not routed to this connector). selection of connector type and location on the board shall be Buyer-approved in writing.

3.6 DC Voltage supply Interconnect. There are $27 \mathrm{MCM}$ DC voltage leads separated into five different sets or requiring five different sources (reference Fig. 3 and 4 ). The testing interface board shall provide a path to each DC voltage lead, where each path begins at the MCM lead matching metalization pad and terminates at a corresponding voltage ring or plane located on the board. Additional paths shall connect each ring or plane to pins of a board-mounted, DC Voltage connector. There shall be adequate current carrying capacity between the DC connector and each ring or plane (and from each ring or plane to individual DC voltage leads) to permit the following current drain from each supply:

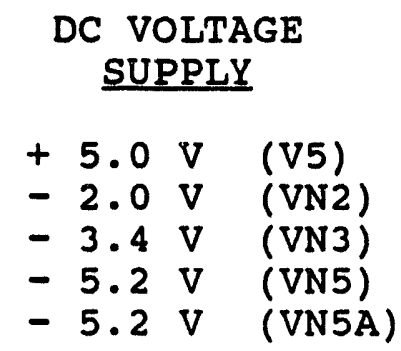

\section{CURRENT DRAIN}

$250 \mathrm{~mA}$
$1580 \mathrm{~mA}$
$250 \mathrm{~mA}$
$3350 \mathrm{~mA}$
$50 \mathrm{~mA}$

GROUND

REFERENCE

GRD

GRD

GRD

GRD

AGRD

As indicated in the following subsection, both GRD and AGRD paths shall connect between this connector and each applicable GRD or AGRD lead of the MCM. Selection of connector type and location on the board shall be Buyer-approved in writing.

3.7 Grounds. The MCM has two separate electrical grounds, GRD and AGRD (analog ground) as indicated in Figures 3 and 4. These two grounds shall be electrically isolated on the interface board (i.e., both DC and AC isolation). Thus, while the DC connector shall contain both GRD and AGRD pins, they shall be isolated from each other, and the number of GRD and AGRD pins in the DC connector shall carry the supply currents cited in the previous subsection. The board design may utilize either DC ground planes or ground rings to provide intermediate connection between the DC connector pins and the pertinent MCM leads.

The ground reference for all LS lines shall be C.RD. In the case of the HS lines, all shall be referenced to GRD, except for three HS lines referenced to AGRD: ANALOG-OUT, ANALOG-OUT and 
DAC-CLK-OUT (reference Fig. 4). The board design shall include a strapping capability to permit the future connection of GRD and AGRD near the board perimeter.

3.8 Losd components. The interface board shall include two axial leaded by-pass capacitors ( 10 and 50 microfarads) between each supply voltage and its corresponding ground. These capacitors may be installed between the voltage and ground rings or planes on the board (reference Figure 4 ).

The interface board shall include an axial leaded diode (1N4002 or equivalent, with anode connected to VN5) and an axial leaded capacitor (100 microfarads) in parallel between VN5 ( -5.2 VDC supply) and VN3 (-3.4 VDC supply). For information, these two components are required for power-up protection and may be installed between the voltage rings or planes on the board.

\section{ELECTRICAL VERIFICATIONS}

The electrical verification for the MCM testing interface shall include the following inspections and tests as a minimum. These inspections and tests shall be conducted by the seller. The resulting hardcopy data and test techniques shall be jointly reviewed by Buyer and Seller with possible repeat testing on a sample basis at the discretion of the Buyer.

4.1 Hs Interconnect Verification. Each of the 22 Hs paths (inclusive of the OSM/SMA connector) shall be tested to verify the $50 \mathrm{ohm}$ characteristic impedance of the line. Each path shall meet the following requirements:

$$
\begin{array}{ll}
\mid \text { (Return Loss) |: } & >=24 \mathrm{~dB} \text { (measured one at a time) } \\
& >=20 \mathrm{~dB} \text { (measured two at a time) } \\
\text { frequency range: } 0 \mathrm{~Hz} \text { to } 5 \mathrm{GHz} .
\end{array}
$$

Two lines may be tested simultaneously if a calibrated "through" is substituted for the MCM and connects two lines during the test. If each of these 22 paths is measured separately, then a co-planar probe shall be used to probe each co-planar HS pad/ground pad at the edge of the MCM cutout. Hardcopy data shall be provided for each tested line and shall include the path number (MCM lead number per Fig. 3), frequency, and the measured return loss.

Any special measurement aids (such as throughs fabricated specifically for these HS path verifications) shall be supplied with the interface board to support like measurements in the future, either by Buyer or seller.

4.2 Is Interconnect Verification. Each of the 29 LS paths shall be verified for correctness of interconnect by performing both a continuity test and an isolation test on each path. Pad probing during this verification (if used) shall not damage the planar 
surface of the pad designed to establish contact with the MCM lead.

The continuity of each path, from LS pad to corresponding IS connector pin, shall not exceed 50 milliohms. The path isolation, measured from each LS connector pin to all remaining Is connector pins, shall not be less than 10 megohms (all GRD pins of the is connector shall be shorted together and treated as a single pin for this test). For both measurement types, a Digital Multimeter (DMM) such as an HP3478A or equivalent shall be used.

Hardcopy data shall be provided for each tested path. The continuity data shall include the path number (MCM lead number per Fig. 3) and the measured resistance. The isolation data shall include the measured resistance between all Is connector pins, taken two at a time (without repeats) and recorded accordingly.

4.3 DC Voltage Interconnect Verification. The DC voltage interconnect shall be verified by performing a continuity test from each voltage pin of the DC Voltage connector to the appropriate DC voltage ring or plane on the board. Each measurement shall not exceed 50 milliohms.

The continuity between each DC voltage pad (at the MCM cutout) and the appropriate DC voltage ring or plane shall be measured. Each measurement shall not exceed 50 milliohms.

Finally, the isolation between each voltage ring or plane and all other voltage rings or planes shall be measured and shall not be less than 10 megohms (omit the measurement between VN3 and VN5 if the diode is already installed).

In all measurement cases, an HP3478A DMM or equivalent shall be used. Also, pad probing during this verification (if used) shall not damage the planar surface of the DC voltage pads.

Hardcopy data shall be provided for each tested DC voltage path. This data set shall include: 1) the measured resistance between the applicable voltage ring or plane and each corresponding voltage pin of the DC Voltage connector (recorded by connector pin number); 2) the measured resistance between each DC voltage pad and each corresponding voiltage ring or plane (recorded by MCM lead number per Fig. 3); and 3) the measured isolation resistance between all voltage rings or planes, taken two at a time (without repeats) and recorded accordingly.

4.4 Ground Interconnect Verification. The HS grounding interconnect for each HS path shall be considered to be verified for each HS path which meets the return loss measurements of section 4.1 .

The IS grounding interconnect shall be verified by performing a continuity test from each GRD pin of the is connector (four minimum) to the GRD ring or plane on the board. Each 
measurement shall not exceed 50 milliohms. Hardcopy data shall be prnvided for each tested GRD path and shall include the measured resistance between the GRD ring or plane and each ground pin of the IS connector (recorded by connector pin number).

The DC voltage grounding interconnect shall be verified by performing a continuity test from each GRD and AGRD $p$ in of the DC Voltage connector to the appropriate GRD or AGRD ring or plane on the board. Each measurement shall not exceed 50 milliohms. The continuity between each of the $\angle 2$ GRD pads (at the MCM cutout) and the GRD ring or plane shall be measured and shall not exceed 50 milliohms. Similarly, the continuity between each of the 4 AGRD pads (at the MCM cutout) and the AGRD ring or plane shall be measured and shall not exceed 50 milifohms. Finally, the isolation between the GRD and AGRD rings or planes shall be measured and shall not be less than 10 megohms.

In all measurement cases, an HP3478A DMM or equivalent shall be used. Also, pad probing during this verification (if used) shall not damage the planar surface of the DC voltage pads.

Hardcopy data shall be provided for each tested GRD and AGRD path. This data set shall include: 1) the measured resistance between the GRD or AGRD ring or plane and each corresponding GRD or AGRD pin of the DC Voltage connector (recorded by connector pin number); 2) the measured resistance between between each GRD or AGRD pad and each corresponding GRD or AGRD ring or plane (recorded by MCM lead number per Fig. 3); and 3) the measured isolation resistance between the GRD and AGRD rings or planes.

4.5 Ioad Component Verification. Each load component shall be visually verified for correct electrical interconnect. All capacitors (if polarized) and the diode shall be verified for correct assembly polarity. Where possiole, all capacitor values shall be verified (by visual inspection). Finally, the transient charging resistance of the shunt capacitors across each voltage ring or plane and the blocking and foward action of the diode shall be verified with resistive measurements. Verification in the form of a check list is permitted in the cited areas.

5. MECHANICAI REQUIREMENTS (ref. Figures 2, 3, and 6 through 9)

The seller shall meet the following mechanical requirements for the testing interface.

5.1 Device orientation and Mating. The MCM device shall be installed from the top surface of the interface board with the heat spreader facing downward. The MCM shall be oriented so that Lead 1 of the MCM (reference Figure 3 ) faces the rear of the probe station. 
5.2 clamping and Alfgnment. The interface board shall include a clamping mechanism to clamp the MCM leads to the interface board pads. The clamping mechanism shall not exceed the length, width, and depth requirements specified for the boot on the blow-by system (reference Figure 6). The interface board/clamp mechanism shall permit alignment of the device leads to the matching pads on the interface board.

5.3 Probe station Interface Reguirements. The interface board shall be mounted into a Buyer-supplied Cascade probe card holder (P/N 101-850) for use on a summit 9200 probe station.

The interface board shall be adapted to the probe card holder so that probing within the MCM seal ring can be accomplished from the top surface of the probe card holder using Buyer-supplied Cascade probe holders (P/Ns MPHM-4BL \& MPHM-4BR) equipped with Cascade XMP or WPH series probes. The location of the interface board's MCM cutout shall be compatible with the reach and depth adjustments of the Cascade probes/probe holders. No interface board features shall interfere with the optically-assisted placement of the probe tips within the MCM seal ring.

Layout of the interface board and adaptation to the Cascade probe card holder shall allow clearance for routing of all DC, low speed, and high speed cables to the interface board connectors. In addition, all interface board connectors shall be located outside of the blow-by head and Thermochuck enclosure (reference Figures 7 and 8 ).

5.4 Blow-by Mechanical Interface. The interface board shall provide a sealing surface on the top side of the board for interface with the blow-by head and boot (reference Figure 7 ).

The adaptation of the board to the summit prober and probe card holder shall be designed so that there is no interference with seating of the blow-by head on the seaIing surface of the interface board (reference Figure 6).

The interface board shall incorporate appropriate slots to allow air flow from the Thermostream blow-by head to pass through the board and provide conditioning and air purge for the Thermochuck enclosure sealed to the bottom surface of the board. These slots shall be within the 3.25 inch internal dimension of the blow-by boot (reference Figure 6) and shall not degrade electrical performance.

The interface board shall be rigid enough to support the compressive seal force of the blow-by test head. The Buyer-supplied blow-by system will be a Temptronic Thermostream, Model TP412A.

5.5 Thermochuck Mechanical Interface. The MCM shall be installed into the interface board cutout with the heat spreader extending through the board to mate with the Thermochuck adapter surface. 
The interface board shall provide a sealing surface on the bottom side of the board for interface with the Thermochuck enclosure (reference Figure 8 ). The Buyer will supply a Temptronic Thermochuck System, Model TP03000 Series.

No wiring, interface board, sealing surface or combination of these features shall extend more than 0.100 inches below the bottom of the installed MCM heat spreader and inside the five inch diameter of the Thermochuck (reference Figure 9). Note that the heat spreader is assembled non-symmetrically on the MCM substrate (reference section 2).

5.6 Tomperature Requirements, The interface board assembly shall be capable of mechanically withstanding the temperature extremes of -70 degrees Celsius to +100 degrees Celsius as provided by the blow-by and Thermochuck systems. In addition, the board shall withstand the temperature shock due to transitions between these temperature extremes.

The interface board shall not degrade electrically over the MCM test temperature range of -55 degrees celsius to +70 degrees Celsius.

\section{MEChANICAI VERIFICATIONS}

The mechanical verification for the MCM testing interface shall include the following inspections and tests, and shall be conducted by the Buyer prior to interface shipment.

6.1 MCY Interface. A mechanical sample of the MCM will be used by the Buyer to verify MCM cutout clearance, alignment, and mechanical clamping of leads to the interface board pads.

6.2 Probe station Interface. The interface board will be physically mounted into the Cascade probe card holder by the Buyer to verify board compatibility with the Cascade probe station and connector clearance relative to the probe card holder hardware. The interface board and probe card holder assembly will be verified by the Buyer for correct device orientation with respect to Lead 1 of the MCM.

With the MCM mechanical sample installed, simulated probing of the MCM will be performed by the Buyer using a Cascade probe holder and probe to verify probe reach and depth to the required probing area of the MCM.

6.3 Blov-by Interface. The seal surface on the top side of the interface board will be measured by the Buyer to verify mechanical compatibility with the blow-by test head and boot.

Placement of air flow holes in the interface board and the mechanical dimensions of the clamping mechanism will be measured by the Buyer to verify that their location is within the inside dimensions of the boot. The height of the clamp in relation to 
the boot sealing surface will also be measured by the Buyer to assure that it does not exceed the inside height dimension of the boot.

6.4 Thermochuck Interface. The seal surface on the bottom side of the interface board will be measured by the Buyer to verify mechanical compatibility with the Thermochuck enclosure.

Clearance between the interface board and the Thermochuck will be gaged by the Buyer using the Thermochuck adapter plate interfaced with the heat spreader of the installed MCM mechanical sample. The interface board and adapter assembly will be visualiy checked by the Buyer to assure that air flow through the flow holes to the Thermochuck enclosure is not restricted due to physical blockage by items such as seals, cables, or clamps.

\section{DESIGN REVIEWB}

At the discretion of the Buyer, design reviews will be scheduled and conducted to assure evolving design and fabrication compliance to the requirements of this document. 


\section{Waveform Synthesizer Sketch of assembled module}

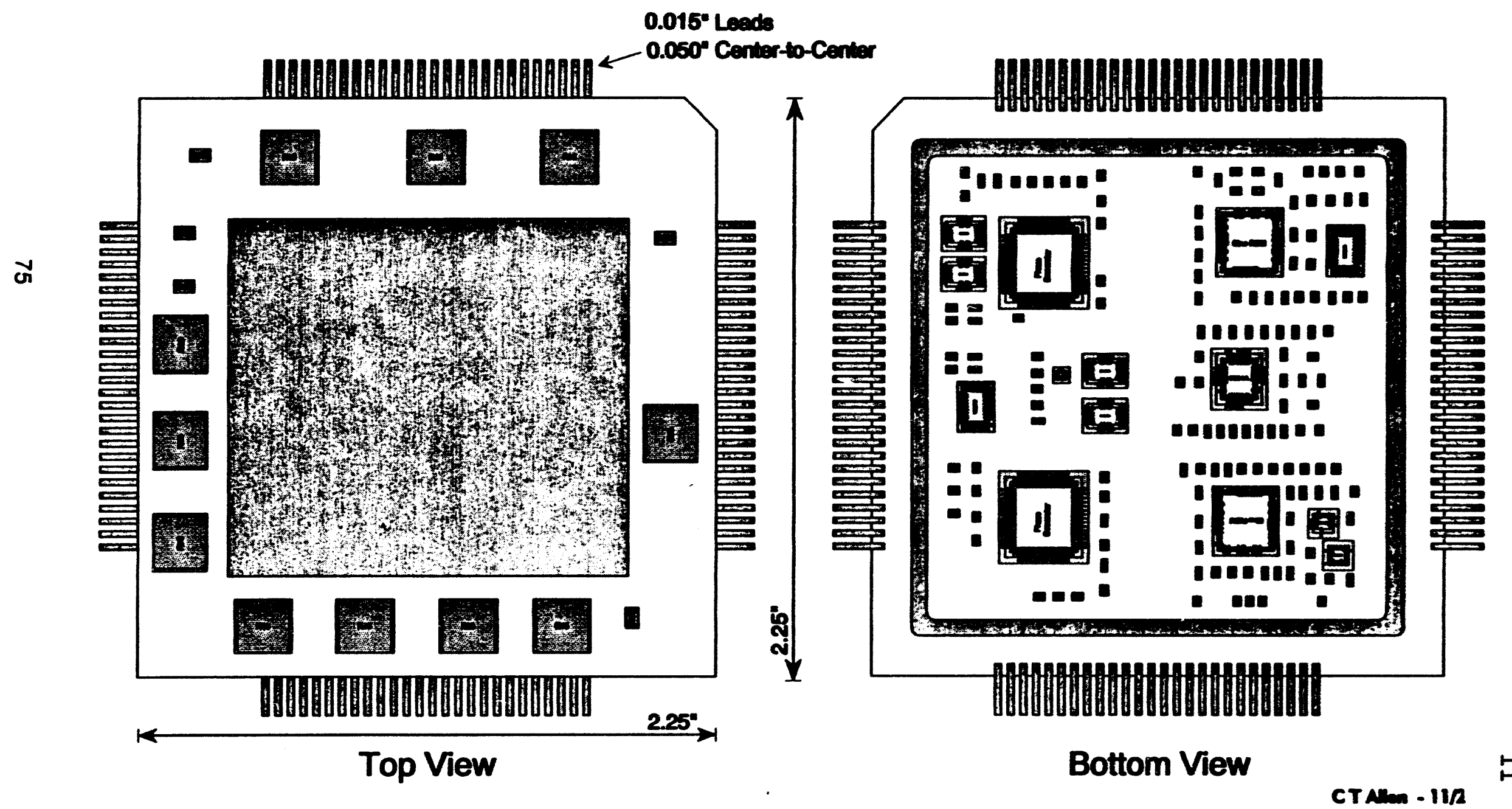

FIGURE 1. WAVEFORM SYNTHEȘIZER LAYOUT 


\section{Waveform Synthesizer Package concept cross-section}

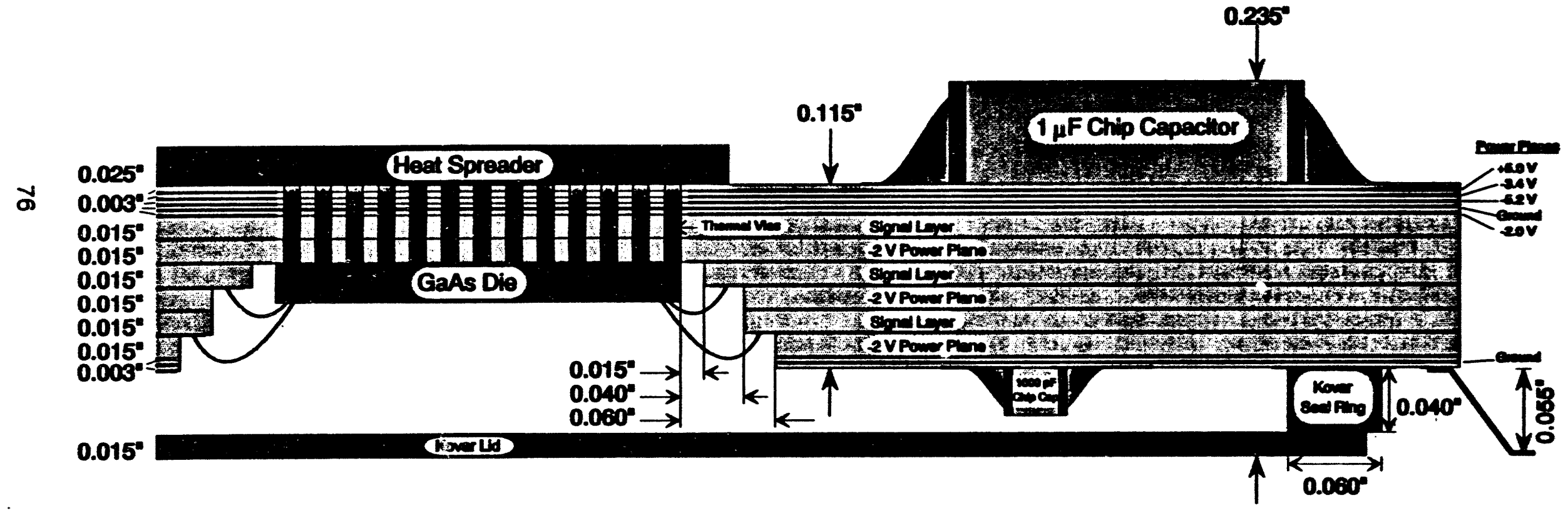

FIGURE 2. WAVEFORM SYNTHESIZER CROSS-SECTION 


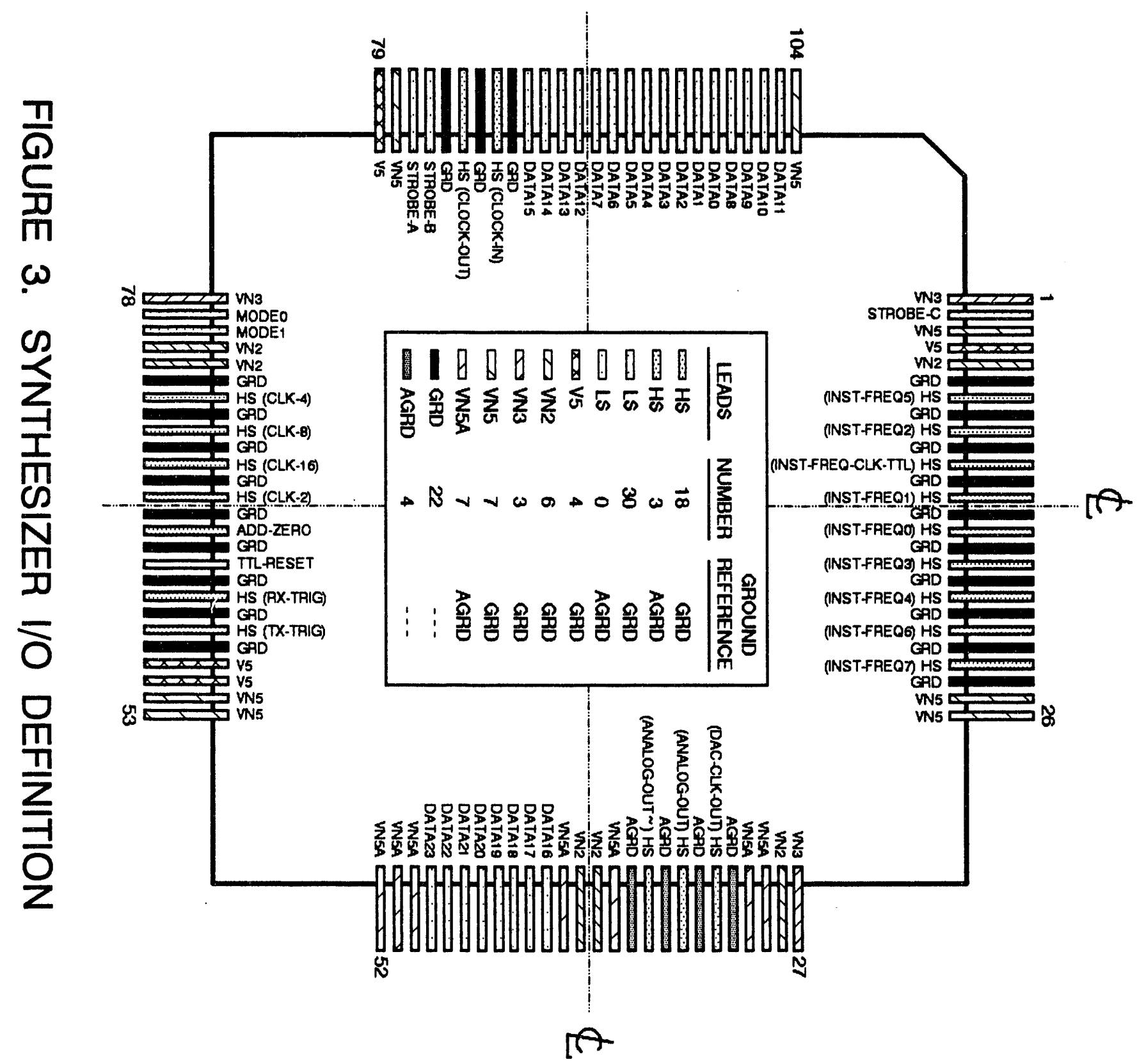




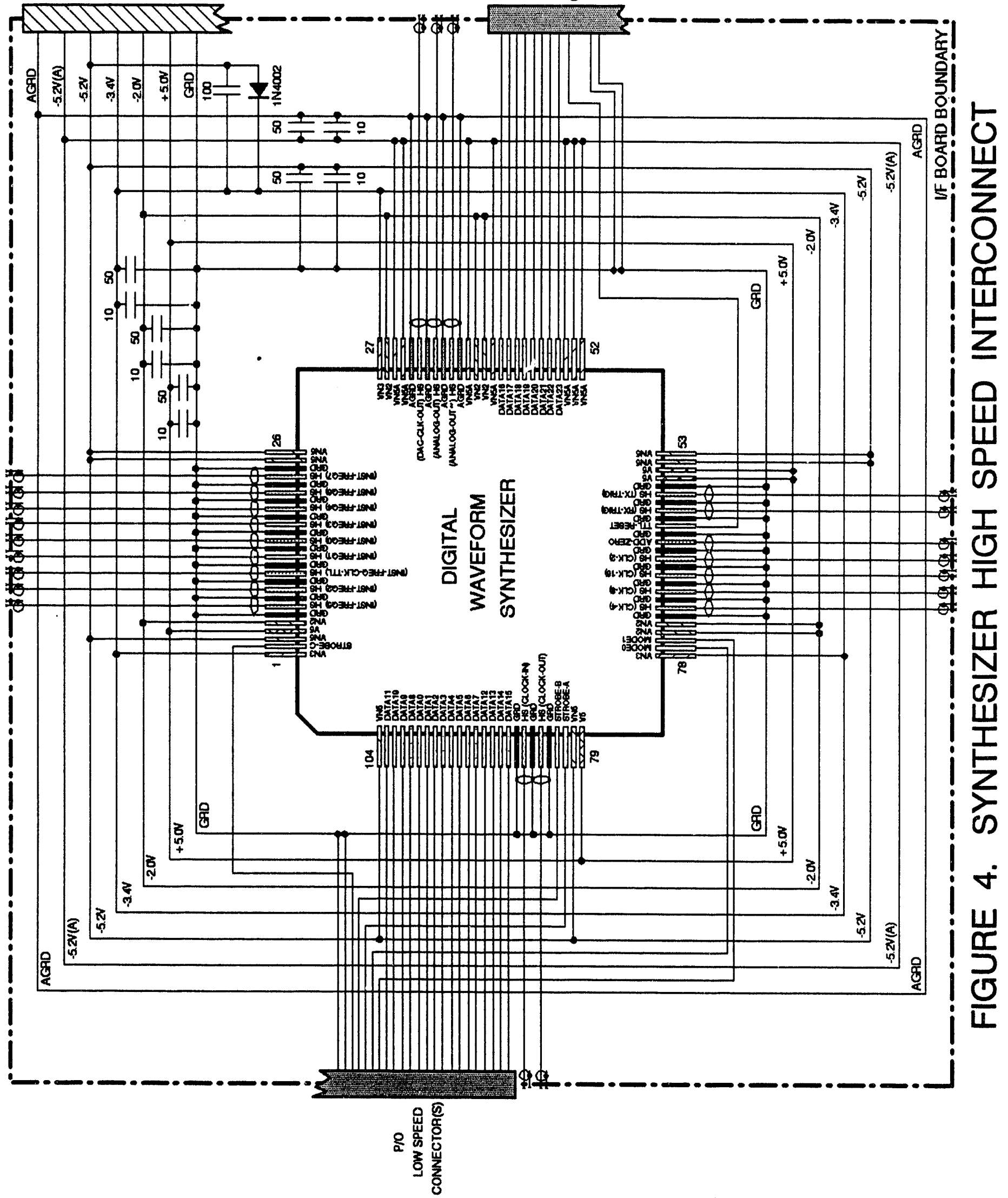




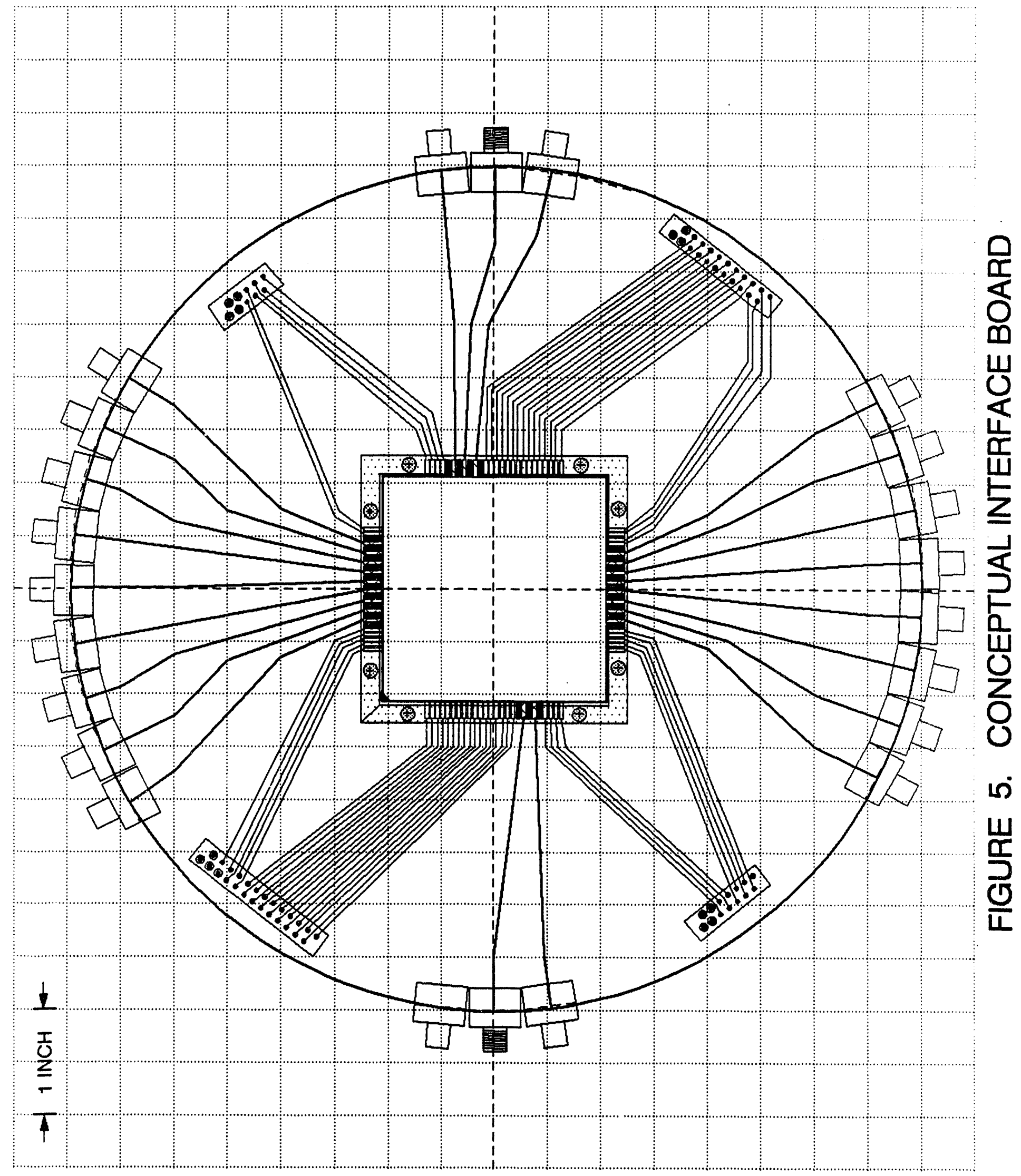




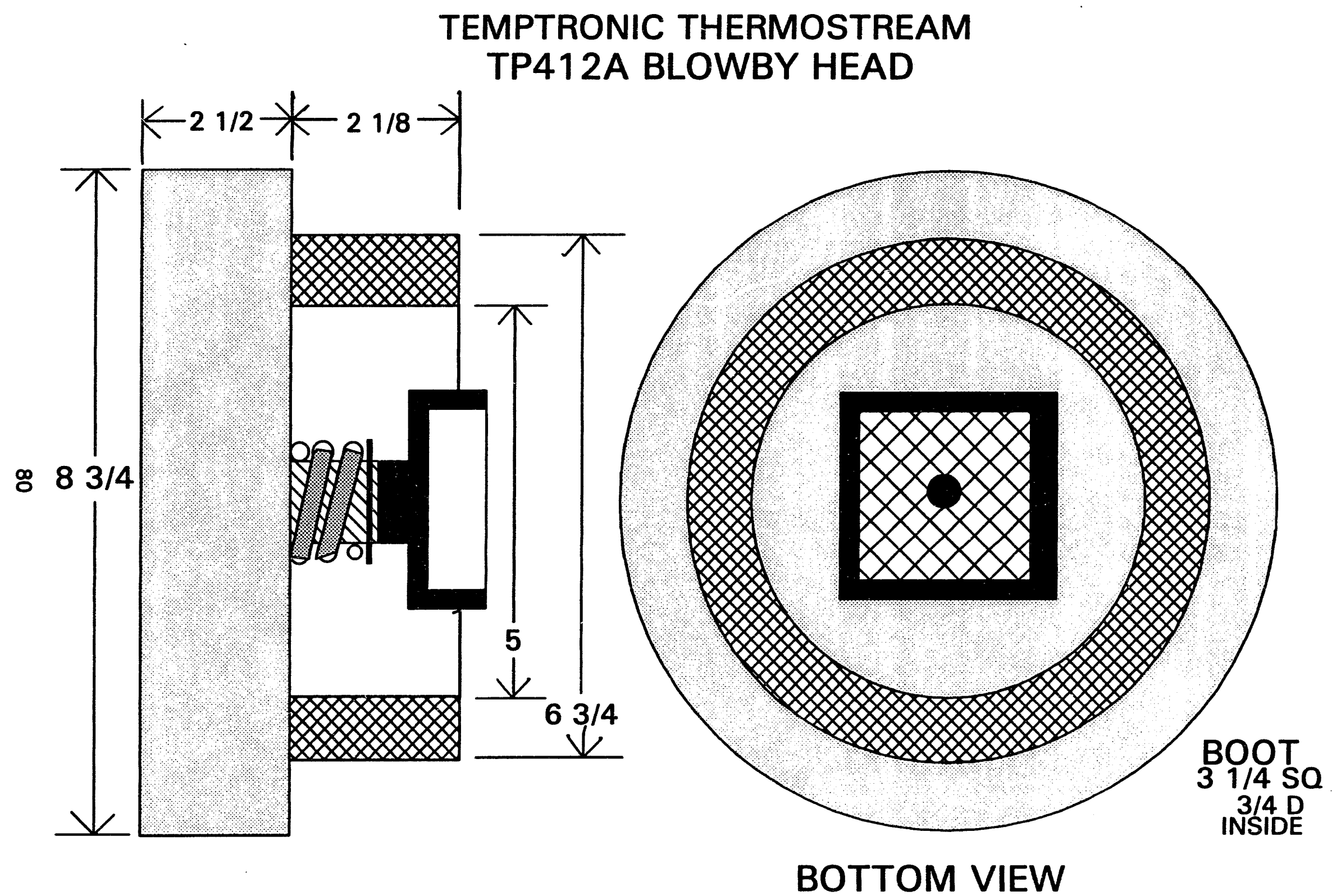

FIGURE 6. EXISTING THERMOSTREAM CONDITIONING HEAD 


\section{MECHANICAL CONSTRAINTS INTERFACE BOARD TOP SURFACE}

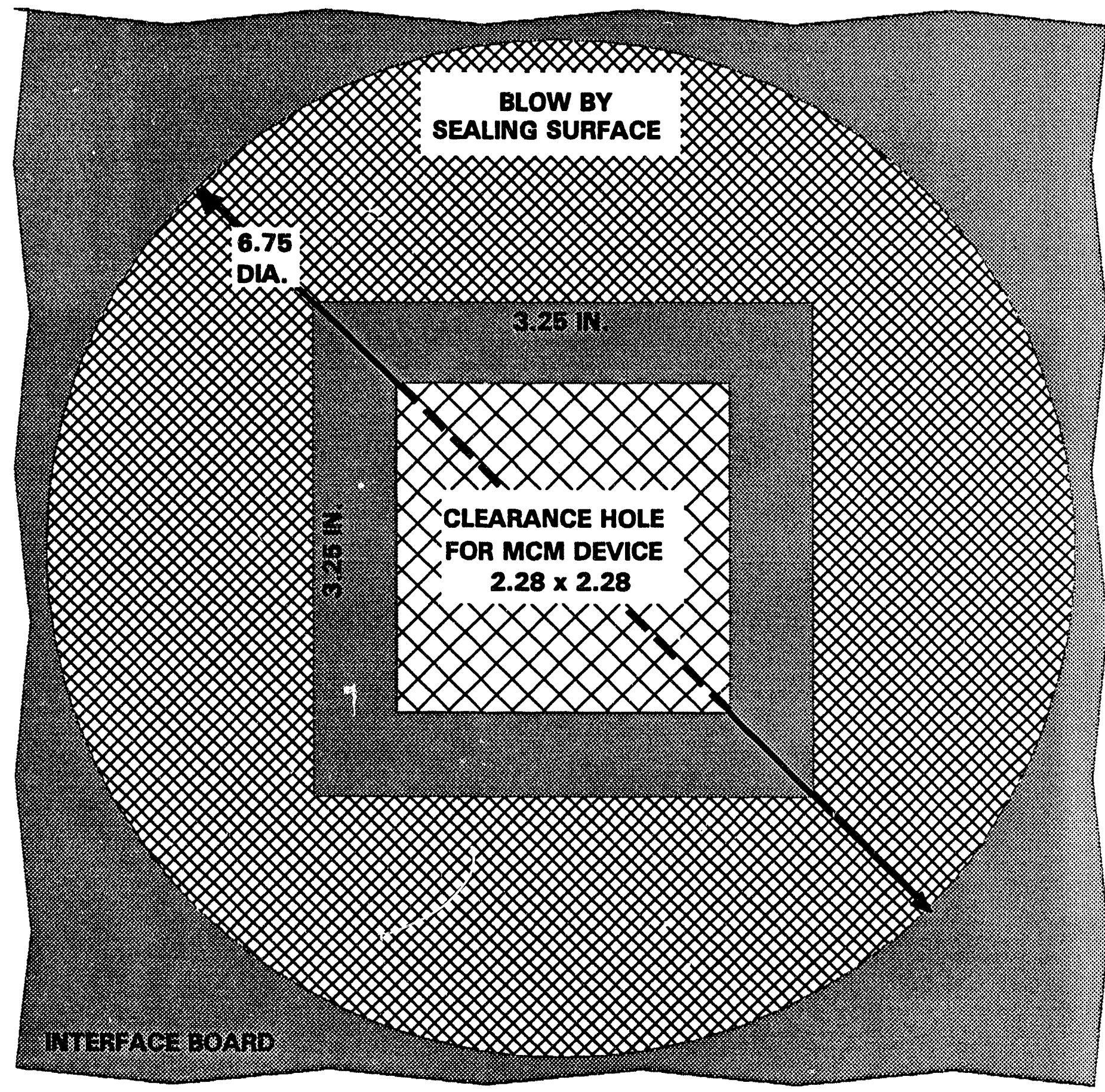

FIGURE 7. MECHANICAL CONSTRAINTS, I/F BOARD TOP SURFACE 


\section{MECHANICAL CONSTRAINTS INTERFACE BOARD BOTTOM SURFACE}

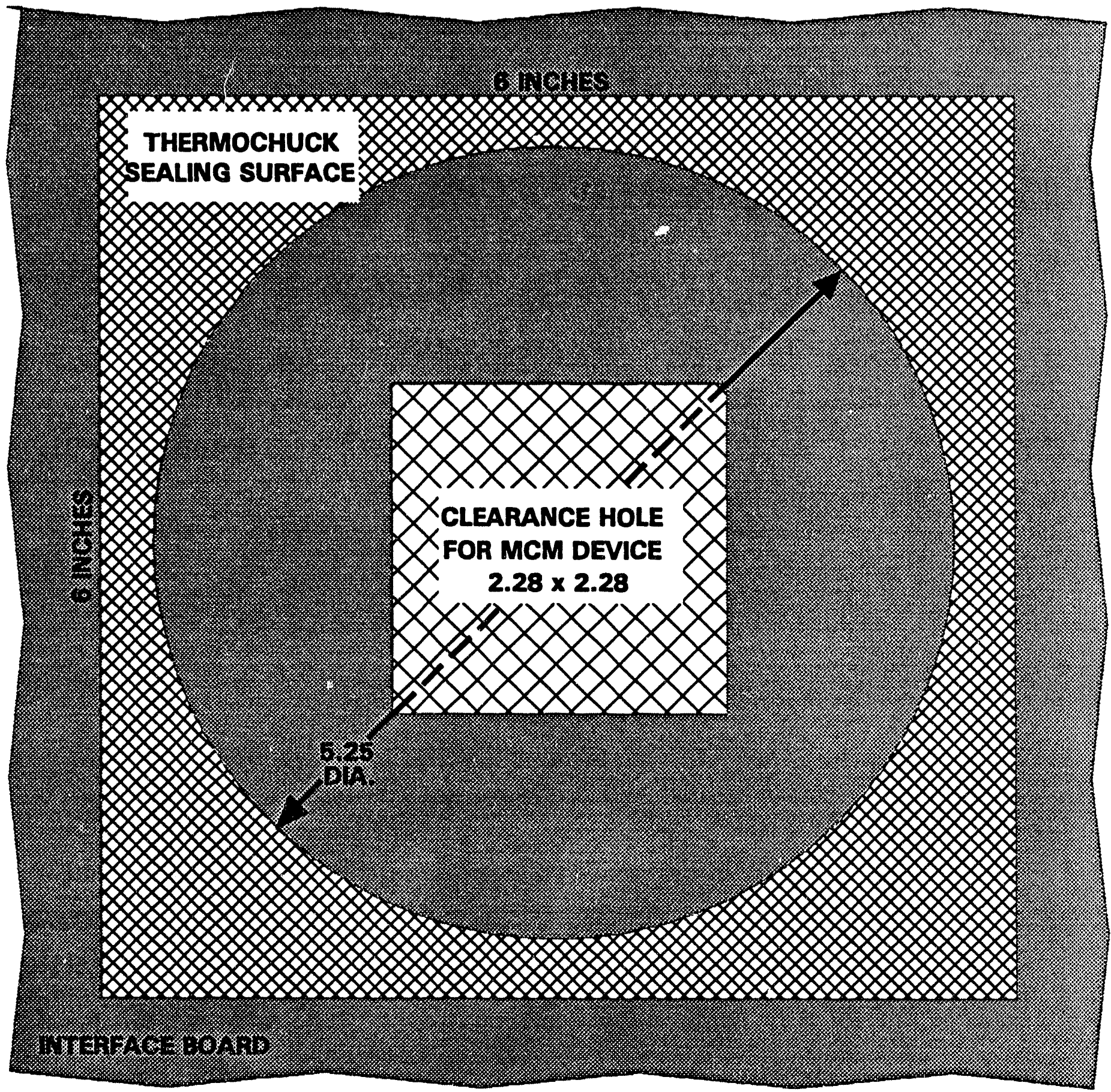

FIGURE 8. MECHANICAL CONSTRAINTS, I/F BOARD BOTTOM SURFACE 


\section{THERMOCHUCK/BOARD CLEARANCE INTERFACE BOARD}

NO WIRING, INTERFACE BOARD, SEALING SURFACE

OR COMBINATION OF THE ABOVE MAY EXTEND MORE THAN .100 INCHES BELOW THE BOTTOM OF THE HEAT SPREADER WITHIN THE 5 INCH DIAMETER OF THE THERMOCHUCK. NOTE: THE HEAT SPREADER IS NON SYMMETRICAL ON THE MCM.

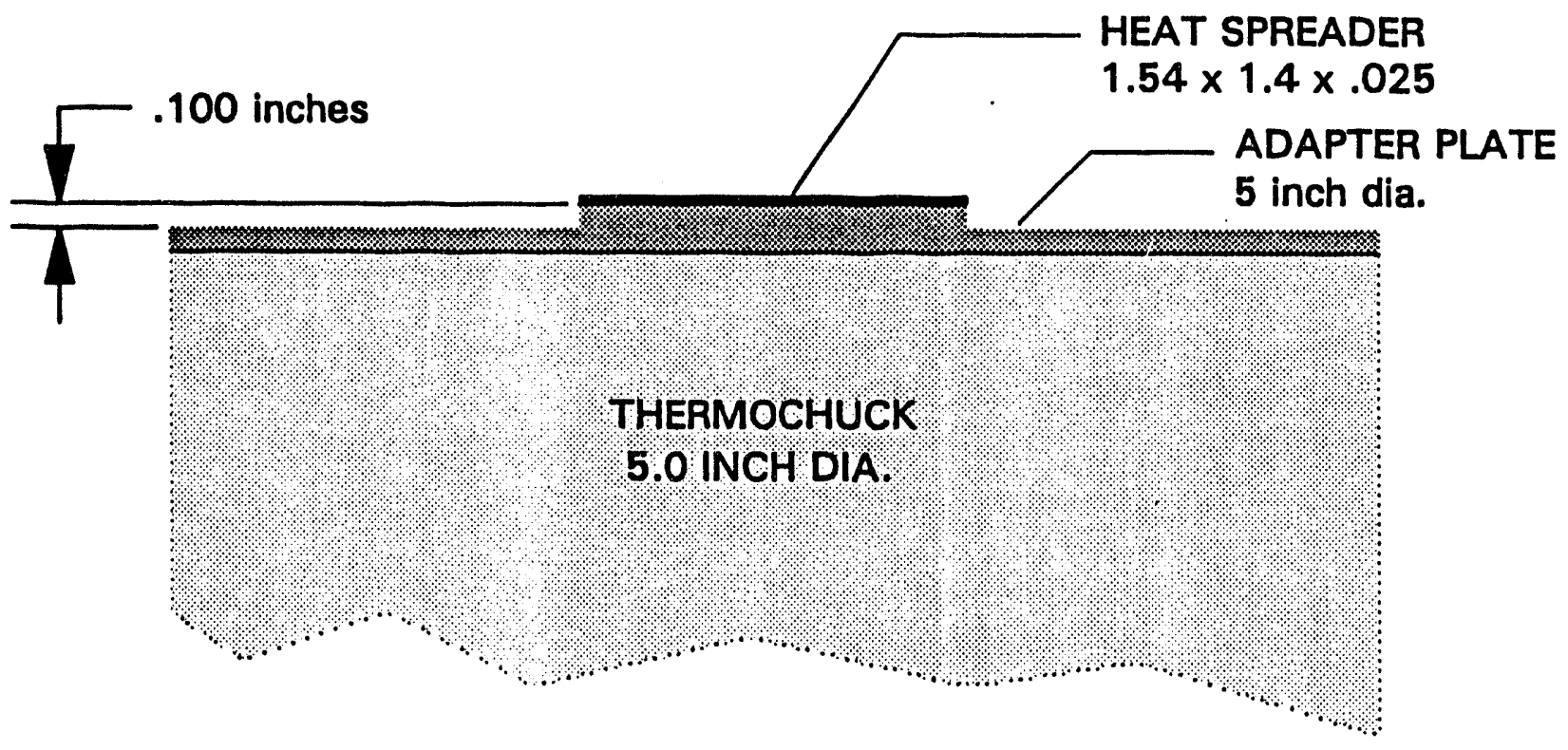

FIGURE 9. THERMOCHUCK / BOARD CLEARANCES 


\title{
Appendix D
}

\author{
DWS Test Interface
}




\section{DICITAY WAVEFORY BYATHESIRER TEST INTERFACE}

The development of the high speed test interface for the Digital Waveform synthesizer multichip module was based on the requirements contained within the "specifications for a High

speed Testing Interface" (ref. Appendix C).

The conceptual aspects of the GigaTest HS interface board and its adaptation to the Cascade and Temptronic equipment are depicted in Figures 1 through 5. Figure 1 illustrates the cross-section of the interface board: 1) the top three metal layers form the stripline structure for the HS interconnect to the MCM HS leads; 2) the next metal layer is the DC power layer where five wedges and rings are used to establish the interconnect between the MCM and the board DC connectors (the MCM requires five separate power supplies); 3 ) the next two metal layers are used to route the low speed MCM leads to the board low speed connectors; and 4) the final metal layer creates the DC/LS ground plane. As noted, the overall thickness of the board is $108 \mathrm{mils}$, and the dielectric of the FR4 board material is taken to be 4.5 . Figure 2 provides the conceptual layout of the board: trace routing (all layers

superimposed), component locations, DC, LS and HS connectors, flow orifices, clamp securing holes, and MCM center cutout.

Figure 3 focuses on the board secured at the probe station and its relationship in space relative to the other station features such as the thermochuck, the probe platforms, and the adjustable HS probes. Some of these relationships are also shown in the top view of Figure 4. Finally, Figure 5 addresses the details of the MCM lead clamp design.

A number of photographic illustrations capture the many facets of the completed high speed interface. Figure 6 captures the entire high speed digital test system with the test console on the left and the high speed interface and thermal conditioning equipment located to the right of the test cabinet. The Cascade Microprobe station is directly to the right of the console, the Thermostream blowby unit to the right of the station, and the Thermochuck Controller to the right of the Thermostream unit.

Figure 7 moves directly to the MCM loading area of the high speed interface equipment where several critical features are visible: 
1) the MCM cutout arsa in the high speed (HS) interface board recelves the MCM with a nominal all-around clearance of about $20 \mathrm{mils}$;

2) the MCM lead mating pads are recessed into the board on all four sides to stripline depth which preserves the impedance quality of the HS ine transitions from MCM to board;

3) the rectangular Thermochuck adapter plate is secured to the top of the Thermochuck and contains vacuum grooves and a centered thermocouple to monitor the top-center plate temperature:

4) the combined adapter plate/theromchuck can be adjusted for $X Y$ location, height and rotation to ensure a match of the plate to the back side MCM heat spreader. Thus, the plate location is directly below and at the proper elevation and rotation to match to the MCM heat spreader when the MCM is inserted with leads aligned in the cutout;

5) the resulting area around the plate is effectively recessed which allows clearance for the surface mount capacitors on the back side of the MCM;

6) the plate vacuum grooves permit a vacuum pull against the bottom of the MCM spreader causing mechanical contact and a thermal transfer path between the MCM and the thermochuck;

7) an aluminum board stiffener, secured to the bottom of the HS board, provides mechanical support and thread features for clamp screws (there are eight threaded clamp screw holes, two per cutout corner):

8) two clamp keying pins are located in the upper left and lower right corners of cutout;

$9)$ the board ground plane is split, at the top and bottom corners on the right side of the cutout to provide isolation between the MCM analog and digital grounds.

Figure 8 depicts the MCM positioned in the board cutout with the leads aligned to the board mating pads. Once the MCM is aligned as such, the vacuum is enabled to pull the MCM backside heat spreader into contact with the adapter plate and hold the MCM in the aligned position while the lead clamp is being keyed into position and secured as shown in Iigure 9. As the eight clamp securing screws are installed, each piano spring finger is forced upward relative to the clamp body by its non-conductive lead contacting pin. Thus, when the clamp is fully secured against the board, all fingers are raised and applying several grams of force to their respective contacting pins which presses each MCM lead against its board mating pad. The clamp is also designed with a center cutout above the MCM to to provide probe access to the cavity area of the MCM for in-process testing. Finally, several large through holes, clustered outside the corners of the MCM on the HS board, provide flow paths for the conditioned aix. flow from the thermostream unit when the head of that unit is docked on top surface of the board. The flow is downward through the board and into a thermal boot surrounding the underside thermochuck. 
Igure 10 illustrates the entire reinforced Hs board and its insertion into the station guides. Again, the split ground plane is evident, as are the 21 high speed stripline paths, buried within the board with each being terminated in a HS coaxial connector mounted to the undersurface of the reinforced board. All of these paths are matched in line length to within 20 mils, and the stripline ground planes are periodically tied together with plated through holes on either side of each buried path. The transition from stripline to coax is accomplished at the coaxial connector interface to the board. The coax center conductor pin mates at right angle to the stripline center conductor, and the coax shell mates to the stripline ground planes which are joined with seven plated through holes around each center conductor. Finally, this figure also depicts the probe platforms located to the left, right and rear of the board.

Figure 11 depicts the Hs probes magnetically anchored to the left and righ probe platforms, and Figure 12 shows the coplanar tip of each probe. These probes have independent $X, Y$ and $Z$ adjustments, and the probe tips are specially fabricated to provide a coplanar spacing of the same width as the $50 \mathrm{ohm}$ terminating chip resistors on the MCM. Thus, the probes may be used to probe any terminating resistor which effectively places the probe tip at a terminated bond pad of an ASIC.

Pigure 13 shows the working test interface where the probes and microscope are swung rearward (out of the way), and the head of the thermostream is docked on the top side of the board. The matched high frequency, coaxial, two foot Gore cables are visible between the board and the interface panel in the foreground. Also, the low speed ribbon cables (2) and the DC cables (2) are visible as they connect directly between the board and the test console. The electrical schematic of the HS interface is shown in Figure 14 where the DC and LS cables connect directly between the board and the test console, and the HS cables are terminated at a HS I/O panel mounted to the front of the probe station. This figure does not demonstrate that there are two identical DC connectors mounted on the board and they are wired in pinparallel configuration. Also, there are two identical LS connectors, but they are not wired in parallel.

Two HS interface boards were produced, assembled and tested $(S / N 1$ and $S / N 2)$. Test data are available on each board and cover all testing as specified in the KCD HS I/F specification. $s / N 1$ proved to be slightly better than $S / N 2$ with a $-19 \mathrm{~dB}$ or better (more negative) return loss of all HS paths up to $5 \mathrm{GHz}$ (S/N 2 had some paths whose return loss was -17 dB at some point in the test frequency range). A plot of Return Loss vs. Test Frequency for $S / N$ is provided in Figure 15 . 


\section{CASCADE KICROTECH}

1 Summit Microprobe Station (9200)

1 Olympus Stereozoom Scope (101-502)

1 Summit Probe Card Holder (101-850)

1 Temptronic Adapter Kit (102-801)

1 Magnetic Probe Holder (MPHM-4BL)

1 Magnetic Probe Holder (MPHM-4BR)

2 10X Probe, GS (XMP-101-1170)

2 10X Probe, SG (XMP-102-1170)

2 Connector/Cable Kit, $40 \mathrm{GHz}$ (101-587)

3 ECL Terminator (523-150)

5 Bias Cable, BNC to SMB (105-001)

3 Cable Ground Isolation Assembly (019-002)

\section{GIGATEST LABS}

1 Adaptation to Cascade and Temptronic

2 MCM Lead Clamp

2 High Frequency Interface Board

$21 / \mathrm{Bd} H S$ SMA Connector (CDI R125 411 211)

2/Bd DCV Connector (IDC 16)

2/Bd LS Connector (IDC 50)

5/Bd 10 UF Capacitor

5/Bd 50 UF Capacitor

1/Bd 100 uF Capacitor

1/Bd Diode (1N4002)

\section{TEMPTRONIC CORPORATION}

1 Thermochuck, 5 inch (BC563003P)

1 Thermochuck Controller (TP03000A-1100-1)

1 Adapter Plate (IR-9202-11)

1 Thermostream system (TP0412A)

\section{L. GORE}

$\begin{array}{rlll}25 & \text { Flex Cable, Coaxial, } 18 \mathrm{GHz} & \text { (G2ZEKV71-024.0) } \\ 6 & \text { Flex Cable, Coaxial, } 18 \mathrm{GHz} & (\text { G2ZEKZEK-048.0) } \\ 4 & \text { Flex Cable, Coaxial, } 18 \mathrm{GHz} & (\text { G2ZEKZEK-072.0) } \\ 2 & \text { Flex Cable, Coaxial, } 18 \mathrm{GHz} & (\text { G2ZEKZEK-012.0) }\end{array}$

\section{HEWLETT-PACKARD}

1 Bias Network, (HP11612A) 


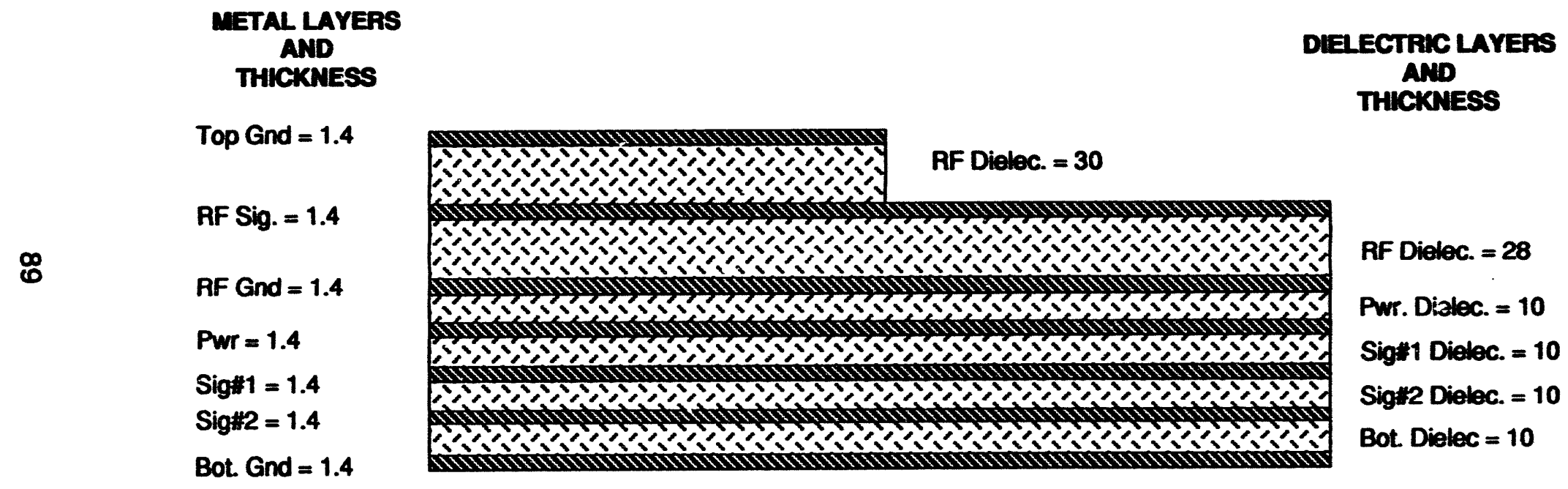

\section{Total Thickness $=108$ mils}




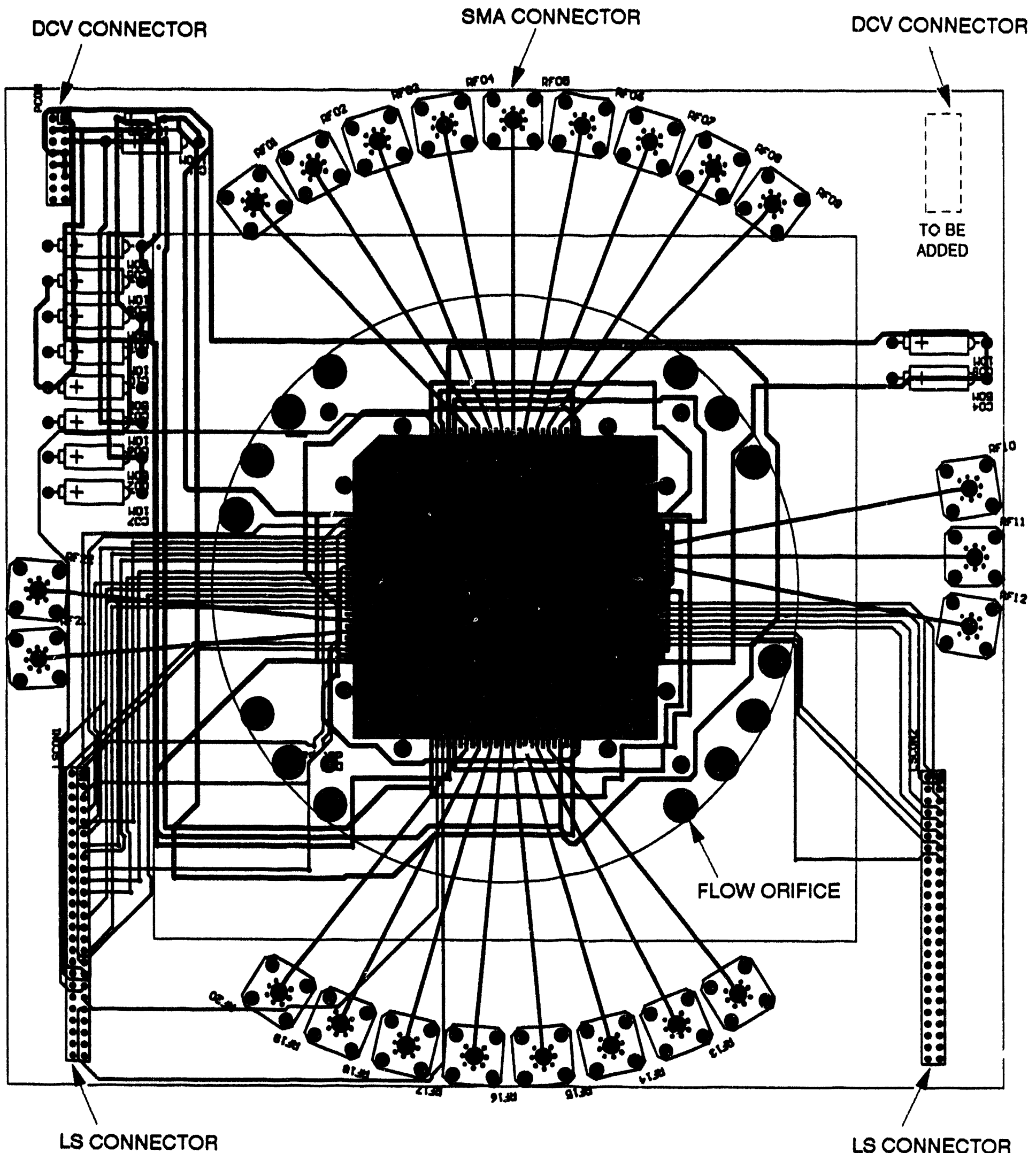

FIGURE 2. HB I/F BOARD WITH ALL METAL LAYERS VISIBLE 


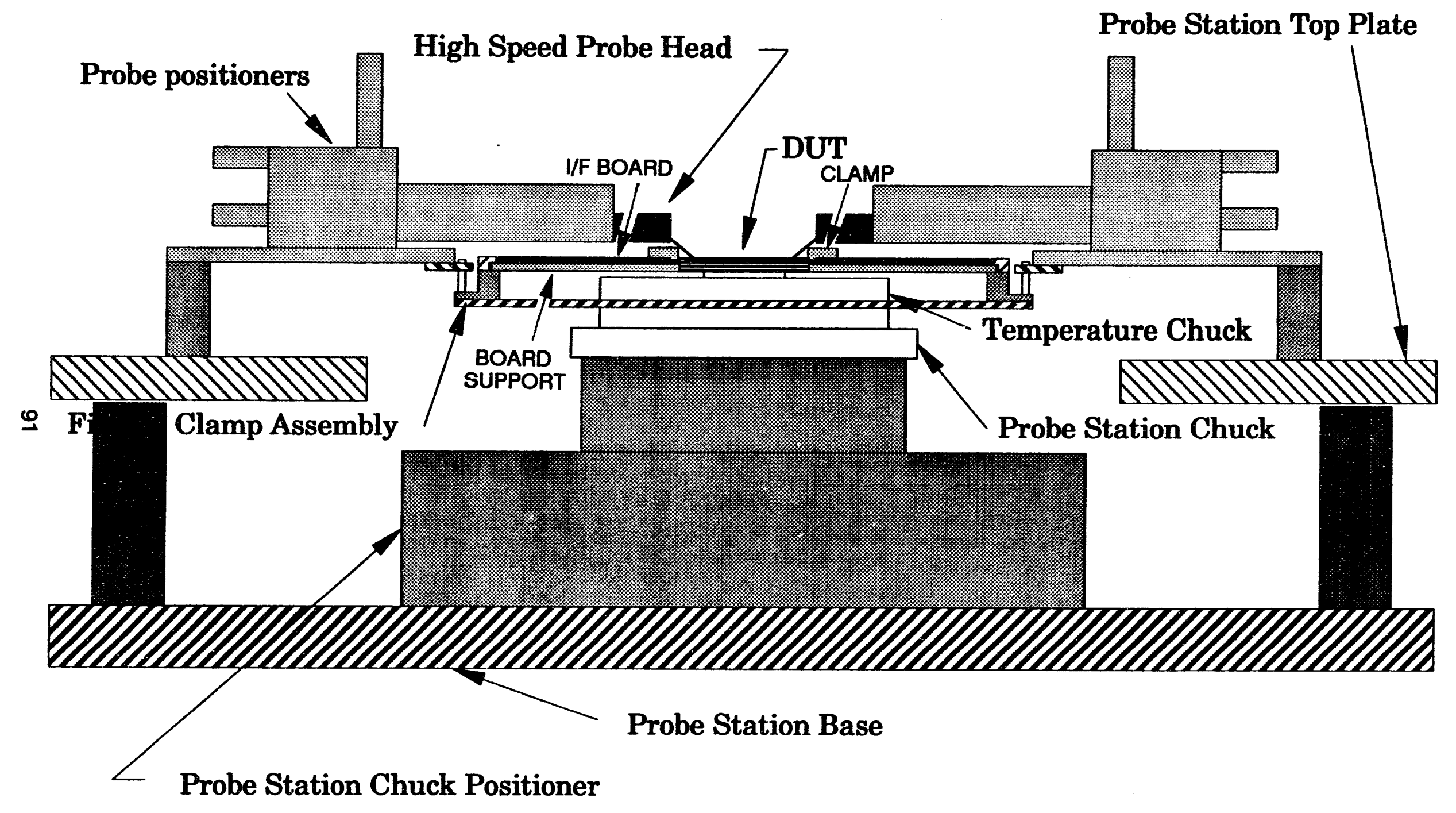

FIGURE 3. PROBE STATION FEATURES (FRONT VIEW) 


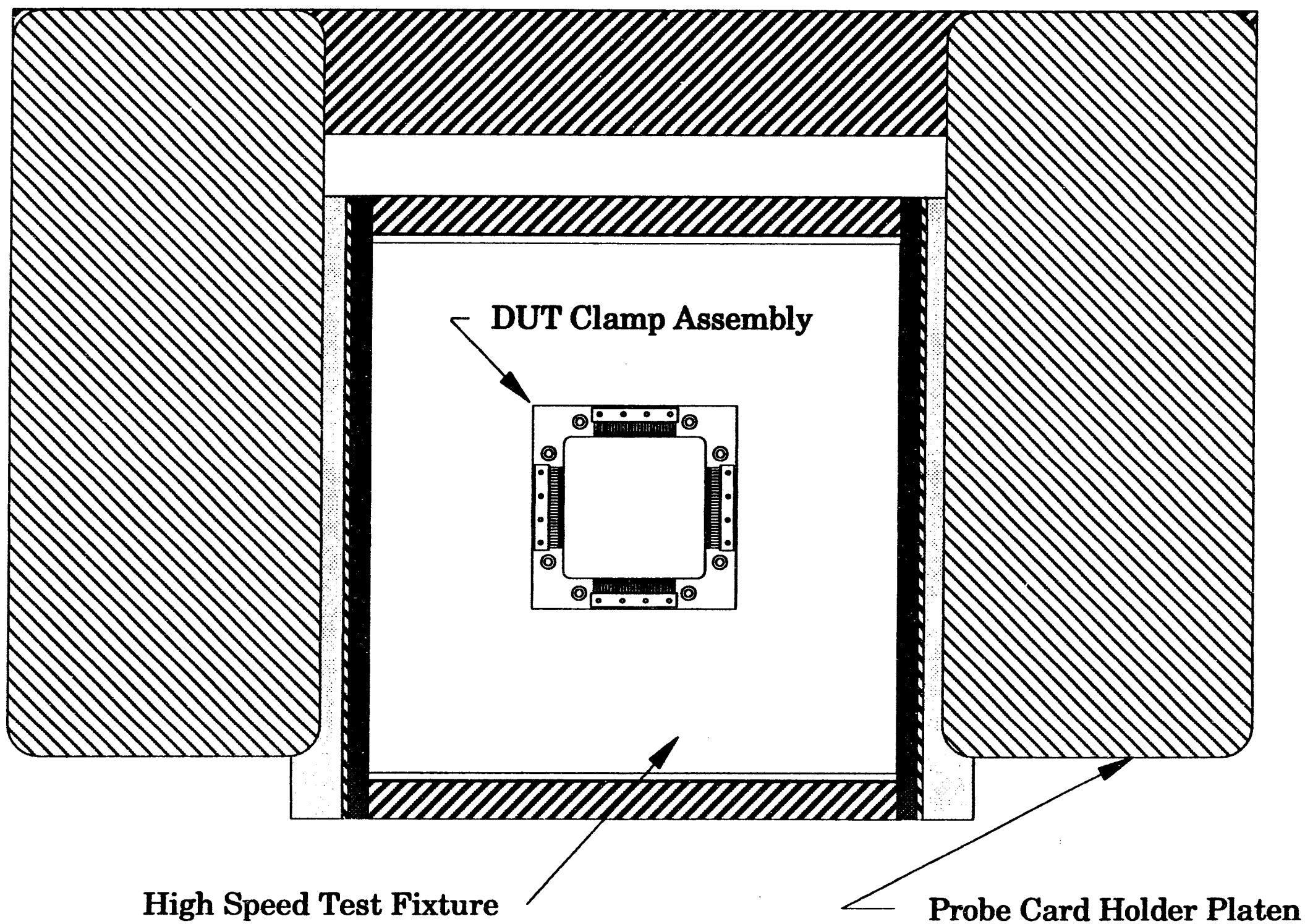

FIGURE 4. PROBE STATION FEATURES (TOP VIEW) 

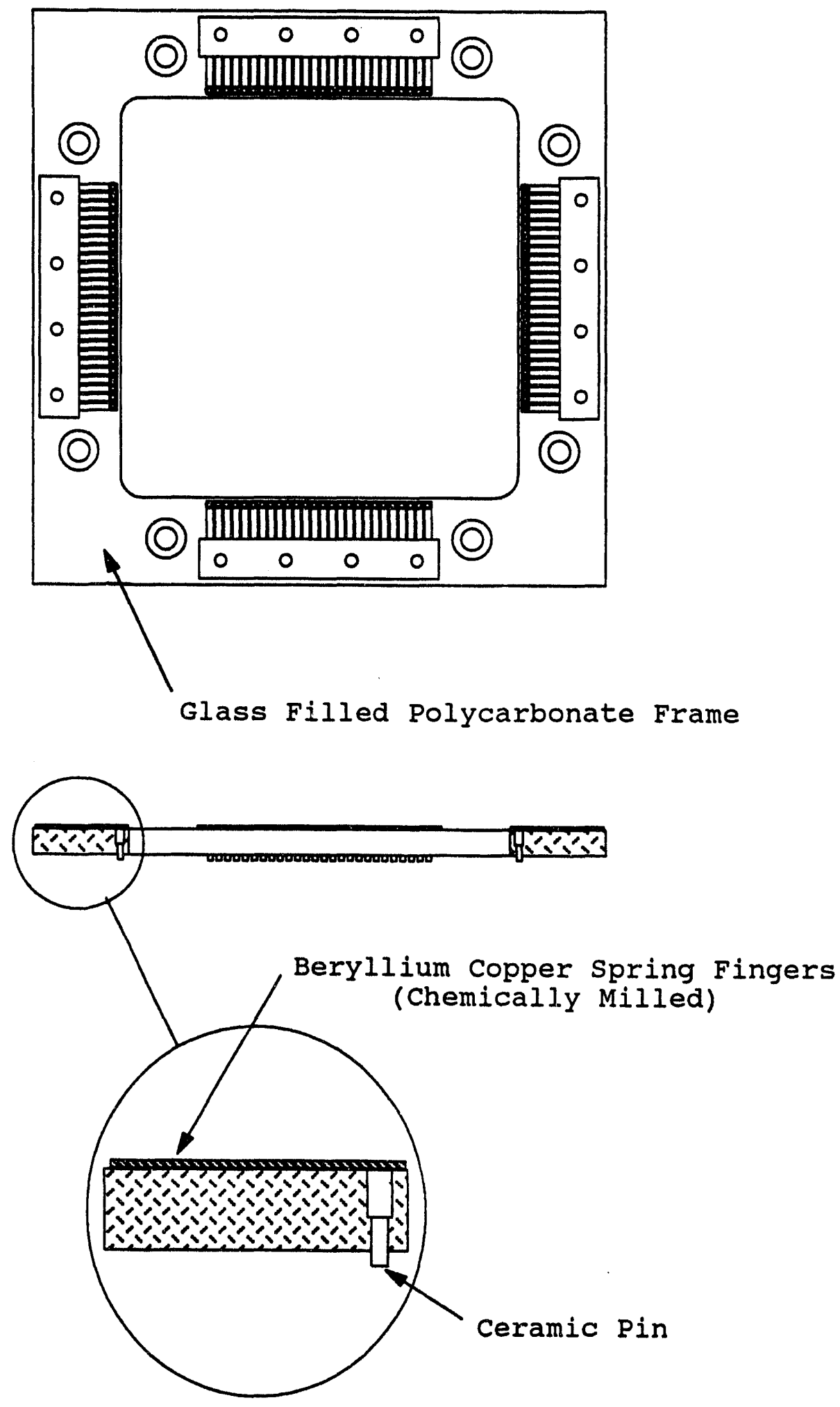

FIGURE 5. MCM LEAD CLAMP DETAILS 


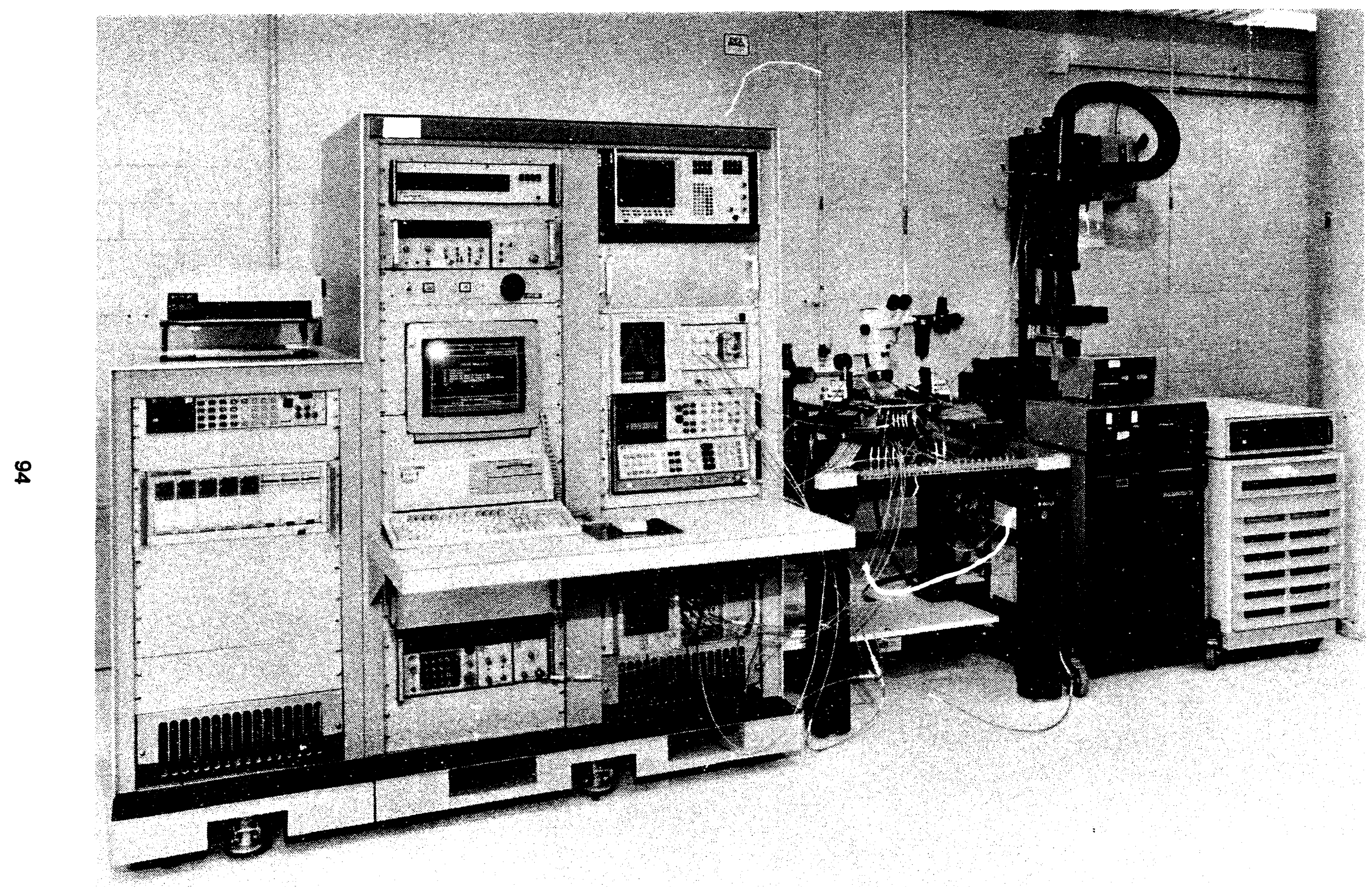

FIGURE 6. HIGH SPEED MCM TEST SYSTEM 


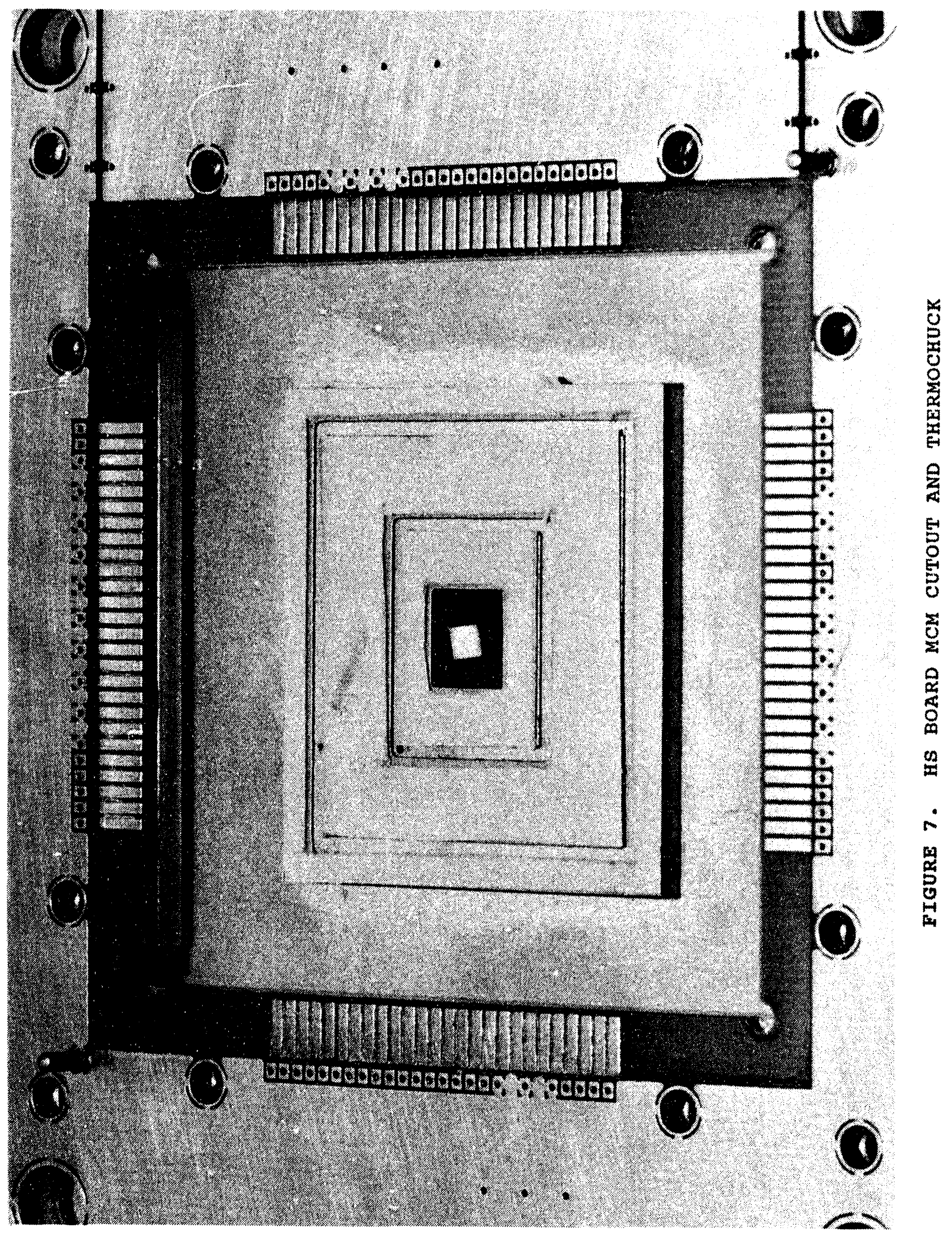




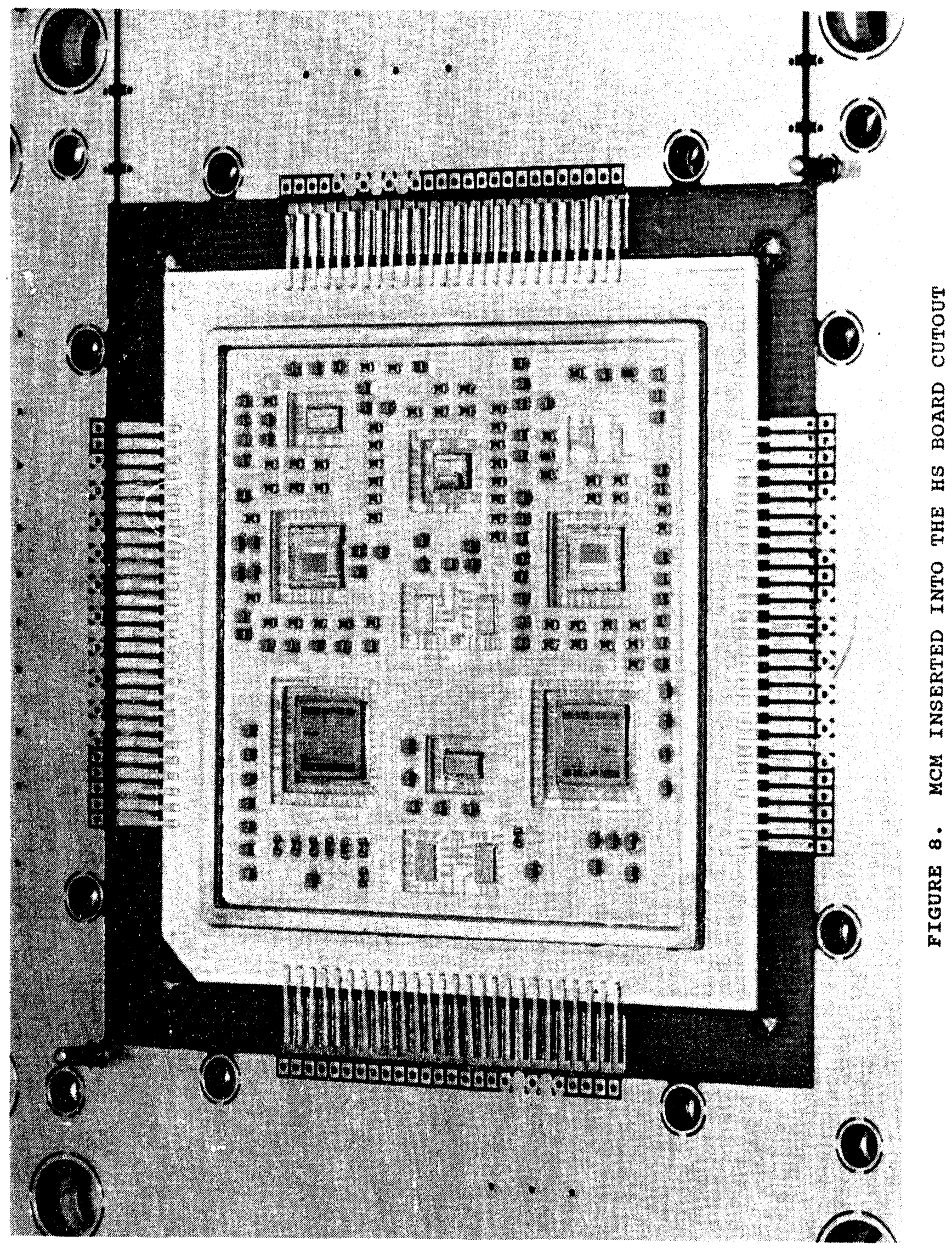




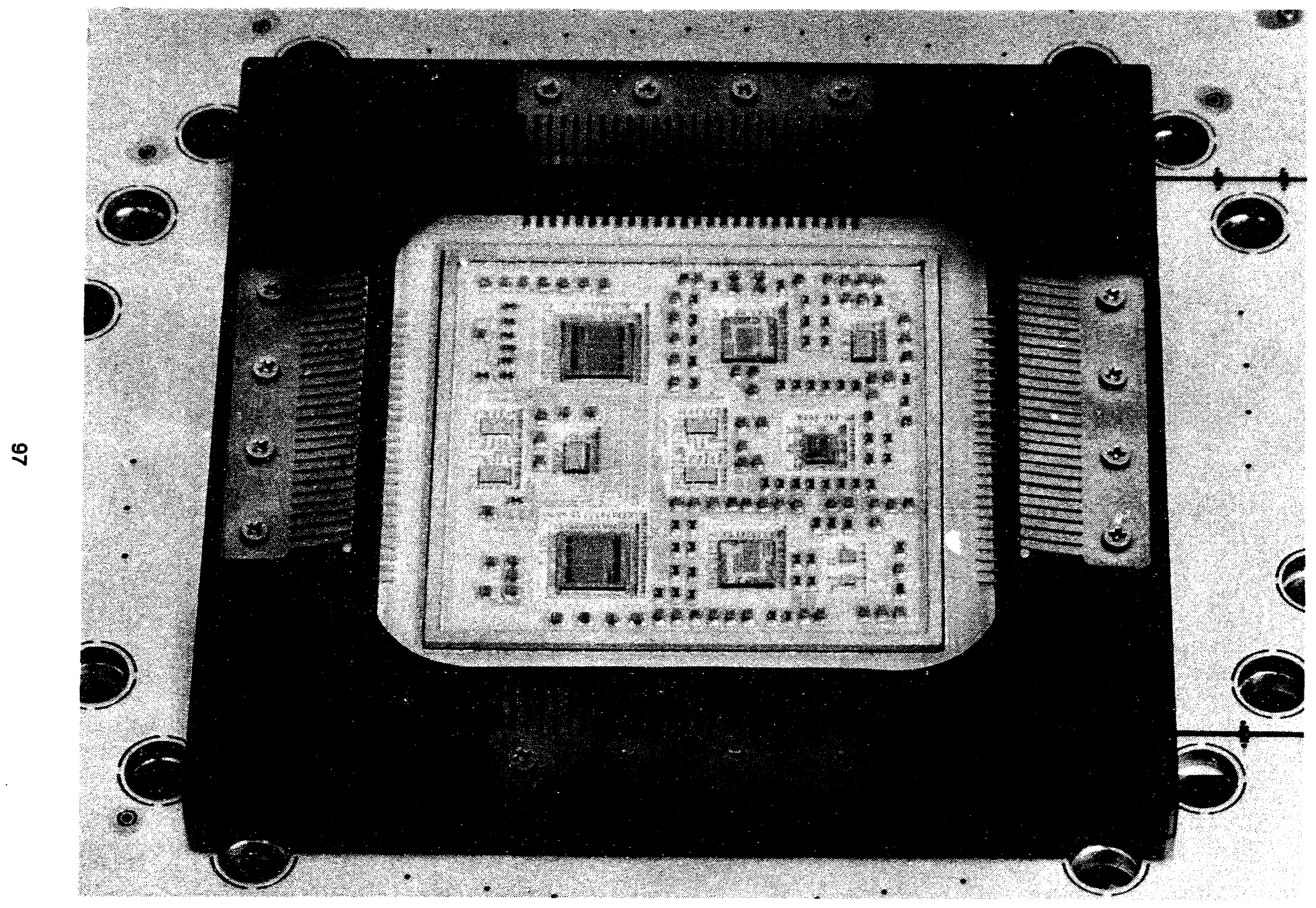

FIGURE 9. MCM LEADS CLAMPED TO THE HS BOARD 


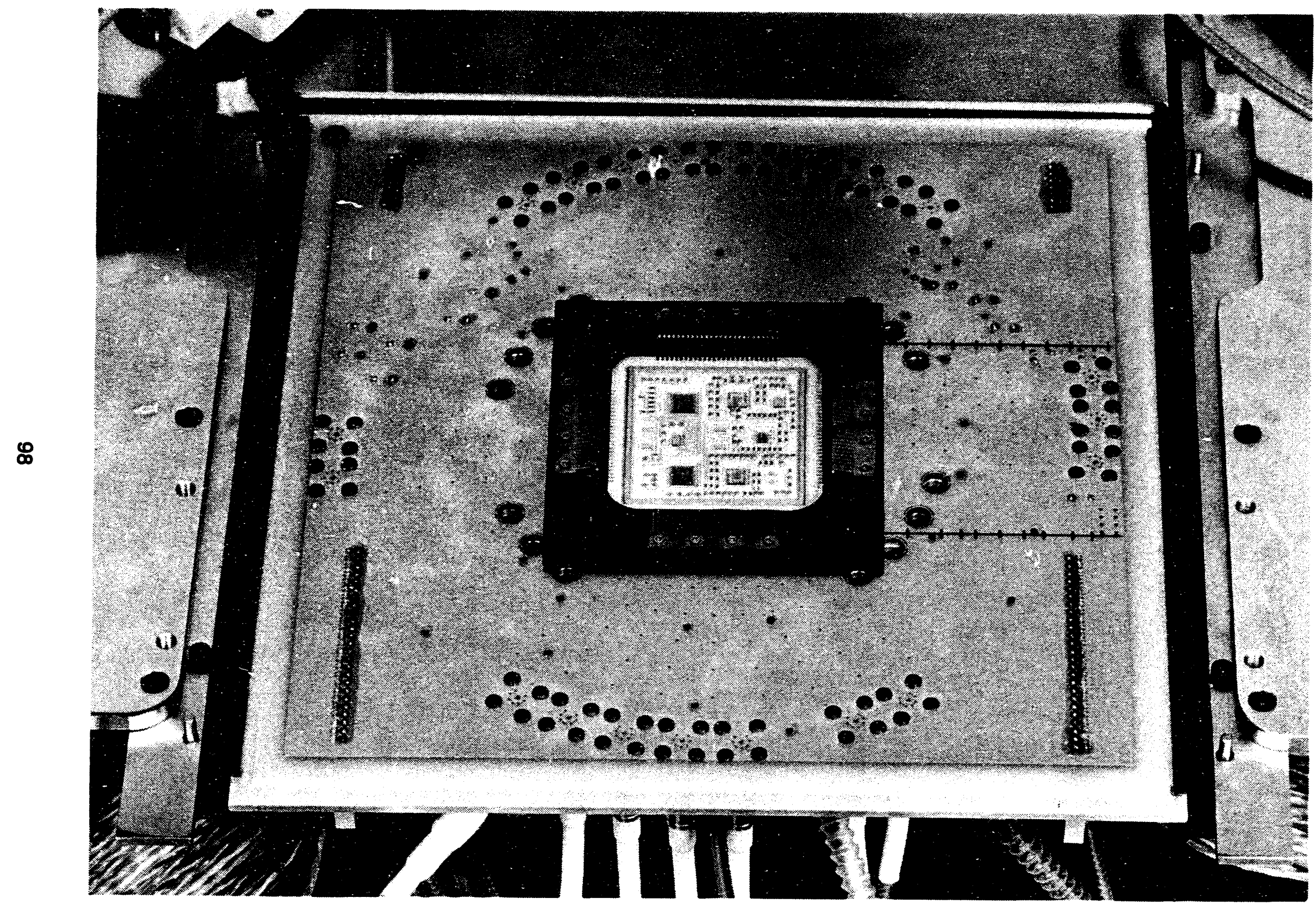

FIGURE 10. POSITIONAL RELATIONS OF MCM, BOARD AND STATION 


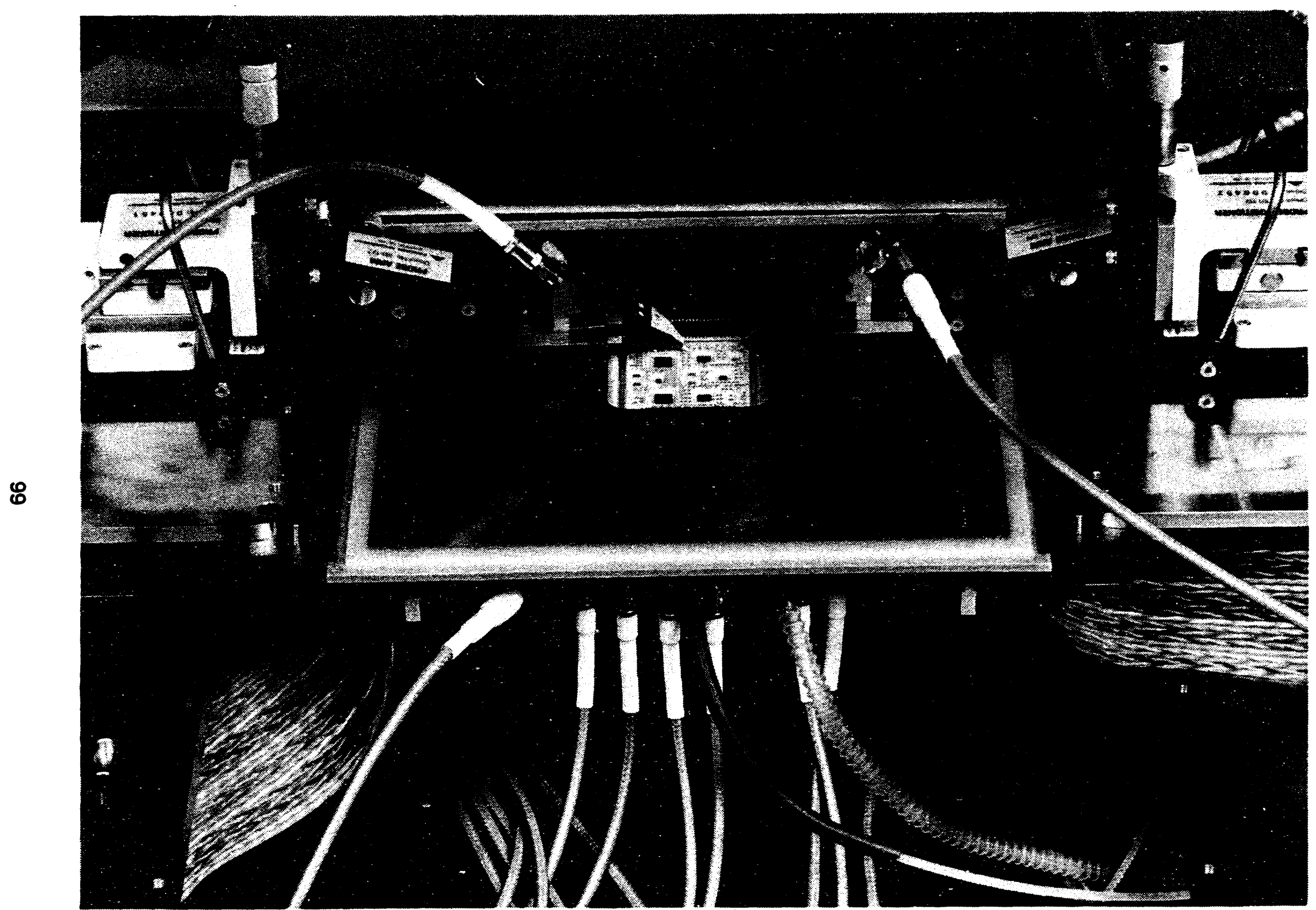

FIGURE 11. HS PROBE SETUP FOR MCM IN-PROCESS TESTING 


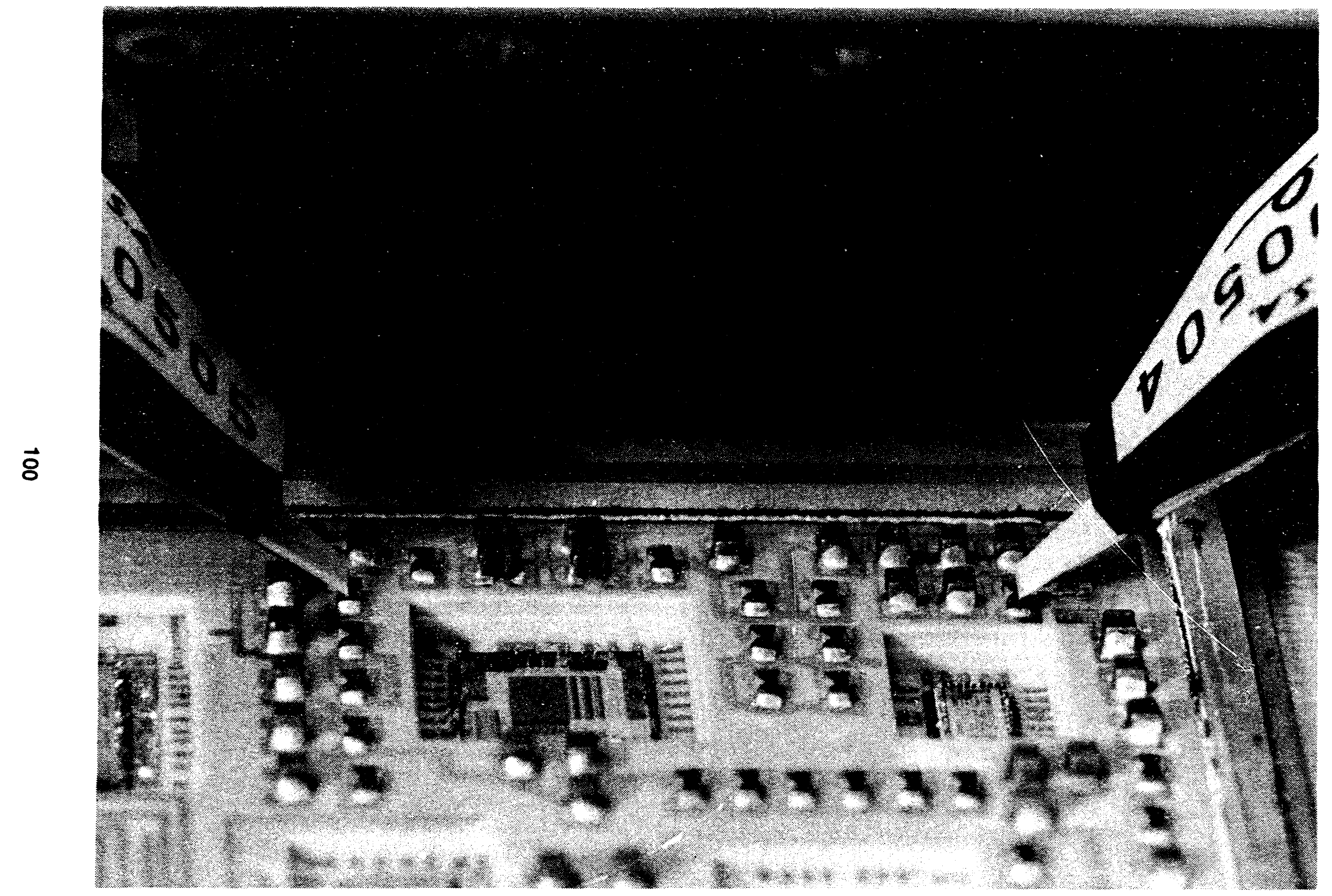

FIGURE 12. HS PROBE TIPS IN CONTACT WITH THE MCM 


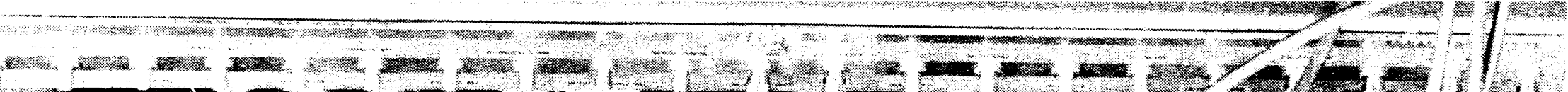

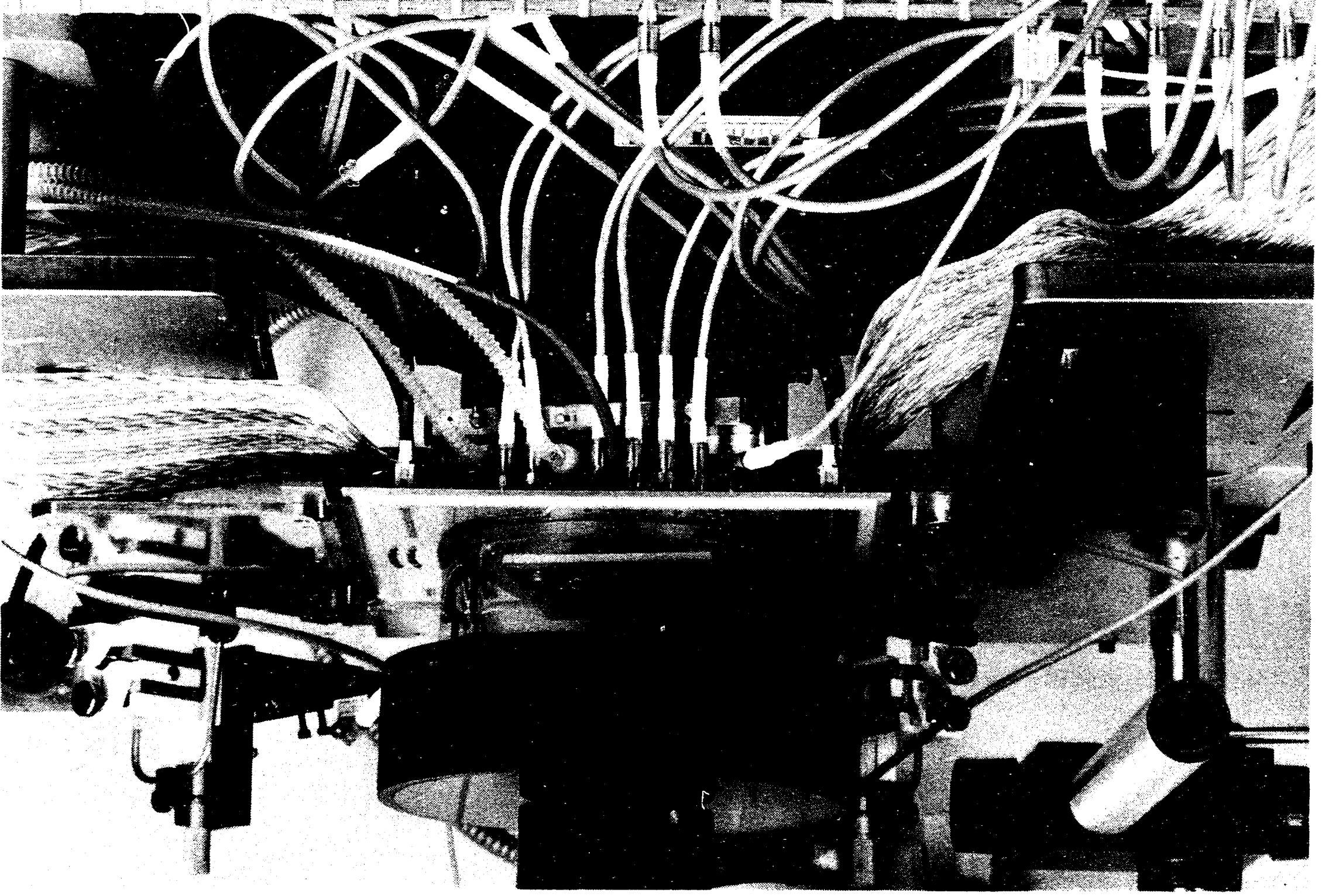




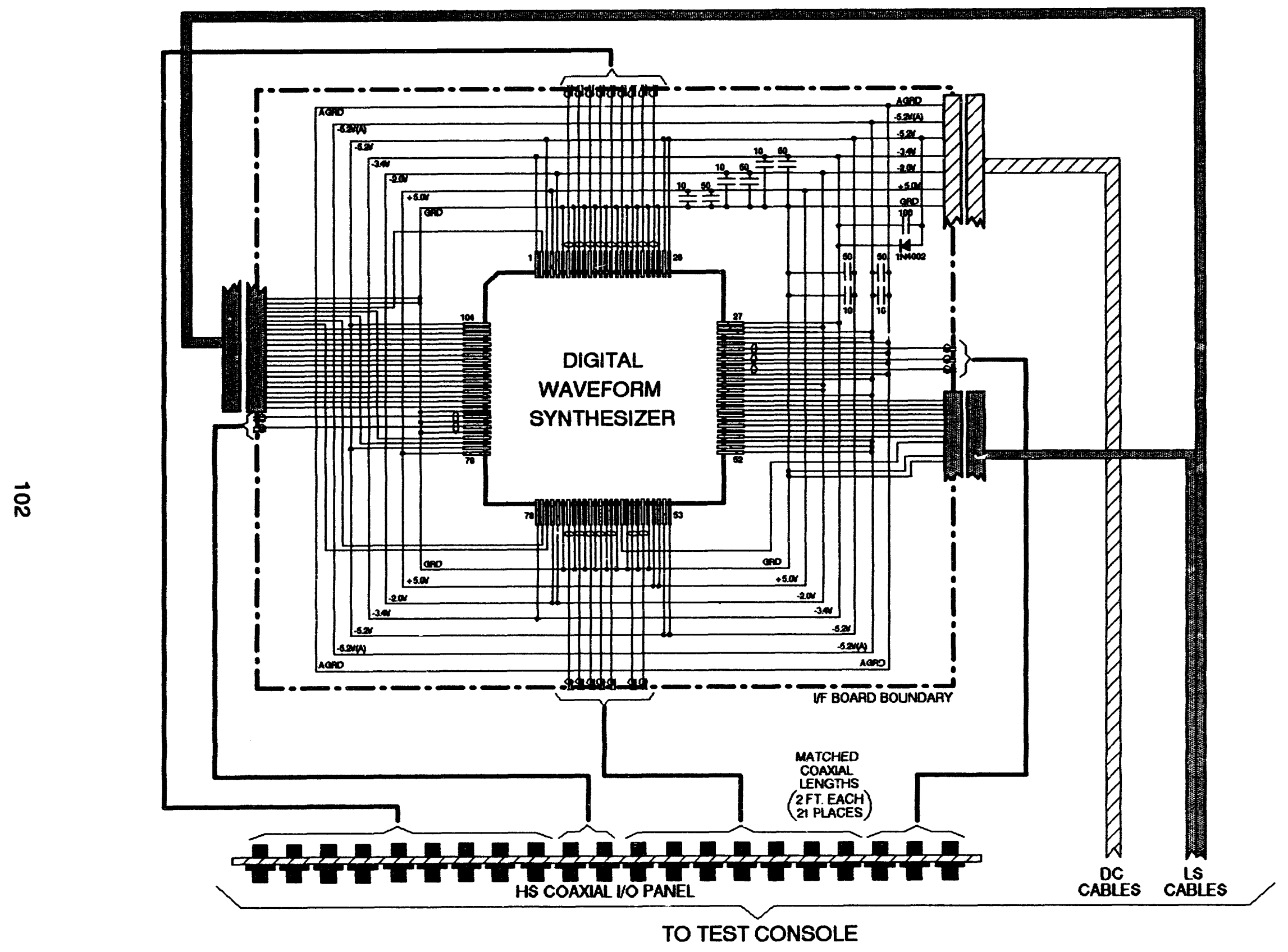

FIGURE 14. MCM ELECTRICAL INTERFACE SCHEMATIC 
ALLIED SIGNAL - HIGH SPEED TESTING INTERFACE, \#1, (PIN 9 - INTST. FREQ2)
$11-J U L-92$ 12:18

RETURN LOSS (dB)

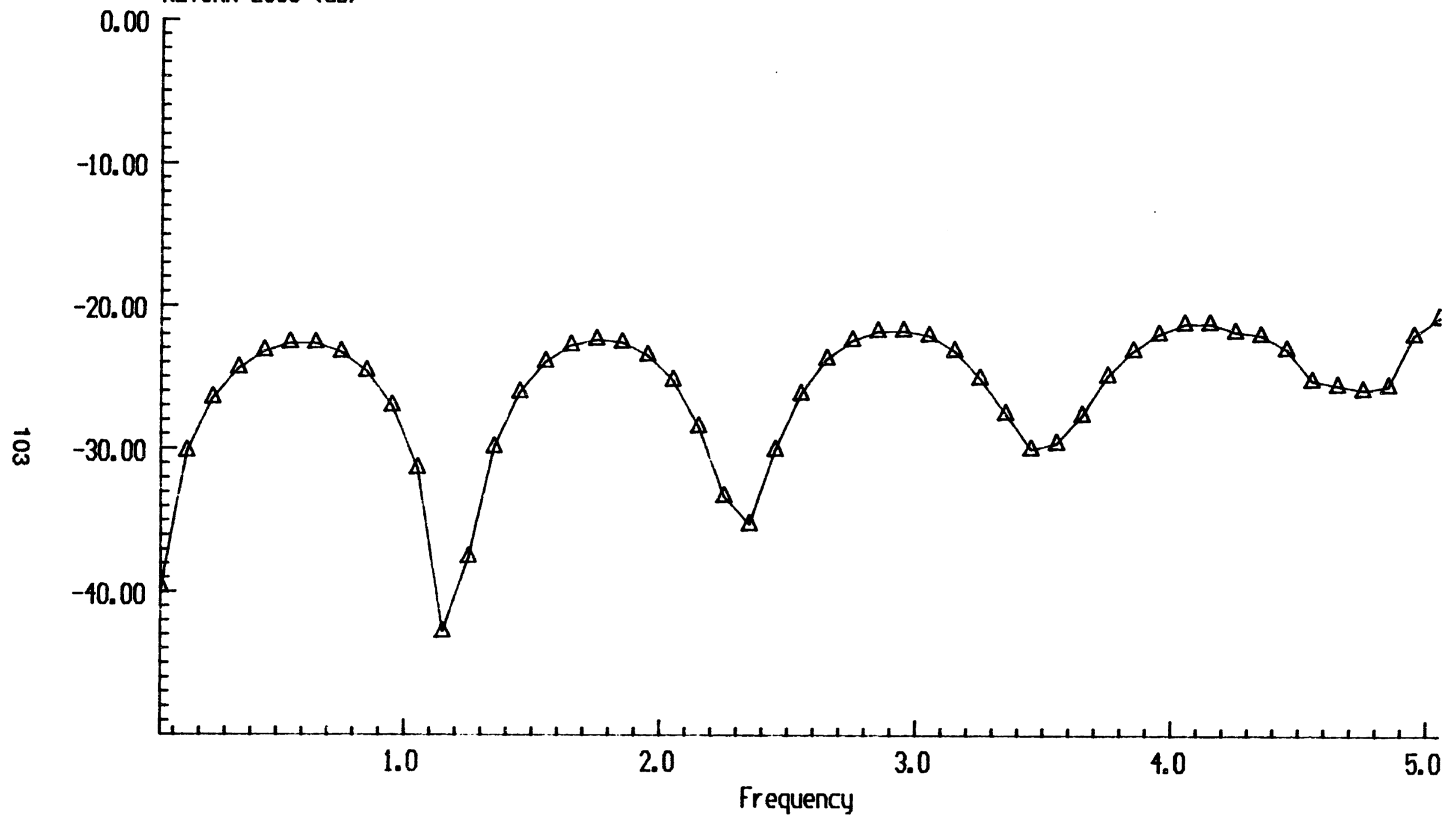

$-\triangle \mathrm{S} 22$ Magn dB Frequency range:

to: $5.05 \mathrm{GHz}$

FIGURE 15. MEASURED RETURN LOSS OF HS BOARD (S/N 1) 

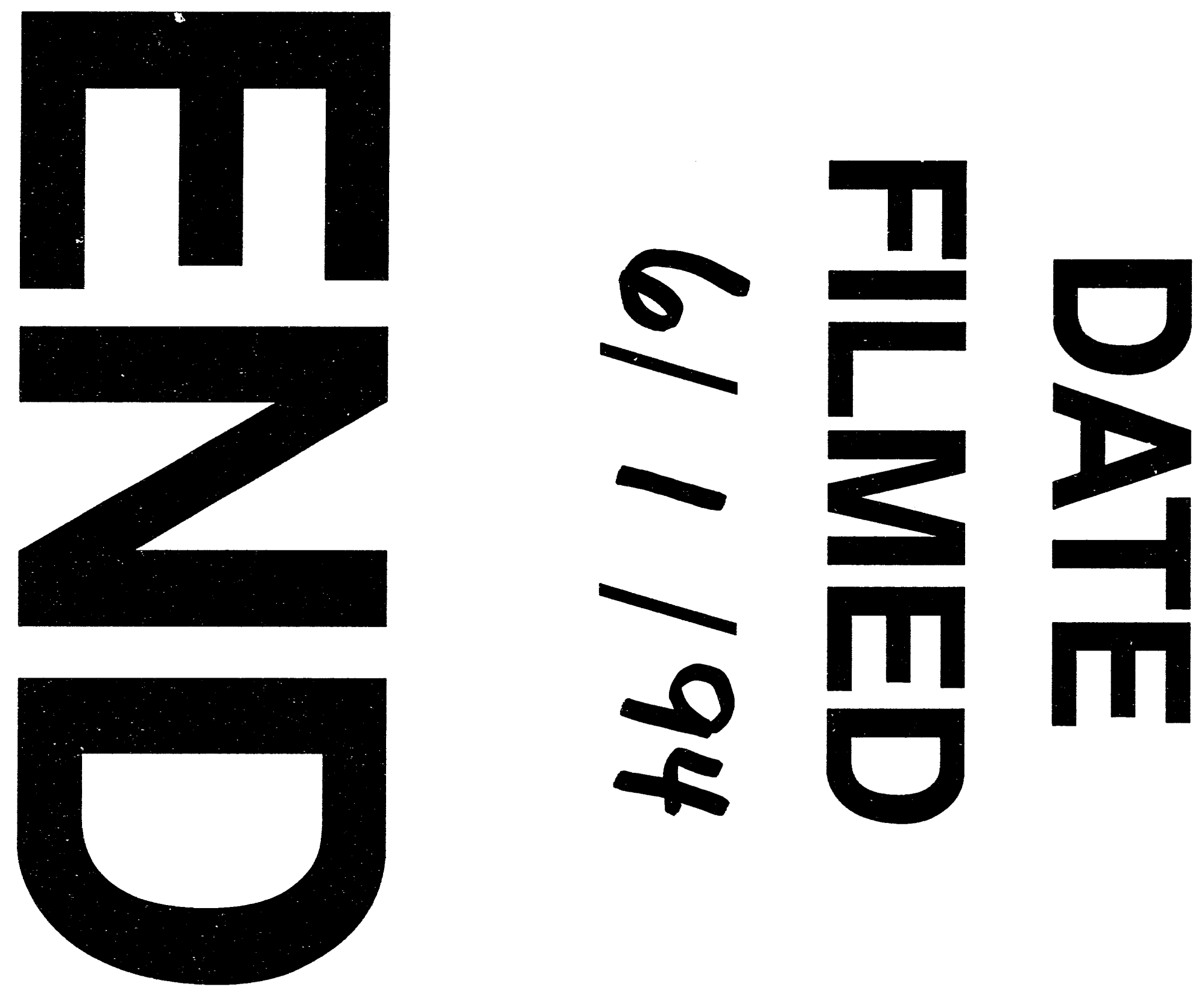
